Portland State University

PDXScholar

Spring 6-11-2013

\title{
Understanding Pervasive Language Impairment in Young Children: Exploring Patterns in Narrative Language and Functional Communication
}

Anna Jeddeloh Waters

Portland State University

Follow this and additional works at: https://pdxscholar.library.pdx.edu/open_access_etds

Part of the Educational Leadership Commons, and the Special Education and Teaching Commons Let us know how access to this document benefits you.

\section{Recommended Citation}

Waters, Anna Jeddeloh, "Understanding Pervasive Language Impairment in Young Children: Exploring Patterns in Narrative Language and Functional Communication" (2013). Dissertations and Theses. Paper 1030.

https://doi.org/10.15760/etd.1030

This Dissertation is brought to you for free and open access. It has been accepted for inclusion in Dissertations and Theses by an authorized administrator of PDXScholar. Please contact us if we can make this document more accessible: pdxscholar@pdx.edu. 
Understanding Pervasive Language Impairment in Young Children:

Exploring Patterns in Narrative Language and Functional Communication

by

Anna Jeddeloh Waters

A dissertation submitted in partial fulfillment of the requirements for the degree of

Doctor of Education

in

Educational Leadership: Curriculum and Instruction

Dissertation Committee:

Emily de la Cruz, Chair

Jason Ranker

Leslie Munson

Wayne Wakeland

Portland State University

2013 
(C) 2013 Anna Jeddeloh Waters 


\begin{abstract}
Research has identified language impairment as a pervasive disability (Bishop \& Edmundson, 1987; Greenhalgh \& Strong, 2001). Classroom communication behaviors have a role in the maintenance of special education eligibility and functional communication difficulties for young children with language impairment. This paper reviews the theoretical and experimental literature on narrative skills and language impairment as well as empirical support for understanding language delays as part of a group of risk factors that affect child development. The present study describes patterns in the communication skills of a small group of young children with a predetermined diagnosis of language impairment using a case and field mixed methods research design. The study contributes to our conceptual understanding of the pervasive nature of language impairment by focusing on patterns in oral narrative skills and their relationship to communication at school, at home, and in the community. Study results differentiate participants by the severity of utterance formulation difficulties as well as social communication differences and emotional health symptoms to identify patterns.

This study was unique in that information from classroom teachers and parents in addition to an analysis of multiple language samples created a thick description of patterns across participants. Discussion elaborates upon patterns in the data and implications for assessment and practice implications for school based services from a speech-language pathologist.
\end{abstract}




\section{Acknowledgements}

This journey would not have been possible without the support and dedication of my husband Jerry and our daughters Edna, 15, and Riley, 12. I also want to give special thanks to my advisor Dr. Emily de la Cruz who gave me the necessary research foundations and feedback to accomplish such an endeavor.

I also want to thank Dr. Christine Chaille` who guided me toward a broad understanding of experience and learning in early childhood and introduced me to the schools in Reggio Emilia, Italy. The Reggio approach to early schooling is a constant inspiration. Many young children have benefited from my travels to Reggio.

I would like to acknowledge the teachers, families and students that participated in this research and whose influence is reflected in my everyday practice as a speechlanguage pathologist. I owe particular thanks to the community of speech-language pathologists in the Portland, Oregon region.

Lastly, I would like to thank my dissertation committee at Portland State University, Dr. Samuel Henry, Dr. Jason Ranker, Dr. Leslie Munson, and Dr. Wayne Wakeland, for asking difficult questions that forced me to reflect on, and refine my research approach and analysis. 


\section{Table of Contents}

Abstract

Acknowledgements

List of Tables

List of Figures

CHAPTER ONE

Research Context

Terms

Language development $\quad 5$

Language impairment 5

$\begin{array}{ll}\text { Language development in primary grade children } & 7\end{array}$

Oral narratives $\quad 8$

Academic narratives $\quad 10$

$\begin{array}{ll}\text { Professional Significance } & 12\end{array}$

$\begin{array}{ll}\text { Present Study and Research Questions } & 14\end{array}$

CHAPTER TWO

Literature Review 16

$\begin{array}{lr}\text { Functional Linguistics } & 18\end{array}$

$\begin{array}{ll}\text { Language functions } & 18\end{array}$

$\begin{array}{ll}\text { Social constructivism } & 19\end{array}$

Creative aspects of language use $\quad 21$

$\begin{array}{ll}\text { Public Health } & 23\end{array}$

Health status $\quad 24$

Social anxiety 28

Communication Disorders 31

Narrative language $\quad 32$

$\begin{array}{ll}\text { Education } & 35\end{array}$

Enriched environments $\quad 36$

Preferred classroom environments $\quad 40$

$\begin{array}{ll}\text { Summary } & 42\end{array}$

\section{CHAPTER THREE}

Research Methods

Mixed Methods Research Design $\quad 44$

Sampling $\quad 46$

$\begin{array}{ll}\text { Participants } & 47\end{array}$

Bailey 49

Carson 49

Daniel 50 
Edward $\quad 50$

Felicia $\quad 50$

Human Subjects 51

Settings $\quad 51$

Procedures $\quad 52$

Quantitative procedures $\quad 52$

Language samples $\quad 53$

Corpus comparisons $\quad 55$

Classroom observations $\quad 56$

Qualitative procedures $\quad 57$

Teacher interviews $\quad 57$

Parent interviews $\quad 59$

Document review $\quad 59$

Qualitative data management 60

\section{CHAPTER FOUR}

Results, Findings, and Analysis $\quad 62$

Quantitative Results, Findings, and Analysis $\quad 62$

$\begin{array}{ll}\text { Narrative microstructure } & 63\end{array}$

Productivity 63

Complexity 65

Verbal facility and rate $\quad 68$

$\begin{array}{ll}\text { Narrative macrostructure } & 74\end{array}$

Classroom observations $\quad 81$

Qualitative Results, Findings, and Analysis $\quad 85$

Themes $\quad 87$

Theme one: utterance formulation $\quad 87$

Theme two: narrative skills $\quad 88$

Theme three: social communication $\quad 90$

Theme four: focus/attention 93

Theme five: social skills 95

Theme six: shutting down during conflict 97

Theme seven: health and emotional health symptoms $\quad 98$

$\begin{array}{ll}\text { Source analysis } & 100\end{array}$

$\begin{array}{ll}\text { Summary } & 101\end{array}$

\section{CHAPTER FIVE}

$\begin{array}{ll}\text { Discussion } & 103\end{array}$

$\begin{array}{ll}\text { Research Question \#1 } & 105\end{array}$

Language impairment 105

Discourse impairment 106

Difficulty self-monitoring and attending to verbal tasks $\quad 110$ 
Difficulty with initiation and failure to persist in communication following a setback

Research Question\#2 113

Integrating Findings with Existing Research 115

Implications for assessment $\quad 118$

$\begin{array}{ll}\text { Practice implications } & 119\end{array}$

Curriculum pull-in 120

Word finding practice and strategies 121

Short narratives 121

Limitations $\quad 122$

Contributions 124

Confirmatory contributions 125

$\begin{array}{ll}\text { Original contributions } & 125\end{array}$

$\begin{array}{ll}\text { References } & 128\end{array}$

$\begin{array}{ll}\text { Appendices } & 148\end{array}$

Appendix A: Nomination letter $\quad 150$

Appendix B: Consent 152

Appendix C: H.I.P.P.A. form 155

Appendix D: H.S.R.R.C. approval 155

Appendix E: English script for Frog Goes to Dinner by Mercer Mayer (1974)

Appendix F: Transcripts $\quad 157$

Appendix G: The Classroom Literacy Environmental Profile $\quad 185$

Appendix H: Narrative scoring schema rubric 200

Appendix I: S.C.E.R.T.S. assessment profile: Conversation partner 201

Appendix J.: Parent interviews 205 


\section{List of Tables}

Table 1: Summary of protective provisions and risk factors from functional linguistics

Table 2: Summary of protective provisions and risk factors from public health $\quad 30$

Table 3: Summary of protective provisions and risk factors from communication disorders

Table 4: Summary of protective provisions and risk factors from education $\quad 42$

Table 5: Data collection strategies 45

Table 6: Participant characteristics $\quad 48$

Table 7: Narrative microstructure: productivity $\quad 64$

Table 8: Narrative microstructure: complexity 66

Table 9: Narrative microstructure: verbal facility and rate 69

Table 10: Characteristics of utterances with error codes in Bailey's transcript \#1 71

Table 11: Classification of word level errors, mazes, and total utterance level errors

Table 12: Narrative macrostructure: narrative scoring scheme total score $\quad 75$

Table 13: Narrative scoring scheme: summary of category scores 79

Table 14: Classroom observation scores $\quad 82$

Table 15: Emergent themes and operational definitions 86 


\section{List of Figures}

Figure 1: Source analysis 


\section{Chapter One}

\section{Research Context}

Language impairment is the most commonly diagnosed communication disorder in school-aged children in the United States, affecting 5\%-7\% of primary grade children (Tomblin, Records, Buckwalter, Xuyang Zhang, Smith, \& O’Brien, 1997). Early school success for children with language impairment is a central point of interest in communication disorders and related fields (Snow, Burns, \& Griffin, 1998). In a representative sample of children over a 19-year longitudinal study, Tomblin et al. (1997) found that only $18 \%$ of affected students received clinic-based or school-based services from a speech-language pathologist (SLP). Language impairment impacted speaking, listening, reading, and written language (Battery, 2008; Castrogiovanni, 2008) and sometimes articulation and motor skills (Stanton-Chapman, Chapman, Bainbridge, \& Scott, 2002). Children who qualified for school-based services from a speech-language pathologist were differentiated by the level of severity of their language impairment or their language impairment was associated with a significant academic impact (Tallal, Dukette, \& Curtis, 1989). Academic impact included thinking and learning skills as well as classroom experience. Another prominent explanation for school-based eligibility suggested that developmental disorders with linguistic symptoms represented a continuum of disorders, including attention deficit and hyperactivity disorder, autism, and language impairment (Botting \& Boucher, 2008). These disorders resulted in discourse limitations and pragmatic difficulties that resulted in poor conversational skills (Redmond, 2003). 
Full inclusion in the general education classroom for children with language impairment in the public schools requires the development of relationships, positive routines, curriculum, and physical environments that enhance academic skills and engage children with mild disabilities in classroom learning. Examining the context in which young children with mild disabilities communicate and how their communication influences their early schooling experience will support evidenced-based decisions specific to assessment planning and direct intervention. The work of remediating speech and language impairments remains a priority for public schools in the United States. There is convincing theoretical and policy rationale for fostering strong speaking and listening skills for students with language-based disabilities to improve critical thinking and the application of literacy and numeracy skills as children get older (Fountas \& Pinnell, 2006; Marzano, 2007; Nippold, 1988).

For some children, developmental differences and delays resolved during the normal course of early childhood (Bishop \& Edmundson, 1987; Tomblin, Xuyang Zhang, Buckwalter, \& O'Brien, 2003). However, for $60 \%$ of children with language delays in preschool, deficits persisted (Manhardt \& Rescorla, 2002) and may be part of more global delays that included speech development, motor coordination, perception, reasoning, social interaction, and early academic achievement. Communication skills are central to a positive classroom experience, and language plays a dominant role in academic achievement (Tomblin et al., 2003). Based on the Common Core State Standards (2010) (CCSS), a set of benchmarks prepared by the National Governors Association Center for Best Practices and the Council of Chief State School Officers for 
kindergarten through $12^{\text {th }}$ grade, narrative discourse for storytelling and the ability to participate in meaningful discussions are expected in first grade. In addition, adequate speaking skills are essential for kindergarten readiness and engaging teacher resources throughout elementary school. The CCSS (2010) included grade level behaviors and skills currently adopted by 45 states as targets for general education students, including children with disabilities. CCSS (2010) communication and language benchmarks in primary education are the focus for SLPs currently working in the school setting. According to Coleman and Pimentel (2011), the CCSS (2010) assumed that young children would read and understand information well enough to benefit from instruction linked to content area learning. Classroom encounters with content were the foundation of the CCSS and included the ability to ask and answer detailed questions, speak, draw and write as a means of communicating knowledge of key concepts and follow agreed upon rules for classroom discourse. Deficits in spoken language, written communication and social interactions have been identified in research as areas of concern for young children with language impairment. Educators and school-based SLPs need an understanding of how classroom communication is constructed and why some routines positively affect language skills and functional communication.

The conceptual framework for the current study was based on the assumption that young children with communication disorders have difficulty creating interactive routines and are less resilient in communication events than typically developing children. According to Campbell and Skarakis-Doyle (2007), to promote collaboration and the sharing of resources in educational settings, educators should use their knowledge of the 
commonalities across developmental impairments. Helping classroom teachers to understand language delay as one of many risk factors rather than a simple function of cognitive resources is a challenge. The most predominant research into the development of children and youth with language impairment has focused on the children themselves isolated from the complex context of everyday behavior (Hoff, 2006). Most research has focused narrowly on the structural language impairment isolated from contributing factors or differential risks, such as the presence or absence of a secondary reading disability. Large studies present spoken language development as linear and uninterrupted. Best practice includes understanding a combination of interventions and improvements in functional communication skills, including but not limited to structural language development. This is particularly true for school-based SLPs. School based SLPs are charged with understanding language development as well as communication skills in the broader social and learning environment.

The present study utilized a case and field mixed methods approach to learn more about how engagement and classroom experiences were unique for young children with spoken language disabilities (Campbell \& Skarakis-Doyle, 2007; Tunge \& Hogan, 2005). Selecting a complementary mixed methods approach to this study supported exploration of different aspects of communication for a small group of young children with predetermined language impairment. For the purposes of this exploratory research, a score of 80 or below on the expressive composite score on a standardized language development test approved by the American Speech, Language, and Hearing Association (ASHA) was used as the criteria for language impairment. 
Direct observation of children's narrative language and structured observations of each classroom accompanied interviews with teachers and parents. To develop a casebased and cross-case understanding specific to child attributes and context descriptions, quantitative and qualitative data were collected simultaneously. A review of research showed general agreement across disciplines that relative strengths in oral language and related skills separated groups of young children that succeed in early schooling from those that do not (Arnold \& Doctoroff, 2003).

\section{Terms}

In the following section, specific terms and their relationship to this study's conceptual framework are discussed.

Language development. Social ecology is an existing theoretical framework that contributed to an a priori assumption that certain patterns are responsible for both typical and disordered language development. Language development is a nested developmental process that includes characteristics of the child, characteristics of home, school, and community as enduring environments, and a child's adaptive responses to communication events (Kirkland \& Patterson, 2005). Children develop language in multiple everyday contexts (Bronfenbrenner, 1994) and developmental growth in oral narrative skills can sustain longer and more frequent conversational interactions across environments and is therefore an important barometer of overall communication development (Goorhuis-Brouwer \& Knijff, 2002).

Language impairment. Language impairment is a health impairment diagnosed as a disorder in the development of language despite adequate educational opportunity 
and normal intelligence, in the absence of any additional disorder that might underlie diagnosed language problems, such as permanent hearing loss or autism (StantonChapman et al., 2002). It is estimated that 1 in 10 pre-school children are affected by language impairment (Hewitt, Hammer, Yont, \& Tomblin, 2005). Over one million children in the U.S. have a language impairment diagnosed by their pediatrician. Children with language impairment may demonstrate deficits in spoken (expressive) language without deficits in receptive language or auditory processing skills, or they may have deficits in both areas of language knowledge at any given time during development. The Diagnostic and Statistical Manual of Mental Disorders (DSM IV, American Psychiatric Association, 2000) stated that language impairment included "having a markedly limited vocabulary, making errors in tense, or having difficulty recalling words or producing sentences with developmentally appropriate length or complexity" (p. 18). The DSM IV (2000) was primarily focused on utterance formulation. Utterance formulation is the type of language required on standardized tests.

Research classifying children into subtypes of expressive language impairment, receptive language impairment, or mixed language impairment has been criticized because children with language impairment rarely maintain a profile of language strengths and weaknesses over time (Law, Garrett, \& Nye, 2004). However, there is resurgence in subtype research specific to the typology of language characteristics as a product of other disabilities, such as attention deficit disorder, Down syndrome and autism spectrum disorders. School-based SLPs are likely to provide services across disability categories. 
Sustaining conversational interactions with peers and adults was difficult for children with language impairment because it required more sophisticated linguistic and social resources (Brinton \& Fujiki, 2006). These resources included complex syntax and story grammar that make a message understood. Basic story grammar included telling the who, what, and where of events outside of the immediate environment (Stojanovik \& Riddell, 2008). According to Curtain and Dahlberg (2004), this style of speaking allowed a child to recast experiences and communicate more effectively in larger groups. Primary education plays a significant role in developing these communication patterns for all children.

Research has shown that children without barriers to early school success leveraged these conversation skills at school for academic learning and social relationships without intervention (Diller, 2007; Evans, 2002). For children who struggle with early schooling, it is important to analyze language skills as a significant contributor to pervasive at-risk status because children who maintained developmental variation at the syntactic and morphological level were more difficult communication partners.

Language development in primary-grade children. Children ages 5-9 years old are learning to express themselves using longer sentences and greater cohesion in conversation so they can actively participate in the academic and social learning that takes place in the classroom. According to Bishop and Nordbury (2005), adequate language skills and opportunity for sustained conversation were important because primary-grade children had more information to share with others than preschool children 
who use language for behavior regulation more than for social interaction or learning about a topic.

These social communication skills develop optimally with a significant spike in vocabulary knowledge and oral language development in children ages 5 to 9 years old (Biemiller, 2003; McMurray, 2007). Rapid expansion of oral vocabulary necessitates a reorganization of language. This reorganization is not unlike stocking and organizing a kitchen pantry in preparation for cooking a meal. A stocked and organized pantry of word knowledge can create a variety of linguistic strategies for comprehension.

In addition to supporting communication skills, existing research has established that language reorganization was necessary for early academic learning. Children developed an awareness of the semantic and phonological relatedness of words (Diller, 2007). Semantic relationships included groupings of words into categories and concepts, and phonological relatedness included groupings of words with similar sound patterns. This understanding of word relationships was used for dual decoding during reading, phonics, and word meaning (Hall, 2003; Ouellette \& Beers, 2010). Oral language skills, such as answering and asking questions and knowing how much and how little to say, supported bids for verbal interaction. Oral language skills were more important for reading comprehension than for decoding (Bishop, McDonald, Bird, \& Hayiou-Thomas, 2009).

Oral narratives. Children use stories at school to tell their teachers how they got hurt at recess, why elephants are their favorite animals, and about their trip to the beach. According to Valencia and Sulzby (1991), story grammar included a setting, characters' 
problems and internal feelings, solutions, consequences, resolutions, and endings. Evaluative dimensions of narrative generally included an interpretive sense of the mental states of the characters and of causal links among events. Studies found that the persistence of spoken language impairment, rather than IQ or vocabulary skills, was a major factor in poor academic outcomes for older children (Catts, Bridges, Little, and Tomblin, 2008; Catts, Fey, \& Proctor-Williams, 2000), including children with language impairment who demonstrated academic achievement in the range of normal on standardized tests at age 8 (Scarborough \& Dobrich, 1990). In other words, conventional measures of early academic achievement were not good measures of future risk.

According to Heilman, Miller, and Nockerts (2010), narrative structure, because of its complexity, was a better predictor of risk than other measures of language, such as standardized tests. In general, children with language impairment had more difficulty with extended classroom discourse. Girolametto, Wiigs, Smyth, Weitzman and Pearce (2001) found that children identified as late talkers by their preschool teachers struggled with linguistic complexity. They produced less sophisticated oral narratives with shorter utterances and fewer complete cohesive ties when compared to children identified as easy to communicate with by the same teachers. Manhardt and Rescorla (2002) found that teachers' subjective evaluations of communication skills affected the quality and quantity of supported story telling over the course of observed classroom interactions for both children with language impairment and other children. They found that only some children with language impairment accessed supported telling to produce causal links, increased syntactic complexity, and/or to demonstrate an interpretation of story events in 
spoken language. Children who were unable to produce basic story grammar independently were less likely to benefit from co-constructed discourse with their classroom teachers. Data from children's oral narratives and teachers' subjective judgments of communication skills may be better predictors of risk when compared to early academic measures.

Academic narratives. Adequate story grammar is not enough to protect children with language impairment from identification as learning disabled when they get older and the demands of language change ( Nippold, 1988). Comprehension strategies, such as comparing, problems/solutions, and order of importance were language tools in academic discourse that children practiced in the primary grades (Marzano, 2007). This academic style of understanding language and speaking academically was a register that allowed children to engage content as well as learn through making connections between subject areas (Rinaldi, 2006). According to Jackson (2003), mastering academic English enabled students to carry out learning publicly in school. Based on his multiple case study design, Jackson found that when schools created environments with unusually high student engagement, children were more likely to demonstrate understanding of different spoken language registers. In addition, he found that engagement and academic language were important contributors to a positive learner identity (Jackson, 2003). Learner identity is the perceived self-efficacy and personal goals that enabled children to play a part in their self-development (Bandura, 2001, 2003), including adaptations and the construction of cultural tools and methods of behavior.

When compared to the features of oral narratives or conversation, academic 
language narrative required a greater number of different words, characteristics of the written language register, greater cohesion, and demonstrating understanding of relationships in science, games, history, and literature (Nippold, 2009). Nippold claimed that children begin to use a more deliberate organization of linguistic resources when they learned separate registers for different social contexts. Features of the written language register, such as dependent clauses introduced by a variety of subordinating conjunctions, such as 'after' or 'unless', indicated that a child recognized some language as academic (Chafe \& Tannen, 1987). The written language register is not memorization of actual features of written text. According to Chafe and Tannen (1987), "Much of the syntactic structures as acquired by children is a consequence of pragmatic and discourse functions, stages of sensory-motor and cognitive development, the development of processing capacities, social development, and various aspects of meaning" (p. 109). There is evidence that children who use features of the written language register in their oral language were more actively engaged in classroom activities and had better on task behavior (Botting \& Conti-Ramsden, 2008). This was because their ability to use precise and explicit language made it easier to monitor communication events and predict future interactions with teachers and content. Acquisition of narrative proficiency is a slow process and analysis of children's narrative organization skills was included in this research study to understand if a child's relative ability in the area of narrative organization had a relationship to their communication skills as reported in interviews with teachers and parents. 
Professional Significance

Children who were determined to have poor language skills in kindergarten were not likely to change their status via maturational processes that resulted in catch-up. The prognosis for children with language impairment without both direct and indirect intervention was not good. In addition to children with language impairment, Manhardt and Rescorla (2002) found that $63 \%$ of kindergarten children described as late talkers by their mothers continued to have weaknesses in oral narrative skills despite expressive language skills in a range of normal on standardized tests.

SLPs provide therapy at school to $9 \%$ of primary children with Individual Education Plans (IEPs) (Battery, 2008). The primary grades are kindergarten, first, and second grades. Efficacy studies in speech-language pathology tended to favor children under age 9 (Kaderavek \& Sulzby, 2000; Nippold, 1988). Services provided by SLPs in elementary school remediated close to $80 \%$ of students with speech, fluency, and voice impairments while remediation rates for children with language impairment varied between $15 \%$ and $50 \%$, depending on how remediation was defined and measured (Goorhuis-Brouwer \& Knijff, 2002). If the remediation criteria included exit from special education and participation in schooling as a non-disabled learner without an IEP, the percentages were even lower.

This lack of remediation for young children with IEPs, as well as for children in general education with weak language skills, contributed to an increase in the number of older elementary-school students with learning disabilities (Hanushek, Kain, \& Rivkin, 1998; Semrud-Clikeman, 2005). The rate of co-occurrence of language impairment and 
learning disabilities was as high as $96.2 \%$ for older children in controlled studies (Sunderland, 2004). The number of students identified as learning disabled increased substantially from about 1.2 million in 1980 to 2.8 million in 1999 (Vaughn \& Fuchs, 2003) and has remained relatively stable while the number of students with autism and other health impairments continued to increase. In the 2010-2011 school year, over 6 million children were in special education. Increasingly, SLPs provided services to students from a variety of classifications. In addition to service provision, SLPs acted as case managers for children with a primary special education eligibility of language impairment, without special education services for reading, writing, math or behavior. These students were 'full inclusion' or 'speech only' in their special education placements.

Students with disabilities described under the category of a communication disorder or learning disability are considered to have mild disabilities when compared to students described under the categories of intellectual disability, emotional disturbance, autism or visual/hearing impaired. The resulting expectations for achievement and classroom experience within the CCSS (2010) include a broad range of discourse skills, including the ability to plan for and participate in discussions.

Understanding the patterns in language use and classroom experience as a means of developing clinical expertise will require cross-disciplinary perspectives. Survey statistics from kindergarten teachers across the country reported the number of children unprepared for school due to poor oral language skills at over 10\% for English speaking children and the number of children who experienced adjustment difficulties in 
kindergarten at 50\% across demographic groups (Rimm-Kaufman, Early, Cox, Saluja, Piñata, Bradley, \& Payne, 2002). For young children with primary language impairment there was general agreement that direct service provided outside of the classroom by a SLP, as a single intervention, was inadequate for children with language impairment (Campbell \& Skarakis-Doyle, 2007; Catts et al., 2008). Making a positive impact on children's successful communication experiences at home, at school, and in the community and increasing their opportunities to practice and receive feedback within the target environment is more likely to foster resilience and support emotional regulation and engagement when compared to clinical interactions in a therapy room.

\section{Present Study and Research Questions}

The purpose of this mixed methods study was to explore the communication skills of a small group of young children with language impairment using multiple data types to describe patterns that influenced schooling. This exploratory research, specifically the data collection activities detailed in the present study, could be refined for potential use with a broad range of learner groups with communication differences. In turn, the design of future interventions would be more responsive to the communication patterns explored (Apel, 2001; Ratner, 2006).

The current mixed methods research explored patterns in quantitative and qualitative data to answer the following research questions:

1. What patterns emerge between functional communication skills and context variables in the classroom environment for primary-grade children with identified language impairment? 
2. Does health status contribute independently to variability in patterns of functional communication skills over time for target children?

The overall research design utilized themes that emerged from data comparisons across participants, beginning with direct observation of participants' narrative language skills. Inclusion of mothers' and teachers' perceptions of participants as communicators made this study unique. 


\section{CHAPTER TWO}

\section{Literature Review}

Functional communication emphasizes the relative health of a linguistic community and membership in the community. From the perspective of functional communication, the challenge primary educators are facing today is that of teaching children the language of schooling. Each primary classroom experience helps predict future academic and social outcomes for all children. Positive experiences had long-term effects, arguably because daily participation in a highly desirable environment influenced ongoing relationships as well as learner identity even when the classroom changed (Hamre \& Piñata, 2001; Schleppegrell, 2009). This appeared to be particularly true in kindergarten (Mantzicopoulos, 2005). Mantzicopoulos (2005) states, “Those with better school achievement tended to report less teacher-child conflict" (p. 439).

Child attributes that have traditionally defined risk, such as demographic variables, social reticence, and poorer health continue to receive a great deal of attention and will be discussed in the following review of literature. These risk factors impacted oral language skills specifically (Stanton-Chapman et al., 2002) and delayed or impaired language skills tended to reduce access to and participation in schooling (Downer, RimmKaufman, \& Piñata, 2007).

The following review of literature is divided by discipline-specific fields that have contributed separate, yet related, bodies of research concerned with the ways that language skills were an independent factor that impacted early school outcomes (Downer et al., 2007; Gazelle, 2006). Investigators from functional linguistics, public health, 
communication disorders and education contributed research toward understanding the development of children's language skills and how language development related to school success.

Thus, the review is divided into four sections, each corresponding to a specific discipline:

- Theories and applied research is described as it relates to three primary theorists from the field of functional linguistics.

- Health status and social anxiety are themes that will be discussed from the field of public health.

- Research from communication disorders described how oral narrative and academic narrative skills as language targets had prognostic value when describing outcomes for children with language impairment.

- The final section describes how enriched classroom environments and children's preferred classroom environments were important themes from the field of education.

The goal of the following review was to highlight research exemplars from functional linguistics, public health, communication disorders and education separately. All disciplines found developmental risks, social behavior, social context and demographic variables important to understanding the pervasive nature of language impairment and the efficacy of potential interventions (Charmaz, 2006; Greene \& Hogan, 2005; Marshall \& Rossman, 2006). 


\section{Functional Linguistics}

Functional linguistics approached the study of language learning as a broad construct by relating language skills and knowledge to other components of the communication system. Three theoretical perspectives from functional linguistics offer a broad foundation in explaining experiences and adaptive responses as they related to language learning for all children. Exemplars of applied research from the perspectives of language functions, social constructivism, and the creative aspects of language use were selected based on their contributions beyond the important, though ultimately mechanical, structural language descriptions that traditionally motivated language development research.

Language functions. The functional communication system included dimensions of linguistic knowledge, planning and sequencing communication events, patterns of interaction and affect (Bandura, 2003; Halliday, 1974; Jacoby \& Ochs, 1995; Luria, 2002) specific to a communication environment. Halliday (1974, 1975) organized these functions into what he called meta-functions. Halliday's taxonomy included experiential, logical, interpersonal and textual functions of spoken language. "The child takes over the culture, the received system of meanings in which he is learning to share" (p. 98). Halliday contended that thinking is linked to the received system of meaning specific to a communication environment because it supports making connections, visualizing, summarizing, and determining importance within a linguistic community.

In other words, children's awareness of the language structure, meaning and purpose was bound to different linguistic communities. Halliday's meta-functions have 
been referred to as schema and were considered culturally bound to linguistic communities because conversational interactions relied on shared background knowledge. Researchers identified several ways to connect the received system of meanings to oral narrative development or the ability to express ideas using a story structure (Bishop \& Norbury, 2005; Halliday, 1974; Krauss \& Glucksberg, 1969). Academic competence and social acceptance (Geoff, Dockrell, Letchford, \& Mackie, 2002) were examples of other precursors to functional communication. Risks specific to language impairment and ongoing difficulties with language behavior may accumulate without intervention, creating both social and communication competence problems. In part, the accumulation of problems was a result of the dynamic nature of communication environments and events.

Social constructivism. According to Vygotsky $(1978,1994)$, the social construction of communication events included who is able or willing to use communication processes and who has access and with what results. Three classes of mechanisms through which inequality was produced or exacerbated emerged: 1) the unequal distribution of communication events, 2) adaptive orientations to communication experiences that reduced the amount or quality of interactions, and 3) individual communication identity.

Luria (2002) provided a report of a three-phase research study consistent with functional linguistics and the relationship between language knowledge and the social environment. In the first phase of research, he compared the speech responses of urban children, rural children, and homeless children during free play, measured in response 
time. Homeless children's average response time was over 3 seconds where urban and rural children responded more quickly. Luria contended that homeless children developed a marked emotional tension with language behavior. For the second phase of the research, Luria designed a controlled experiment to study the contingent responses to words among the same children. He organized data into an index of constancy and variety among the semantic relationships in the associations. He found that uniform responses were quite common among rural children (37\%). The majority of responses by urban and homeless children occurred only one time. The homeless children's responses were not semantically related. Luria was unable to find a pattern in the strategies these children were using to associate and they were excluded from the final analysis.

Based on a third phase of research that included observations, Luria concluded that group identity explained the diversified yet organized environments experienced by urban children, resulting in a fund of associations. Uniform responses from rural children reflected the cultural value of collective experience. Luria (2002) stated, "Since its primary function is to promote communication, an individual's speech develops under conditions of maximum interaction with others; the more intimate, the more lively this interaction, the more rapidly will speech develop, and the richer will be its content" (p. 72). Rich semantic association and functional responses to bids for social interaction, according to Luria, did not necessitate variety, but were rich in reflecting group membership. Luria (2002) concluded that all schooling was group oriented and blamed formal schooling that isolated rural children from their general historical circumstances in explaining the stereotype that rural persons are backwards. 
Creative aspects of language use. Chomsky claimed that children are born with an innate ability to understand the creative aspects of language use (CALU) that resulted in an ability to generate and communicate novel syntax from linguistic data mined from communication events (1982). Theoretically, as children develop, their own linguistic structures and vocabulary had the capacity to support sequences of conversational interaction that undergirded communication competence (Glaser, 1981).

Using a multiple-baseline and single-subject research design, Hoff and Naigles (2002) analyzed a large set of independent variables to describe the computational processes in lexical (vocabulary) development among two-year-old children over time. A multiple-baseline research design was possible because no more than $50 \%$ of the children's speech contained more than two-word combinations in the baseline phase of the research. This is significant because it allowed the researchers to focus on the data providing features of linguistic input rather than the generative processes in children's own productions. Their measures of the data-providing properties of maternal speech included the total number of utterances produced, the number of word tokens (i.e., the total number of words) in the input samples, the number of word types (i.e., the number of different words), and the mean length of utterance or number of words in each mothers' utterance (MLUw). MLUw measured the degree of syntactic complexity in the mother's speech. It is an index of the richness of the linguistic environment. They included a second measure of social engagement represented by the number of maternal utterances that were topic-continuing replies to child speech. Topic continuing response, 
topic recasting, and primary frame responses were similar concepts that explained adult responses to a child's utterance.

Rather than compare children to one another, Hoff and Naigles (2002) controlled for differences and analyzed growth over time for each child:

To assess differences among the children with regard to the size of the vocabularies they used in spontaneous speech, all of the children's transcripts were truncated to the size of the shortest transcript so that the estimates would not be contaminated by differences among the children in the amount of their verbal output. (p. 425)

Unlike previous theories that supported a match between maternal speaking style and early child language, Hoff and Naigles (2002), found that the number of word types in input was a significant predictor of child vocabulary when analyzed alone, but that the syntactic complexity of input accounted for more variance.

The combined results of this and previous studies suggest that the process of word learning makes use of both the human child's social interest and ability to interact with others, and the child's computational ability to extract information from the speech presented in those interactions. (p. 430)

Table 1 summarizes the risk factors and protective provisions based on themes from functional linguistics. As discussed, the linguistic environment and social environment provided significant protective provisions. This finding supported the case that classroom-based interventions are a pragmatic solution to preventing pervasive language impairment (Goldberg, 2005) and that classroom context variables were likely to influence oral language development over time. 
Table 1

Summary of protective provisions and risk factors from functional linguistics.

\begin{tabular}{|c|c|c|}
\hline & Protective Provisions & Risk Factors \\
\hline attributes & $\begin{array}{l}\text { children's awareness of } \\
\text { language structure, meaning, } \\
\text { and purpose } \\
\text { social competence }\end{array}$ & $\begin{array}{l}\text { maladaptive orientation to } \\
\text { communication } \\
\text { interaction } \\
\text { emotional tension during } \\
\text { communication } \\
\text { interaction }\end{array}$ \\
\hline environment & $\begin{array}{l}\text { intimate, lively interaction } \\
\text { frequent presentation of a } \\
\text { word } \\
\text { complex syntax in } \\
\text { communication interactions } \\
\text { social acceptance }\end{array}$ & $\begin{array}{l}\text { unequal distribution of } \\
\text { communication events }\end{array}$ \\
\hline
\end{tabular}

In addition, the themes in functional linguistics supported the case for a longer sample of spoken language as a meaningful source of data as reflected in the current research study because:

- Syntactic complexity helps build linguistic and social entry points into the linguistic environment.

- Longer units of speaking provided multiple ways to obtain information about word meaning.

- Children used complex syntax and semantic knowledge to successfully bid for social interaction and contribute to the linguistic environment.

\section{Public Health}

Children's general health status, anxious behavior and demographic characteristics have an important role in understanding patterns in functional 
communication skills for target children. It was estimated that children with special health care needs required more time and services from health care providers than children in general (Bryan, Burstein, PenChiang, \& Ergul, 2006). 'Special health care needs' is an umbrella term that refers to 200 chronic conditions, including physical problems, cognitive deficits, developmental delays and behavioral or emotional conditions. The medical field continues to describe the relationship between languagebased disabilities and health impairments as bidirectional.

Research from the perspective of public health described an interaction between conditions at birth that mediated health in early childhood. Problems hearing, developing language, and learning attention skills were described as symptoms rather than as primary diagnoses (Lasky, Jon, Rosenfeld, Priest, Krasinski, \& Heartwell, 1983; Wood, Valdez, Hyashi, \& Shen, 1990). However, in 1998, chronic middle ear disease was cited as one of the leading causes of learning and attention problems in U.S. public schools by the federal government (Battery, 2008).

Rather than diagnostic descriptions, researchers in public health were more likely to use rating scales such as the Hirsch Complexity Rating System, a 4-point scale with 0 indicating a healthy child. In addition to special health care needs, rating scales reflected chronic stressors, such as family financial difficulties, behavioral and social dimensions of less good health, in addition to illness.

Health status. Public health researchers consistently found that ratings of child health status over time predicted academic achievement in studies that have statistically controlled for the effects of socioeconomic risk factors including family income, minority 
status, and maternal education (Stanton-Chapman et al., 2002; Wood et al., 1990).

Additionally, longitudinal studies showed that the combination of multiple risk factors over time affected how parents reported health status rather than illness (Craig, Evans, Meisels, \& Plunkett, 1991; Zill, 1995). Based on 100 audio-taped visits to a randomly selected group of pediatricians, Burstein, Bryan, Chao, Berger, and Hirsch (2005) found that "patterns of communication involving parents and children with complex, chronic health conditions differed substantially from encounters involving healthy children" ( $p$. 259) because parents took time to report real life issues related to ongoing concerns about health and development. Parents of children with chronic health conditions in one study were more likely to report problems at school than problems at home (Bryan et al., 2006). Health status was a significant contributor to social problems in large research populations of young children. In general, risk factors at birth included less than 32 weeks gestation, low birth weight, parental history of learning problems and multiple births (Stanton-Chapman et al., 2002). Health factors included chronic colds, asthma, allergies, poor sleep patterns and a short attention span (Wood et al., 1990; Zill, 1995). According to Zill (1995), health status was a more appropriate variable in research with children because any one diagnosis would falsely show a single-effect explanatory model. He goes on to say that a flexible research strategy is needed because potential interventions must respond to the pragmatic reality that young children with a disability have multiple risk factors.

Bryan et al., (2006) researched the effects of health status on measures of intelligence, language, behavior, and parents' level of stress with a recruited sample of 
112 three- to five-year-old children, using the Hirsch complexity rating scale to group research participants. Their research was unique because the language targets included composite spoken language and receptive language scores from the Test of Early Language Development, Third Edition (1999) (TELD-3). They found that children with health problems scored discrepantly lower than healthy peers on both intelligence and language measures yet within each assessment's range of normal (standard scores of 85115). The most statistically significant correlates existed on the Spoken Language Quotient and the Expressive Language Quotient. On the Spoken Language Quotient the mean standard score (based on a normal distribution, with 100 representing the $50^{\text {th }}$ percentile) for healthy children was 106.22 and 94.52 for children scoring 1-3 on the Hirsch scale ( $\mathrm{p}=.007)$.

Spernak, Schottenbauer, Ramey and Ramey (2006) used a longitudinal design with participants from the National Public School-Head Start Transition Demonstration Study, from kindergarten (in 1992) to grade 3 (in 1995). They divided their sample of 3915 participants into two groups: poor health (fair or poor) and good health (excellent, very good, and good). The division was based on mothers' ratings on a 1-5 scale (excellent, very good, good, fair or poor). In addition to measures of academic achievement, the researchers targeted receptive vocabulary using the Peabody Picture Vocabulary Test-Revised (1982) (PPVT-R) as an indicator of academic achievement. Mean scores for children with poor health in kindergarten (82.93) and third grade (82.42) were significantly discrepant from healthy children in kindergarten (85.33) and third grade (89.85). The reported T-value of $-4.633(\mathrm{p}<.001)$ is the strongest correlation 
reported in this body of research. These findings indicated that former Head Start children in good health made significant gains in vocabulary in the primary grades (Spernak et al., 2006). Children in poor health maintained their status as language delayed three years after entering school as measured by the PPVT-R (1982).

In addition to early health factors, children with attention-deficit/hyperactivity disorder (ADHD) have developmentally inappropriate levels of impulsivity, hyperactivity, and inattention that may cause functional impairments in communication. Children with ADHD have delayed onset of first words and word combinations, discourse limitations producing cohesive narratives, and social communication difficulties, including inappropriate conversational behavior (Redmond, Thompson \& Goldstein, 2011). One explanation for language delays in ADD/ADHD was that many developmental disorders have linguistic symptoms and are therefore part of a family of disabilities including ADHD, autism and language impairment. According to Redmond (2011), ADHD was associated with a unique profile of psycholinguistic strengths and weaknesses, including significantly shorter stories, more off-task speech and more frequent speech disruptions.

Bignell and Cain (2007) investigated pragmatic aspects of communication and language comprehension in relation to poor attention and/or high hyperactivity in a nondiagnosed group of children ages 7-11 years identified as at risk for ADHD/ADD by their classroom teachers. They found that children with poor attention/without hyperactivity rather than high hyperactivity alone were associated with social communication weaknesses and difficulties with figurative language. In a meta-analysis of research on 
language impairment and sustained attention, Ebert and Kohnert (2011) concluded that deficits in sustained attention were part of the language impairment profile and that improvements in attention drove improvements in language skills.

Social anxiety. In addition to health problems and attention difficulties, children with limited language skills were at risk for socially anxious behavior and internalizing problems (Brinton \& Fujiki, 2006). According to Gazelle (2006), socially anxious children kept at a distance from peers and adults because solitary behavior protected them from verbal performance and other social evaluative activities. There is evidence that children with language impairment altered interpersonal development due to socially anxious behavior (Rubin, Coplan, \& Bowker, 2009). The result could be delayed or disordered social cognition (Botting \& Conti-Ramsden, 2008). According to Parisse \& Maillart (2009), without intervention, children with language impairment were at risk for a negative interaction-consciousness that had the potential to affect working memory, a cognitive skill. They claimed that subtle disruptions in the development of the memory system disrupted typical language learning and cognitive skills. Ongoing difficulties with conversation may create an affective filter that influenced relationships at school differently than relationships at home or in the community (Spencer and MarkstromAdams, 1990).

While children with language impairment had difficulty with verbal performance, they were unlikely to have socially inappropriate or disruptive behavior (Bishop \& Norbury, 2005; Brinton \& Fujiki, 2006). Brinton and Fujiki (2006) found that older children with language-based learning disabilities demonstrated strong social skills but 
limited social activity at school. Most of the students in their mixed methods research were described as good friends and helpful, even though these children's participation in school was limited when compared to children without language impairment. They claimed that long-standing avoidance of verbal interaction at school resulted in significant internalizing behaviors that reduced the ability of these children to maintain positive social relationships at school with a variety of peers and teachers. However, Rubin, Coplan and Bowker (2009) found that socially anxious 10-year-olds were as likely as other children to have a mutual best friend.

Research has established that individual differences in language abilities moderated withdrawal and school adjustment (Hamre \& Piñata, 2001). According to Usher and Pajares (2008), children with language impairment "falsely interpret their anxiety as a sign of incompetence "( $(\mathrm{p}$ 754). In a review of school practices, Arnold and Doctoroff (2003) found that programs for low-income and low-achieving children rarely targeted both academic growth and mental health "despite their clear connection" (p. 534). They found that, although targeted interventions were limited, "Early interventions that address both academic and social context show the most longstanding gains " ( $p$. 534). Outcomes in their research included less grade retention, a decrease in reported behavior problems, social gains into middle school, and increased graduation rates.

Table 2 summarizes the protective provisions and risk factors identified from themes in the reviewed public health research. Like Table 1, environmental context provided significant protective provisions from the perspective of researchers in public health. Findings from public health research, specific to the relationship between health 
risk/social anxiety and oral language skills, supported integrating these descriptors into the current research study.

Table 2

Summary of protective provisions and risk factors from public health.

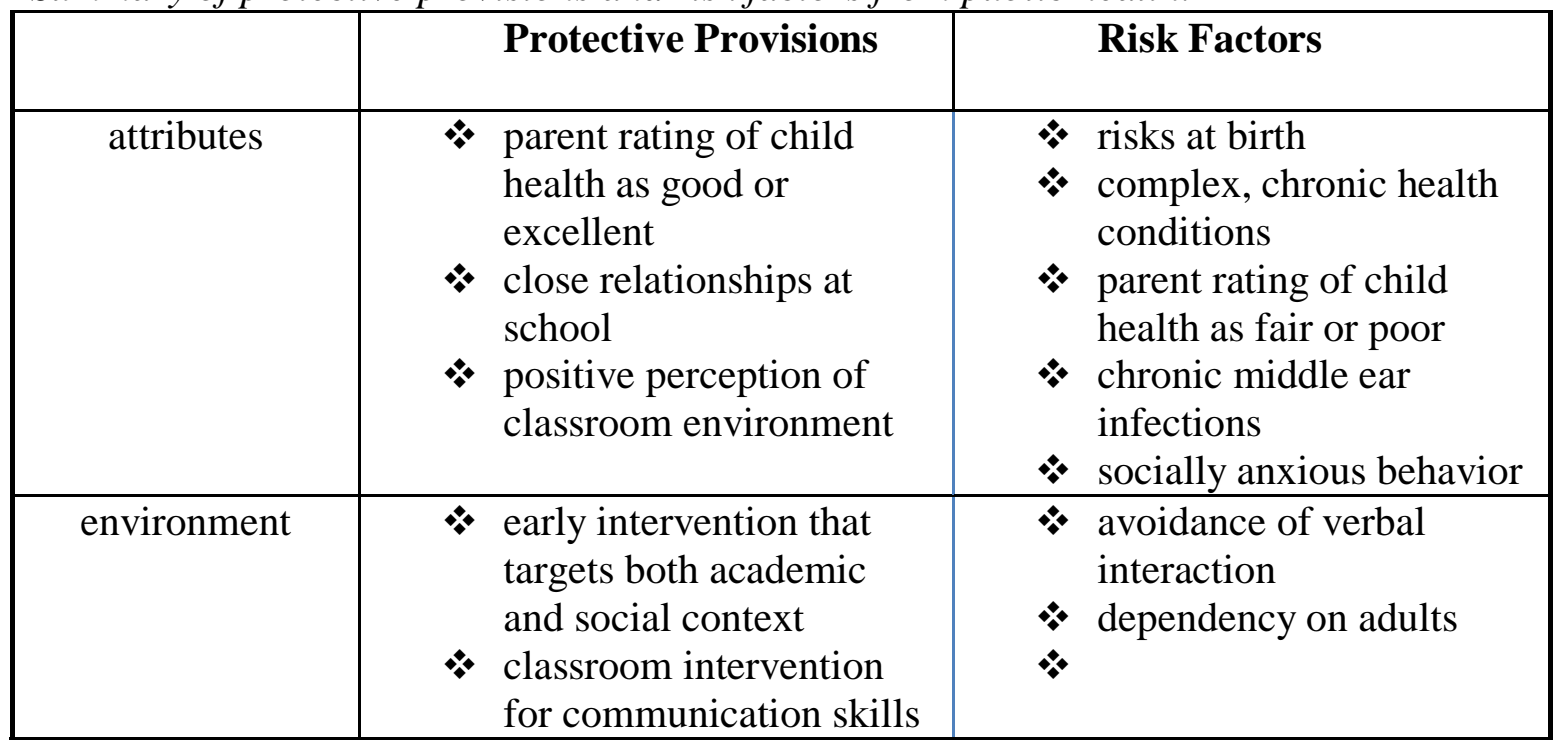

In a review of research on social withdrawal in childhood, Rubin, Coplan and Bowker (2009) outlined a developmental framework within which pathways to and from social withdrawal in elementary school children were mediated by language skills, academic achievement, and classroom climate. They found that successful intervention for language skills and knowledge decreased social withdrawal and that intervention for social withdrawal positively affected language skills and knowledge. They also reviewed research on classroom culture and found that when relationships to others in the classroom were "characterized by less closeness and greater dependency" (p. 157), children had a predictive risk for a number of school adjustment difficulties. Close relationships and autonomy in classroom learning were variables in defining children's positive perception of their classroom environment (Brock, Rimm-Kaufman, Nathanson, 
\& Grimm, 2009). The researchers found that children's positive perceptions had a statistically small association with better social outcomes in one school year. More importantly, they found that previous perceptions and academic/social outcomes predicted later perceptions.

\section{Communication Disorders}

Based on their research of a large epidemiological sample of 7,218 children identified as language impaired in kindergarten, Catts, Fey, Zhang, and Tomblin (1993) found that strong oral narrative skills had a relationship to normal academic achievement for some children with language impairment. They claimed that positive relationships and sustained conversations with adults in the classroom resulted in a scaffolding of logic that informed future elicited discourse that was qualitatively different, separating those children with language impairment who met academic achievement benchmarks from those who did not. Children with language impairment were more difficult communication partners and required intervention.

In an analysis of conversations between primary-grade children with and without language impairment and their teachers, Stojanovik (2006) found significant disparities in the type and amount of conversation. For children without language impairment, 50\% of responses from teachers were an extension of what the child had said. Topic-continuing replies occurred only $38 \%$ of the time for children with language impairment. In addition, $42 \%$ of conversational turns contained a syntax or grammatical error for children with language impairment compared to $12 \%$ for children without language impairment (Stojanovik, 2006). 
Narrative language. Many school age children with language impairment used sentence length syntax and grammar similar to children without language impairment (Greenhalgh \& Strong, 2001). However, many showed syntax and grammar difficulties in narrative language and expanded discourse even in the absence of more global language deficits (Manhardt \& Rescorla, 2002). The four domains of narrative ability included: a) story grammar (Valencia \& Sulzby, 1991); b) linguistic complexity (Kaderavek \& Sulzby, 2000); c) word complexity (Greenhalgh \& Strong, 2001); and d) use of evaluative information (Feldman, 1976). In large studies designed to provide causal explanations, the amount of complex syntax in spontaneous discourse (Craig, Connor, \& Washington, 2003) and narrative ability (Catts et al., 2008) were the strongest predictors of reading comprehension achievement in primary-grade children with and without language impairment.

Research has established that narrative language skills predicted relationship quality at school (Ladd \& Birch, 1999). Hamre and Piñata (2001) found that oral narrative skills correlated with school adjustment in kindergarten and had predictive value in understanding early school success, academic skills in the middle grades, and later identification as learning disabled (Hamre \& Piñata, 2001).

In field research using teachers' perceptions of children's language abilities, Dickinson, McCabe, and Sprague (2003) found that children who met teacher expectations were the same children who were academically successful and that teachers in general had difficulty describing needs in oral language development (Dickinson, McCabe, \& Sprague, 2003). He found that without support, the teachers in his study 
spent far more time talking to children with advanced language skills than other children. When asked, teachers made a concentrated effort to interact with target children each day. Interaction in the classroom environment was important because children's productions of extended discourse drew on both structural knowledge about a text's internal organization (Halliday, 1974) and social knowledge about the interaction functions of narrative (Kozulin, 1990). As language developed, narrative structure organized and integrated understandings in different ways to achieve different goals (Krauss \& Glucksberg, 1969).

Formal schooling requires children to produce several types of narrative discourse including personal accounts, summaries, expository accounts of how things work, and fictional narratives. Existing research has shown that oral narrative skills develop rapidly and are considered a meaningful source of information in research with young children (Boudreau, 2008; Kratochwill, Brody, \& Piersel, 1979; Peets, 2009). In addition, strong oral narrative skills provided a foundation for more complex academic narrative language. In summary, language development, specifically discourse and narrative skills in the early grades, had a relationship to social and academic achievement (Kaderavek \& Sulzby, 2000; Nippold, Hesketh, Duthie, \& Mansfield, 2005). According to Russell and Grizzle (2008), "engagement in the classroom drives the development of important structural language competencies and social cognition" (p. 61).

Table 3 summarizes the themes from the field of communication disorders. In general, it illustrates how language behavior and discourse patterns that engage children 
with teachers and content provided the needed practice for the development of narrative skills, academic language skills, and comprehension strategies.

Table 3

Summary of protective provisions and risk factors related to themes in communication disorders.

\begin{tabular}{|c|c|c|}
\hline & protective provisions & risk factors \\
\hline attributes & $\begin{array}{l}\text { strong narrative skills } \\
\text { positive relationships at } \\
\text { school } \\
\text { teacher's report that a child } \\
\text { is 'easy to communicate } \\
\text { with' } \\
\text { recognizing school } \\
\text { language as an academic } \\
\text { register }\end{array}$ & $\begin{array}{l}\text { difficulty monitoring } \\
\text { communication events } \\
\text { lack of basic story } \\
\text { grammar } \\
\text { lack of complex syntax } \\
\\
\text { difficulty with } \\
\text { comprehension } \\
\text { strategies }\end{array}$ \\
\hline environment & $\begin{array}{l}\text { teachers making a } \\
\text { concentrated effort to } \\
\text { interact with target children } \\
\text { supported telling } \\
\text { more than one adult in the } \\
\text { classroom } \\
\text { topic continuing replies } \\
\text { from teachers } \\
\text { sustained conversations }\end{array}$ & $\begin{array}{l}\text { maladaptive attitude } \\
\text { toward conversational } \\
\text { interaction at school } \\
\text { less time talking to } \\
\text { adults and peers in the } \\
\text { classroom }\end{array}$ \\
\hline
\end{tabular}

Children removed from their classroom for remedial instructional groups and special education services may be further disadvantaged because they miss the dynamic cues the classroom environment provide for children to learn academic content. There was evidence that children with language impairment had difficulty learning comprehension strategies (Catts et al., 1993). This was because difficulties with the written language register impacted reading comprehension and children were confused when they wanted to demonstrate a comprehension strategy, such as order of importance 
(Boudreau, 2008). Confusion and embarrassment exacerbated maladaptive attitudes regarding relationships and conversational interactions in the general education classroom, causing children to remain confused (Scarborough, Dobrich, \& Hager, 1991). Research from the field of communication disorders illustrated that language skills and understanding communication are child characteristics that provided protective provisions for classroom learning. For children who struggle with language, risk factors accumulated because being a difficult communication partner negatively influenced interactions and relationships at school. On the other hand, increasing opportunities to practice communication in the classroom environment had a compensatory role in improving the foundational language skills needed for classroom learning.

\section{Education}

Two themes emerged from a review of literature from the field of education specific to classroom context variables that responded to the needs of children with mild disabilities. The first research theme comes from an a priori assumption that biological and genetic risk factors can be compensated for through enriched environments (Somersalo, Solantaus, \& Almqvist, 2002).

The second body of research looked specifically at children's preferred classroom environments (Brock, Nishida, Chiong, Grimm, \& Rimm-Kaufman, 2008). These studies were more likely to prioritize student engagement and independence related to classroom context variables.

In general, educational research continuously confirmed that the quality of the classroom environment had a greater compensatory role for children with greater 
vulnerability (Buyse, Verschueren, Doumen, Van Damme, \& Maes, 2008; Gazelle, 2006). The synergistic relationship between child attributes, children's spoken language skills and evidence of environmental support over time was consistent with a post-critical philosophy and the need for research that seeks to understand how children with disabilities respond to different classroom environments.

According to Greene and Hogan (2005), research designed to study the range and variety of activities, roles, and reciprocity between a child and an everyday setting should be conducted. They go on to say that understanding the events of the immediately experienced levels of the classroom environment can produce significant results specific to the goals of early schooling.

Enriched environments. For many of the reasons discussed earlier in this review, conversational and discourse analysis research from the field of education has established that children at risk for academic underachievement participate in fewer and shorter verbal exchanges with adults and peers (Cazden, 1988; MacLure, 2003; Pendergast, 2003; Rimm-Kaufman et al., 2002).

Cazden (1988) and Pendergast (2003) established that within verbal interaction in the classroom, pro-social behavior in children allowed for greater control over recurring discourse patterns and that outsider children were often in a position of deficit in comparison. Outsider status in discourse studies encompassed non-white children, children whose home language is different from English, children living in poverty, and children with disability (McLure, 2003). Interaction patterns included descriptions of discourse structures, such as initiation+response+evaluation (IRE), primary frame 
response, and non-solicited contributions (Delpit, 1995; Neale \& Test, 2011). In other words, these patterns consisted of the amount and type of initiated responses that pulled teachers and children into conversation. They included prosodic features, eye gaze, body alignment and affect. Inhibition and social disinterest appeared to be related responses to challenging interaction patterns (Corrigan, 2008).

Meyer, Wardrop, Hastings, and Linn (1993) found that the frequency and nature of teacher-child interactions were potent indicators of the 'value added' to children's achievement as a function of attending kindergarten. In an investigation of Meyer et al.'s (1993) exploratory findings, Piñata, La Paro, Payne, Cox, and Bradley (2002) observed over 200 classrooms and found that child-centered aspects of the classroom (the teacher allowing children some freedom and choice, the absence of negativity among peers or between adults and children, and the presence of a positive, supportive emotional tone to interactions) were "associated with higher child social competence as rated by the teacher and observed competence and on-task behavior, as well as literacy and mathematics competence, as rated by teachers two months later" (p. 234).

Piñata et al. (2002) used an observation protocol that included interaction patterns with 223 kindergarten children with developmental delays to investigate evidence of social relationships to evaluate teacher quality. They found that the children in their study were likely to have more positive academic and social outcomes when classroom instruction was marked by "instructional conversations between teachers and target children, a heavy emphasis on literacy instruction, and provision of feedback to students that [had] an evaluative aspect and the goal of improving performance" (p. 236). 
Several researchers further defined literacy instruction to mean multi-modal activities, such as interactive read aloud, access to a variety of media materials for speaking, reading, and writing, and displays of children's work (Downer, RimmKaufman, \& Piñata, 2007; Sideridis \& Greenwood, 1998). In addition, teacher behavior, such as being well prepared and efficient in providing children with opportunities to engage (Downer, Rimm-Kaufman, \& Piñata, 2007), were directly linked to the variety and amount of curriculum materials in the classroom (Valencia, Place, Martin, \& Grossman, 2006).

An adequate amount and variety of literacy materials was very important. Research established that children with language impairment had self-imposed limitations for social interactions within literacy events (Georgakopoulou, 2006; Shanker, 2002), including playing with books, being read to and listening to stories at home. These children need intense and multiple opportunities to interact with literacy at school.

In a study by Scarborough, Dobrich, and Hager (1991), children who developed as poor readers in elementary school amused themselves with books only 2-3 times per week at two and three years of age, while children who became normal readers typically did so almost daily. According to Hood, Conlon, and Andrews (2008), phonological awareness and vocabulary skills mediated children's enjoyment of being read to and interacting with books. The social interaction required to understand written texts by non-readers has been established in research as a necessary context for early literacy learning (Bond and Wasik, 2009; Corrigan, 2008). 
In addition to improving the quality and amount of literacy materials, Bond and Wasik (2009) used an intervention in classrooms with high numbers of children at risk for early school failure called a 'conversation station'. The conversation station was comparable to a literacy center in the researched classrooms. It had materials and a physical location. However, the station changed the role of the teacher from wandering the room to being a literacy prop in the conversation station. They found that children loved to draw pictures and talk about their favorite things, bring books to the station and that teachers reported a stronger connection with the students because they had an opportunity to learn about each student through reliable, sustained conversation when compared to teachers in the role of wandering the classroom. Additionally, in some classrooms the station included pictures and props children brought from home. This example was supported by research that academic achievement is fostered in classrooms where children and teachers are friends, there are changing displays of children's work and children have opportunities to work 1:1 with the teacher (Brock et al., 2008; Ladd \& Birch, 1999).

Wolfersberger, Reutzel, Sudweeks and Fawson (2004) used a grounded theory design that began with teacher focus groups to understand voluntary literacy behavior as it related to the classroom environment and materials. The focus group teachers described the pivotal role that materials and student work played in the classroom and the role of classroom culture in encouraging authentic literacy events. The teachers and researchers visited actual classrooms and began establishing categories of materials such as displayed student work, amount and type of books, and physical environments to 
define literacy rich classrooms (Wolfersberger et al., 2004). The next step in the research process was a review of relevant literature and reworking categories related to the material culture and evidence of student engagement with literacy events. The research concluded with publication of the Classroom Literacy Environmental Scale (2004) (CLEP) observation-scoring guide that quantified the classroom environment as it related to authentic literacy events.

Preferred classroom environments. While activities and materials in the classroom environment were important, research comparing children's preferred environment and actual classroom environments found that children were not concerned about actual activities (Rimm-Kaufman et al., 2002; Stipek \& Byler, 2004). Young children were more likely to report a preference for classrooms with a patient teacher, lots of pictures, and opportunities to be with friends (Ok Seung Yang, 2000). Stipek and Byler (2004) used an observation protocol and survey data to evaluate relationships at school for at-risk children in first and second grade. They found that when children had choices both in the context of teacher-planned activities and during choice time, teachers were more likely to provide encouragement and guidance rather than direct instruction. They found that children preferred classroom environments where discipline was brief and non-disruptive rather than formal. This was similar to findings from other researchers who found that children benefited from brief social skills instruction specific to classroom activities (Brock et al., 2009).

Fraser and Fischer (1982) used a correlational design with three cognitive and six affective dependent variables to understand preferred science classroom environments. 
They found that students wanted control over their learning as active participants rather than passive learners. They also found that students were more likely to prefer classrooms where they participated in planning the activities and were acknowledged for thinking creatively. Although Fraser and Fischer (1982) did not address friendship specifically, their findings were supported by evidence that children produced more lively communication and more features of academic language when they were engaged with peers they considered friends (Gazelle \& Ladd, 2003; Guilar, 2006; Jones, 2002).

In their research, Guo, Justice, Kaderavek, and McGinty (2012), found that children's language and literacy development was correlated with a strong physical literacy environment that included literacy areas in the classroom when compared to other factors such as number of books. McMahon, Richmond and Reeves-Kazelskis (1998) compared emergent reading classrooms to reading readiness classrooms from both an enriched environment perspective as well as a preferred classroom perspective. The researchers created an index of emergent literacy instruction and an index of didactic reading instruction. They found that the physical environment (including the number of books) and teacher expertise specific to early reading instruction in classrooms that emulated real life literacy events were superior for relationships, engagement, and amount of literacy activities experienced for individuals and groups of children.

Table 4 summarizes relevant themes from research in education. Social exchange in the classroom environment, including children's control over the content and discourse, described some of the protective provisions. 
Table 4:

Summary of protective provisions and risk factors from education.

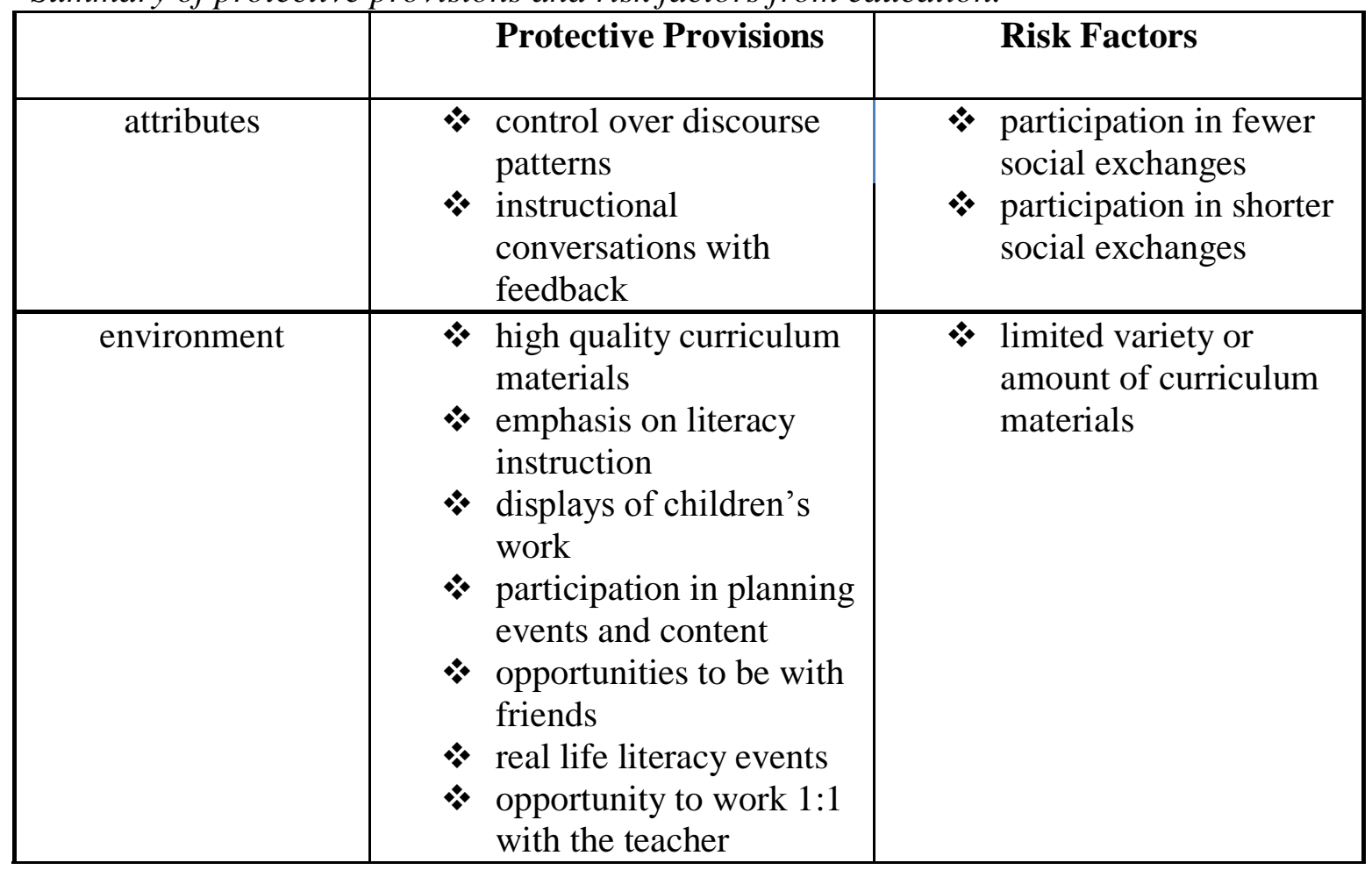

\section{Summary}

Understanding how classroom environments can help sustain improvements in oral narrative skills for target children would contribute significantly to understanding evidence-based interventions. A review of existing research supported a multidisciplinary and multiple strategy approach to investigating patterns in oral language skills and functional communication for primary-grade children at risk for early school failure due to language impairment. Child attributes, including relative health status and social reticence, were important to understanding these patterns. Bishop and Norbury (2005) found that many classroom communication routines challenged the children and youth with language impairment in their randomized longitudinal study because the 
participants had marked difficulties generating ideas relevant to the communication context when compared to children without language impairment. They further defined relevant from a functional perspective, stating that providing the listener with too little information, misunderstanding the broader topic of conversation and being stuck on a particular type of idea were common descriptions of conversational inadequacy. They found that these skills were problems for children with language impairment across communication events, but were more exaggerated at school than in other communication environments (Bishop \& Norbury, 2005). 


\section{CHAPTER THREE}

\section{Research Methods}

This chapter describes the overall research design and the procedures used in this study. The purpose of the study was to understand the patterns in oral narrative skills for young children with language impairment and the way teachers and parents described children as communication partners.

\section{Mixed Methods Research Design}

Mixed methods was selected to understand the situated patterns in the participants' communication and to use data for a practical synthesis rather than for generalization (Johnson, Onwuegbuzie, \& Turner, 2007). According to Small (2011),

mixed methods research is distinctly the method of choice in the $21^{\text {st }}$ century for practiceoriented research using networked data rather than formal statistical analysis. Mixed methods was selected to approach the research from a broad perspective and include multiple stakeholders in the process (Charmaz, 2006). Mixed methods data collection methods provided added context. According to Charmaz (2006), mixed data collection combined conventional methods for direct observations with interviewing and reviewing documents.

The use of direct observation and field research supported thematic analysis. The research design provided an informed understanding of classroom environments and stakeholders' understandings when describing functional communication. 
A case and field mixed method research design was used to collect data from direct observation of students' oral narrative skills, interviews with teachers and parents, classroom observations, and a review of assessment and IEP documents for a small group of participants. Quantitative and qualitative data were collected simultaneously. Table 5 provides a description of data collection strategies used for each participant.

Table 5

Data collection strategies.

\begin{tabular}{|c|c|c|c|}
\hline data & type & measure & citation \\
\hline $\begin{array}{l}\text { transcribed } \\
\text { language samples }\end{array}$ & quantitative & $\begin{array}{l}\text { Systematic Analysis } \\
\text { of Language } \\
\text { Transcripts (SALT) }\end{array}$ & $\begin{array}{l}\text { Miller, J. \& Iglesias, A (2010). } \\
\text { Systematic analysis of language } \\
\text { transcripts (SALT), research version } \\
2010 \text { [computer software], SALT } \\
\text { Software, LLC. }\end{array}$ \\
\hline $\begin{array}{l}\text { transcribed } \\
\text { language samples }\end{array}$ & quantitative & $\begin{array}{l}\text { Narrative Scoring } \\
\text { Schema (NSS) }\end{array}$ & $\begin{array}{l}\text { Heilman, J., Miller J., Nockerts, A. } \\
\text { and Dunaway C. (2010) Properties of } \\
\text { the narrative scoring system. } \\
\text { American Journal of Speech- } \\
\text { Language Pathology. 19, 154-166. }\end{array}$ \\
\hline $\begin{array}{l}\text { classroom } \\
\text { observations }\end{array}$ & quantitative & $\begin{array}{l}\text { Classroom } \\
\text { Environmental } \\
\text { Literacy Profile } \\
\text { (CLEP) }\end{array}$ & $\begin{array}{l}\text { Wolfersberger, M.E., Reutzel, R., } \\
\text { Sudweeks, R. and Fawson, P. (2004). } \\
\text { Developing and validating the } \\
\text { classroom literacy environmental } \\
\text { profile (CLEP): A tool for examining } \\
\text { the print richness of early childhood } \\
\text { and elementary classrooms. Journal } \\
\text { of Literacy Research, 36(1). }\end{array}$ \\
\hline $\begin{array}{l}\text { teacher-structured } \\
\text { interview }\end{array}$ & qualitative & $\begin{array}{l}\text { Communication } \\
\text { Partner Stage } \\
\text { S.C.E.R.T.S. } \\
\text { Assessment System }\end{array}$ & $\begin{array}{l}\text { Prizant et al., (2006). The SCERTS } \\
\text { model: A comprehensive educational } \\
\text { approach for children with autism } \\
\text { spectrum disorders. Baltimore, Md: } \\
\text { Paul H. Brookes Publishing. }\end{array}$ \\
\hline $\begin{array}{l}\text { parent-structured } \\
\text { interview }\end{array}$ & qualitative & $\begin{array}{l}\text { Communication } \\
\text { Partner Stage } \\
\text { S.C.E.R.T.S. } \\
\text { Assessment System }\end{array}$ & \\
\hline documents & qualitative & $\begin{array}{l}\text { Individual } \\
\text { Education Plans and } \\
\text { assessment reports }\end{array}$ & \\
\hline
\end{tabular}


Sampling. A chain referral sampling method was used in the community of SLPs in northwestern Oregon (Penrod, Preston, Cain, \& Starks, 2003). Information and referral documents (See Appendix A) were mailed to SLPs and phone calls were made one week later to confirm that SLPs had received the documents and to answer clarification questions. Following this initial sampling phase, the researcher was contacted by SLPs from a variety of settings (Penrod et al., 2003) that included private clinics, hospital clinics, university clinics, and schools. Most contacts were from SLPs wanting specific information about the research. One large nonprofit clinic was not able to make direct referrals to the research due to policies related to federal grants and internal research practices.

Initial referrals for participation in the research included 16 children with a predetermined diagnosis of language impairment. This initial group met the language impairment criteria based on a score of 80 or below on a standardized language test from an American Speech-Language-Hearing Association approved list of expressive language tests. Following initial referral, parents were contacted by phone to review the criteria specific to school-based services as outlined on their child's IEP and to confirm the child's age. Parents were asked if a second diagnosis of autism or mental retardation described their child. Five children were receiving more than 60 minutes per day of special education services in a pullout model in addition to weekly services from a SLP. These students did not meet the full inclusion criteria defined as less than one hour per day in special education. Three children were over the age of 9 years. One child was a 
four-year-old preschooler. Two children had a medical diagnosis of autism. The remaining five children participated in the study.

Participation was dependent on written consent given by each child's parent(s) (see Appendix B) and each child's ongoing consent to participate in the protocols designed for eliciting three oral narrative retells. Each participant's family contacted their child's classroom teacher and school principal prior to any data collection.

Children for whom poverty and educational restraints could be a risk factor were not included in this exploratory study because extensive poverty research confirmed that parent lexical diversity, parent responsiveness to child language, and parent promotion of language development were negatively impacted by low-income status (Delpit, 1995). Poverty as a risk factor was beyond the scope of this study.

Participants. The participants in this study included five children from an initial referral sample of 16 children. Felicia, Carson, and Daniel were receiving services at school in addition to services in the community from a SLP working in a private clinic. Their private provider referred them to participate in the study. Bailey and Edward were receiving services at school only. They were referred by their school-based SLP. See Appendix A for the participant criteria provided to SLPs for nomination.

All participants were from families where the mother had completed a 4-year college degree. Maternal education level was a general index of socio-economic status to rule out the impact of poverty on language development. Participants displayed normal hearing as determined by a pure tone screening completed by a school-based SLP and documented in a written assessment report. Participation was based on an expressive 
language composite score of 80 or below on a comprehensive language test. Test names are listed in Table 6 . Table 6 also provides basic information about the five participants. Table 6.

Participant characteristics.

\begin{tabular}{|c|c|c|c|c|c|}
\hline participant & grade & $\begin{array}{c}\text { maternal } \\
\text { education } \\
\text { level }\end{array}$ & assessment & $\begin{array}{c}\text { expressive } \\
\text { language } \\
\text { score }\end{array}$ & $\begin{array}{l}\text { total } \\
\text { score }\end{array}$ \\
\hline Bailey & 2 & 16 & $\begin{array}{l}\frac{\text { Test of }}{\text { Language }} \\
\text { Development- } \\
\text { Primary 4 } \\
\text { (TOLD P4) }\end{array}$ & 67 & 77 \\
\hline Carson & 2 & 17 & $\begin{array}{l}\text { The } \\
\text { Expressive } \\
\text { Language Test } \\
\text { (ELT) }\end{array}$ & 69 & 94 \\
\hline Daniel & kindergarten & 17 & $\begin{array}{l}\text { Clinical } \\
\text { Evaluation of } \\
\text { Language } \\
\text { Fundamentals- } \\
\text { Preschool } \\
\text { (CELF-P) }\end{array}$ & 79 & 79 \\
\hline Edward & 1 & 16 & $\begin{array}{l}\text { Clinical } \\
\text { Evaluation of } \\
\text { Language } \\
\text { Fundamentals } \\
\text { (CELF) }\end{array}$ & 75 & 78 \\
\hline Felicia & kindergarten & 18 & $\begin{array}{l}\frac{\text { Preschool }}{\text { Language }} \\
\underline{\text { Scale (PLS) }}\end{array}$ & 79 & 97 \\
\hline
\end{tabular}

The following simple case descriptions are based on reports and statements included in each participant's assessment report. They are included to provide the reader with a basic profile of each participant based on documents that established evidence of language impairment. 
Bailey. Bailey, a current second grader, began receiving services from a SLP at age three for both speech and language delays. Bailey's first grade teacher reported that she avoided social situations and classroom discussions and that she "can't think of what to say" when called on. During testing, Bailey answered without providing the most important information. When asked to define the word "shoe," her response was "is make you safe". At the same time on test items that required following directions and identifying concepts and qualities nonverbally, Bailey demonstrated skills similar to other children her age. In settings outside of the classroom, such as recess and in the speech room, Bailey was described as outgoing. At the time of this study, Bailey was receiving speech-language services at school as well as monitoring of her reading and math skills in the general education classroom.

Carson. Carson, a current second grader, began receiving services from a SLP at age 3 because he was not putting words together. He was last evaluated as a first grader with concerns he was struggling with "putting together a coherent story or being able to retell a story". Carson had difficulty with specific language during testing, stating that a microphone was used "so voice can be high" and, when asked about a mechanic shop, responding "at the fixing center". Carson demonstrated above average skills on receptive vocabulary and average scores on listening comprehension. At the time of testing, Carson had marked difficulty with language strategies, such as sentence repetition, a memory task, and using language to predict an outcome. At the time of this study, Carson was receiving speech-language services at school as well as weekly services from a SLP at a private clinic and monthly counseling from a psychiatrist due to anxiety. 
Daniel. Daniel, Carson's brother and a current kindergartener, began receiving services from a SLP at age 4 because he was not putting words together. At that time Daniel was using 2-4 word combinations such as "more train cars" and "it fixed". The report goes on to say, "When [Daniel] was unsure of a word to use he would mumble or use jargon or make up a word, like unercycle". Daniel was described as curious about everything. At the time of this study, Daniel was receiving speech-language services at school as well as weekly services from an SLP in a private clinic.

Edward. Edward, a current first grader, began receiving services from a SLP at age five for an articulation disorder. In the winter of first grade, he was evaluated for language impairment. Edward's kindergarten teacher described him as having difficulty with storytelling and answering questions. She reported that he gets very close to her to communicate. She also reported that he had difficulty with getting started in the classroom and needed more reminders than other children. During testing, Edward had difficulty recalling sentences and describing word relationships. It was stated in the report that Edward retold $30 \%$ of a storybook, leaving out the basic setting and ending of the story. However, on sub-tests that measure following directions, making up meaningful sentences, and receptive vocabulary, Edward demonstrated skills similar to other children his age. At the time of this study, Edward was receiving weekly speechlanguage services for 30 minutes and 60 minutes per week of reading/writing tutoring services at school.

Felicia. Felicia, a current kindergartener, began receiving services from a SLP at age 4 and was described at that time as a late talker by her parents. Felicia used language 
during doll play and to label pictures. It is stated that she did not answer questions. In addition to language impairment, the report stated that Felicia was diagnosed with an anxiety disorder at the same time. She was reported to have had chronic middle ear infections from birth to age three. The report noted that Felicia had difficulty with social interactions during this initial evaluation. Her narrative skills were not evaluated. At the time of this study, Felicia was receiving speech-language services at school as well as speech-language and occupational therapy at a private clinic. Felicia did not meet the final criteria of a score greater than 1.0 standard deviation below the mean, which was based on an age and transcript length comparison group. Felicia did not demonstrate an oral narrative deficit based on her initial language sample transcript collected at the start of the current research. She was excluded as a full participant in the study because her narrative language was similar to a comparison group. Felicia's transcript data is provided for comparison purposes only.

Human subjects. Approvals for all aspects of this research study were secured from the Portland State University Institutional Review Board, a human subject review committee (see Appendix D). Stipulations protecting documentation included a locking file cabinet and a password-protected computer for digital documentation and data. Protecting participant identity included changing real names to pseudonyms to protect privacy. For organizational purposes, the names are alphabetical and in order of initial language sample date.

Settings. The settings of this study included four public schools in the northwestern section of Oregon. Language sample data for three of five of the 
participants were collected at school in a small conference room or speech therapy office. Language samples for Carson and Daniel were elicited in their home at a kitchen table. Teacher interviews and classroom observations were conducted in each participant's classroom. Two parent interviews were conducted at the participants' homse and two were conducted at the participants' schools.

Procedures. In the following section, the rationale and procedures for data collection are described. Standardized procedures and training for each measure used during data collection were the sole responsibility of the researcher. A concurrent data collection method, where qualitative and quantitative data were collected together rather than sequentially, was selected. For composition purposes, however, quantitative procedures are discussed first, followed by qualitative procedures. Quantitative procedures included standardized elicitation protocols for language sample collection, transcription, and analysis. Procedures for classroom observations used a quantified scoring guide. Secondly, qualitative procedures for structured interviews with each participant's current classroom teacher and the mother of each participant are described, followed by procedures for reviewing selected educational documents, including evaluation reports and IEPs.

Quantitative procedures. Procedures for language sample analysis using descriptive statistics followed standardized transcription and coding of errors specified in the Systematic Analysis of Language Transcripts Research Version (2010) (SALT). SALT is a software tool used by a variety of disciplines to document language development in typical children, children with developmental disabilities, and children 
learning English as a second language (Miller \& Iglesias, 2010). SALT (2010) provided transcription rules and analysis of word counts as well as categorizing and summarizing different linguistic features within each language sample (see Appendix F).

Language samples offered several advantages over standardized tests, including the ability to collect data on a variety of language forms without the bias associated with repeating standardized tests. Language samples have a strong ecological validity because language samples reveal difficulties with formulation and meaning making that standardized tests cannot. In addition, children with language impairment have been shown to have a higher rate of errors in language samples than non-disabled children even when they score within an average range on standardized expressive language tests (Bishop, 1994).

Describing internal sentence level structures is considered an analysis of narrative microstructure (Heilmann, Miller, Nockerts, \& Dunaway, 2010). According to Justice, Bowles, Kaderaveck, Ukrainetz, Eisenberg, and Gillam (2006), narrative microstructure includes a combination of measures to describe productivity: word output, utterance output, and lexical diversity; and measures to describe complexity: syntax organization, mean length of utterance, and proportion of complex communication units.

Language samples. Each participant completed three narrative retells of a wordless picture book by Mercer Mayer. Standardized elicitation for retell procedures provided the children an initial model script (see Appendix E) and book look to assist in developing an understanding of the story structure. Retell procedures ensured that 
language samples were elicited in a way to support the best opportunity for narrative productions. In addition, a quiet and familiar setting was used.

The participants' narrative productions were recorded using audio and video digital technology and were downloaded to a password-protected computer. These recordings were used during transcription. Following three hours of transcription training using standard transcription conventions in SALT (2010), the primary researcher transcribed each language sample (see Appendix F).

Accuracy of the transcription and coding process was examined at three levels: utterances, mazes, and other errors and word/utterance errors were transcribed separately for each language sample. This ensured that each language sample was listened to at least three times. After the initial transcription, each language sample was reviewed a second time to confirm that utterance segmentation rules were accurate. $\mathrm{C}$-units or communication units are utterances that cannot be further divided without losing meaning. Discrepancies between the initial transcription and the revision were referenced with the SALT (2010) manual. A second listening supported coding all mazes and other errors types including abandoned utterances. Word level and utterance level codes were added during a third transcript review. Several discrepancies were resolved by utilizing the utterance level error code. The utterance level error code (EU) at the end of a C-Unit was used if there were more than two error codes already assigned to an utterance or when the error was considered syntactic and could not be assigned to a specific word. Prior to analysis of a language sample, SALT (2010) provided a final check for errors in transcription. 
Corpus comparisons. For all micro-structural analysis, age and transcript length matched comparisons were made following the conventions for the Narrative Student Selects Story (NSSS) corpus data set (Miller \& Iglesias, 2010) for each transcript. The NSSS (2010) data, available in the SALT research version (2010), is a corpus of language samples from 330 typical developing children ages 5, 6, 7, 8, 9, 11 and 13 years old from cities and towns in Wisconsin. None of the children qualified for free and reduced lunch. Corpus data comparisons in SALT (2010) provided standard deviation results, mean scores and score ranges.

Written transcripts were referenced while watching and listening to the language samples to complete the macro-structural analysis procedures following scoring rules for the Narrative Scoring Schema (NSS) (Miller \& Iglesias, 2010). Standard measures analysis was recorded following each retelling using NSS (2010) procedures in SALT (2010). The NSS (2010) is a subjective assessment of language skills beyond the microstructure level. The NSS (2010) incorporated seven measures of the narrative transcript into a single scoring rubric and included a total narrative score (see Appendix H). The NSS (2010) was an indicator of three narrative developmental stages, immature 0-10, emerging 11-25, and proficient 26-35.

Following two hours of initial training provided by the SALT (2010), each transcript was reviewed against the video-recorded narratives and assigned a score of 0-5 for each of the seven categories: introduction, character development, mental states, referencing, conflict resolution, cohesion, and conclusion. After scoring, analysis of descriptive statistics comparing participants' NSS (2010) scores to corpus NSS (2010) 
scores from the Narrative Story Retell (NSR) corpus in SALT (2010) resulted in standard deviations, means, and score ranges based on an age and transcript length comparison group. The NSR (2010) database, available in SALT's researcher version, included story retelling language samples from 330 typically developing English speaking children ages four years four months to 10 years 10 months who lived in California or Wisconsin. This corpus is specifically designed to explore patterns in the NSS (2010).

Classroom observations. The Classroom Literacy Environmental Profile (CLEP), a scaled scoring guide validated and published in 2004 (Wolfersberger et al., 2004), was used to collect data on participants' classrooms toward the end of the 2011-2012 school year. The scoring guide is a 33-item scaled observation, using 1-7. The CLEP (2004) has items that assess:

1. Literacy events including extra consumables used to explore book making and comfortable seating for independent reading.

2. Literacy products and displays of student work.

3. Literacy tools including the size and organization of a classroom library. Classroom observation data provided added context to the study by ensuring that each participant was being educated in an adequate classroom environment (See Appendix G).

The CLEP (2004) was validated using generalizability evidence based on teacher focus groups. The focus groups provided inter-rater agreement data, based on multiple occasions to rate classrooms and determine acceptable levels of generalizability. In other words, the CLEP (2004) score ranges are based on a high level of inter-observer 
agreement as well as observe/re-observe agreement in actual classrooms over time.

Classroom observations were completed over the course of two visits when the classroom was not in use. On the first visit, the researcher moved about the classroom to survey the general classroom space and then completed each item on the checklist, looking specifically for the level of implementation. On the second visit, each item was reviewed. If there was a discrepancy, the higher score was given. On several occasions, teachers were asked about documentation of books read or other record keeping of literacy events because they were not always public. Scores reflect both private teacher documentation and public documentation. On the second visit, still digital photographs were taken of the classroom, classroom library, and student-created literacy products.

The CLEP (2004) item scores were entered into two subscales: subscale 1 for provisioning the classroom with literacy tools and subscale 2 for arranging classroom space and literacy tools, gaining student interest in literacy events, and sustaining students' interactions with literacy tools. Individual item scores were totaled and averaged, resulting in subscales matching interpretive descriptions for a) 1.0-2.4 impoverished, b) 2.5-3.9 minimal, c) 4.0-5.4 satisfactory, or d) 5.5-7.0 enriched.

Qualitative procedures. Teacher interviews were conducted in May 2012 before or after school. Parent interviews were conducted at the end of data collection. Current IEP documents were collected in the fall of 2012 to ensure they were the most current plan for each participant at the time of the dissertation defense.

Teacher interviews. Interviews with classroom teachers for each participant were conducted in the classroom after written consent from the teacher was documented and a 
written description of confidentiality was reviewed. Teacher interviews were not audiorecorded. Data was collected from notes and written direct quotes taken in face-to-face interviews. Interviews questions were guided by communication skills during Social Communication, Emotional Regulation and Transactional Supports (2006) (SCERTS). A SCERTS assessment was published in 2006 as part of comprehensive educational approach for children with Autism Spectrum Disorders and other communication disorders (Prizant, Wetherby, Rubin, \& Laurent, 2006). According to Prizant et al. (2006), these are the primary areas of concern among teachers and parents who work with young children with communication disorders and other developmental delays. The SCERTS (2006) interview is designed for children who have the ability to interact in reciprocal conversations with a variety of conversation partners even though they may have qualitative impairments in social interaction and social relatedness, difficulties in acquiring and using conventional communication, or impaired language abilities.

The interview question worksheet explored the teachers' perspectives on participants' interactions in the classroom and at school; their emotional responses to communication events, whether the child was easy or difficult as a communication partner and what features of the physical or social environment in the classroom helped the participant with communication.

Interviews were scheduled when the researcher was in the classroom for the initial classroom observation. Each teacher was provided a copy of the structured interview questions at that time for them to consider prior to the interview. Each interview was scheduled for one hour in the teacher's classroom and was followed by a second 
classroom observation. Two teachers added additional information while the researcher was on site and this follow-up information was noted. Each teacher was given a $\$ 50.00$ gift card to a local bookstore for her participation.

Parent interviews. Interviews with each participant's mother were conducted in the family home or the speech room of the school. Written consent for the interview and audio recordings was included in the original consent for participation in the research project (see Appendix B). The same SCERTS (2006) assessment that guided interview questions used for the teacher interviews was used to guide the interviews with each participant's mother. With the exception of Edward's mother, responses were transcribed verbatim within a week of the interview and were grouped into short paragraphs or meaningful units (see Appendix J). Edward's mother responded over the phone to the SCERTS (2006) questions. Notes and selected direct quotes were transcribed.

Mothers were asked about their child's communication skills at home and in the community and their child's emotional responses to communication events, including peer and sibling interactions. Parents also reported information about their child's health and development. Most parents reported about school and community services their child was receiving within the context of the interview questions. Children were not present during the interviews. The interviews ranged from 20 minutes to 65 minutes in length.

Document review. Prior to a review of records, each parent provided written consent for the exchange and release of protected health information on a Health Insurance Portability and Accountability Act (HIPAA) regulation form provided by the 
Oregon Department of Education (see Appendix C). A review of evaluation reports and the current year's IEPs was considered important for this study because they provided written documentation of the needs of the child in a way that is different from the way the needs of the child were described in the interviews. The IEPs were provided by the school-based SLP working with each participant in the spring of 2012. The assessment reports were provided by the evaluating SLP, who in some cases was from a private clinic, and were up to two years old. In each case, there were at least two SLPs involved in documentation for each participant and in one case, there were six different SLPs noted in the documents.

Qualitative data management. Hard copy data was organized into a three-ring binder for each participant and stored in a locked file cabinet. Following each interview, data was transcribed into paragraphs. Data sorting began immediately following the first teacher interview using the highlighting of words, phrases, or paragraphs on hard copy transcripts. This was followed by paragraphing of text and entering each unit into the Coding Analysis Toolkit (CAT) (Lu \& Shulman, 2008) to organize and manage the qualitative data. Paragraph length units were entered into CAT (2008) following the conventions for a raw database.

CAT (2008) is a computer-assisted qualitative data management and analysis software. This digital workspace is password protected and can be accessed through the Internet. After establishing an account with a unique username and password, CAT (2008) allowed the primary researcher to upload sets of uncoded data files at no cost. The CAT was selected because it has a relative advantage over other software when a 
single coder, in this case the primary researcher, is being used. According to Lu and Shulman (2008), the CAT had efficiencies with a single coder who planned to code and then interpret because coding the data relied on the coder's ability to accurately and consistently identify examples. Databases and code files could be shared if a researcher decided on an adjudication process for validity purposes.

Open coding resulted in key terms, including speaking, feelings, parenting, socializing, class work, conflict, being understood, and storytelling. Key terms became guideposts for deciding units of meaning in the data.

Qualitative data management included a review of the data that showed $80 \%$ of items for social communication and social skills were cross-coded. Separate themes were maintained. Key terms, including "being understood" and "storytelling," were re-defined as utterance formulation and narrative skills to be more congruent with quantitative results as well as IEP goals. Categories, units, and direct quotes in the raw data set were reviewed prior to the final coding to define themes based on a survey of examples.

The final coding included 118 units. This process resulted in the final codes: a) utterance formulation/difficulty putting words together, using grammar, word finding skills; b) narrative skills/storytelling, retelling, reporting about events, and sequencing events in narrative; c) social communication/social skills /negotiation, protesting, planning, friendship, and developmental behavior; d) attention and focus/persisting in difficult tasks, joint attention, attention to learning in a group, and memory; and e) conflict/shutting down, emotional events, and negative self-regard. The final coded data set was referenced in analysis of themes and source analysis. 


\section{CHAPTER FOUR}

\section{Results, Findings, and Analysis}

Research results, findings, and analysis are presented in four sections. The first two sections include quantitative results. Results and analysis from language sample transcripts are presented first. Analysis included relative patterns in each transcript for productivity, complexity, verbal facility and rate, and narrative macrostructure. A more detailed analysis of maze patterns is provided. Secondly, classroom observation data is summarized. An analysis of scores on the CLEP (2004) is discussed. The third section is devoted to thematic analysis of qualitative data. Seven emergent themes organized the data: a) utterance formulation; b) narrative skills; c) social communication; d) attention/focus; e) social skills; f) conflict; and g) health/emotional health symptoms. Mixed methods analysis supported defining themes. The fourth section re-organizes the themes as they relate to a source analysis. Case and source analyses were utilized as a means conceptualizing the data.

\section{Quantitative Results, Findings, and Analysis}

The mixed method research design explored language sample transcripts collected at three points in time for Bailey, Carson, Daniel, and Edward and one time for Felicia. To explore patterns in participants' narrative language, descriptive statistics were used in an analysis of the quantitative data set as scores related to corpus data from the SALT (2010). To add context to the research, each participant's classroom was observed and scored using the CLEP (2004). Results support that functional communication requires multidimensional linguistic proficiency. 
Narrative microstructure. Quantitative analysis of each language sample was conducted using SALT for narrative microstructure. Descriptive statistics were based on corpus group comparisons. The number of children in each corpus comparison group varied depending on the participants' ages and transcript lengths. Scores from Felicia's transcript were included for comparison purposes only. Her overall NSS (2010) score was above the corpus mean and eliminated her from participation in the ongoing research.

Productivity. The measures selected to describe productivity included total number of words (TNW), total number of different words (NDW), and number of complete and intelligible utterances (\#C\&I). The number of children in each corpus group and results for measures of productivity are summarized in Table 7. Total number of words, number of different words, and complete and intelligible utterances were measures that described productivity, and deficits were based on difficulty with vocabulary variation and lexical diversity in narrative discourse. Unintelligible and abandoned utterances have been shown to have a negative impact on the functional communication skills for children with language impairment. Therefore, an analysis of the number of complete and intelligible utterances within a total number of utterances was included. 


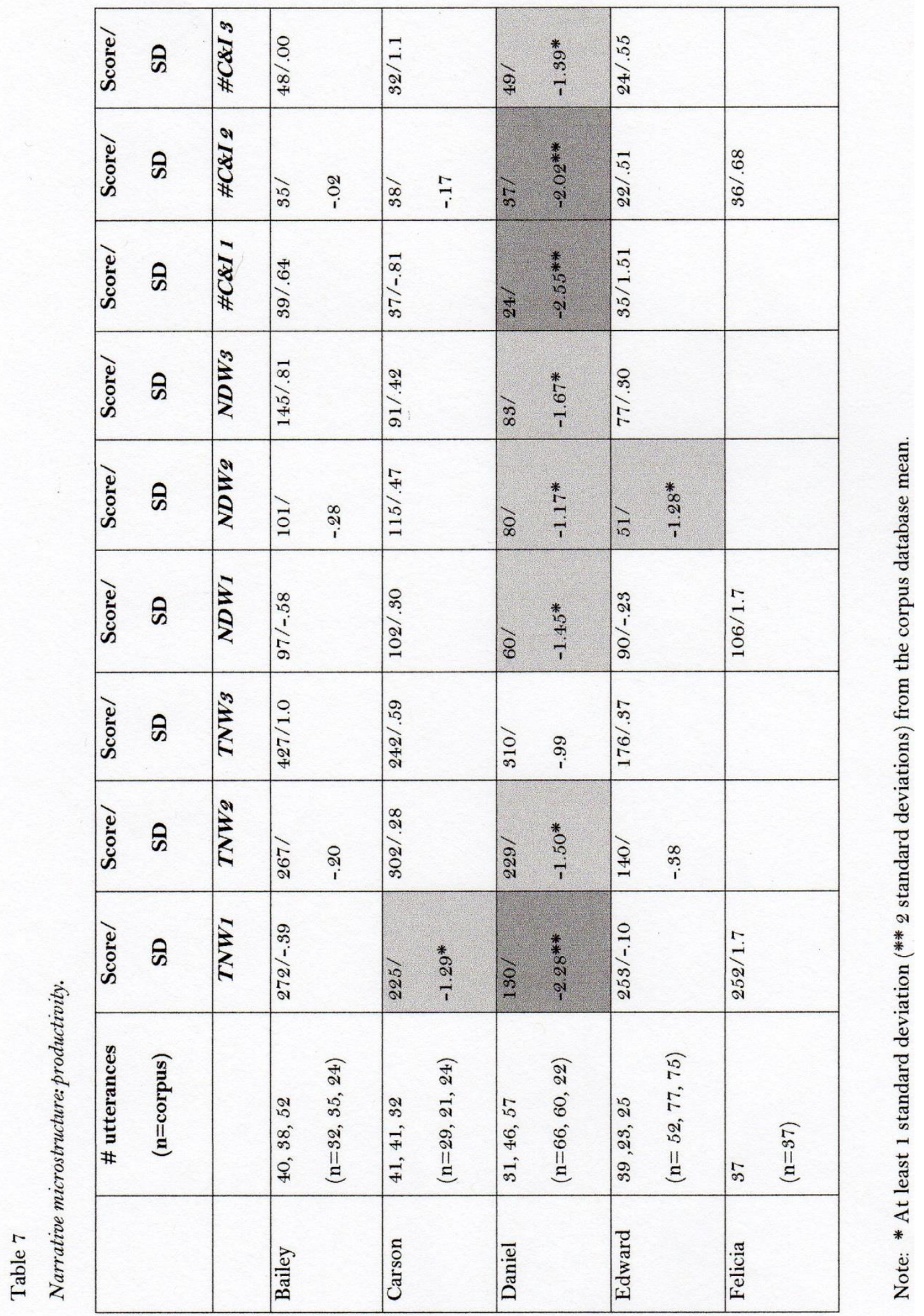


Carson's first language sample and Daniel's first and second language samples showed a deficit in total number of words when compared to corpus data. Edward's second language sample and Daniel's first and second language samples showed a deficit in number of different words when compared to an age and transcript length matched peer group.

Total number of utterances per language sample and total number of complete and intelligible utterances for each language sample indicated that with the exception of Daniel, participants did not have difficulties with intelligibility or completion at the utterance level. Each of Daniel's language samples had a high number of abandoned utterances.

These results suggest that with the exception of Daniel, measures of productivity did not differ significantly from the corpus comparison groups across transcripts for the other participants. Measures of productivity in Daniel's transcripts indicated a pattern of deficit in narrative production. Daniel's scores for complete and intelligible utterances on the first and second transcript were more than two standard deviations below the mean, indicating that Daniel's communication at the utterance level was significantly impaired.

Complexity. The four measures used to describe complexity included mean length of communication unit in words (MLUw), mean length of communication unit in morphemes (MLUm), word level errors (EW), and verbal facility and speaking rate. Individual scores and standard deviations from the mean, based on age and transcript length, matched peers in the corpus and are summarized in Table 8. 


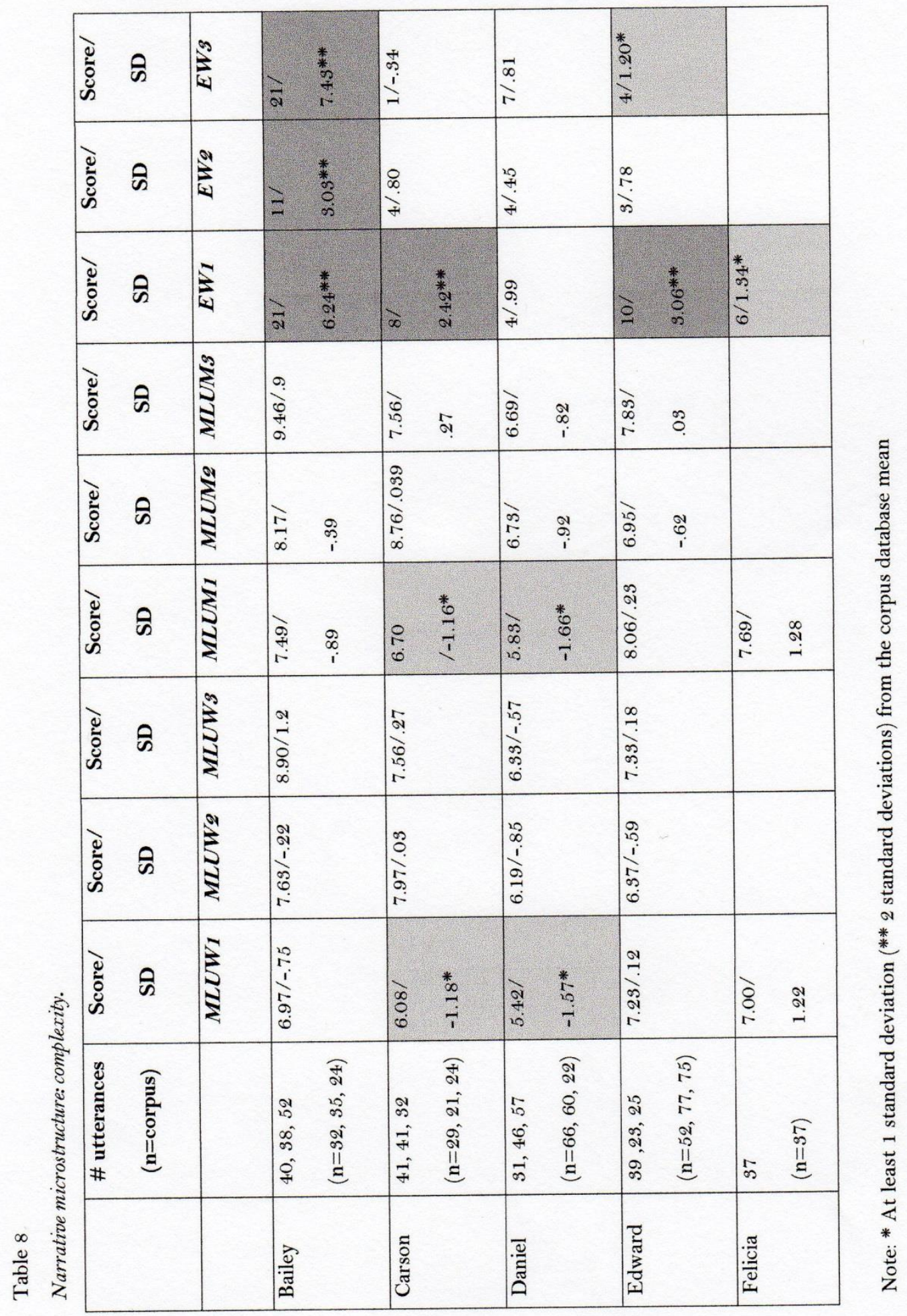


Reduced utterance length was a pattern in Carson's first transcript and Daniel's first transcript. This pattern was confirmed in the MLUm measures reported in Table 8. Utterance length deficits represented another marker of language impairment in young children. A pattern of reduced utterance length was an indicator of less mature syntax. One explanation for the improving trend in Daniel and Carson's transcripts was that MLU is a measure that is sensitive to the sampling context. An upward trend in Bailey's MLU confirmed this finding. Results indicated that participants made more word level errors than the corpus comparison groups across transcripts. This was true for Bailey's and Edward's transcripts where other measures of complexity were similar to the corpus comparison mean.

Word level errors on Edward's first transcript and Carson's second transcript were very high. Bailey's word level errors were very high across all three transcripts. This indicated that participants struggled at a higher rate with word finding and grammar on some days when compared to other days. One explanation for the downward trend in errors at the word level for Carson and Edward was that the complexity of past tense narrative verb structure was more likely to be a problem in their first retelling when compared to subsequent retellings. Familiarity with the sampling context had a positive impact on MLU for all participants. However, an increase in MLU and familiarity with the sampling context did not have the same affect word level errors for Daniel and Bailey.

Results for narrative complexity indicated that participants had delays in progressing toward more accurate word finding even when other linguistic measures, 
such as MLUw, MLUm and number of different words, were comparable to corpus means. Participants continued to demonstrate lower levels of proficiency in the areas of correct word choice and grammar when compared to age-matched peers (Redmond, 2003).

Verbal facility and rate. Number of utterances with mazes (UWM), words per minute (WPM), and elapsed time (ET) summarized in Table 9 describe verbal facility and rate. Revisions, also coded as mazes in SALT, were rewording or reformulations that clarified meaning or contributed accuracy to the language to support meaning making. Other coded mazes included filled pauses, repetitions, and abandoned utterances.

Results indicated that participants as a group had fewer overall mazes than comparison groups on their initial language sample, and Edward had fewer mazes than the comparison group on all three transcripts. With the exception of Edward, participants needed extra time to formulate their oral narratives when compared to age/transcript length matches in the NSSS (2010) corpus data.

Elapsed time was included in Table 9 as a second way to describe verbal rate when comparing participants' data to corpus data. With the exception of Edward, results for rate indicated a lower level of automaticity in oral narratives. A need for more planning time within the narrative context affected narrative production rate rather than actual speaking rate. In other words, participants were fluent speakers, but to process a narrative re-tell they needed frequent short pauses, more time between utterances, and repetitions of words and phrases to move the processing of the story re-tell forward. 


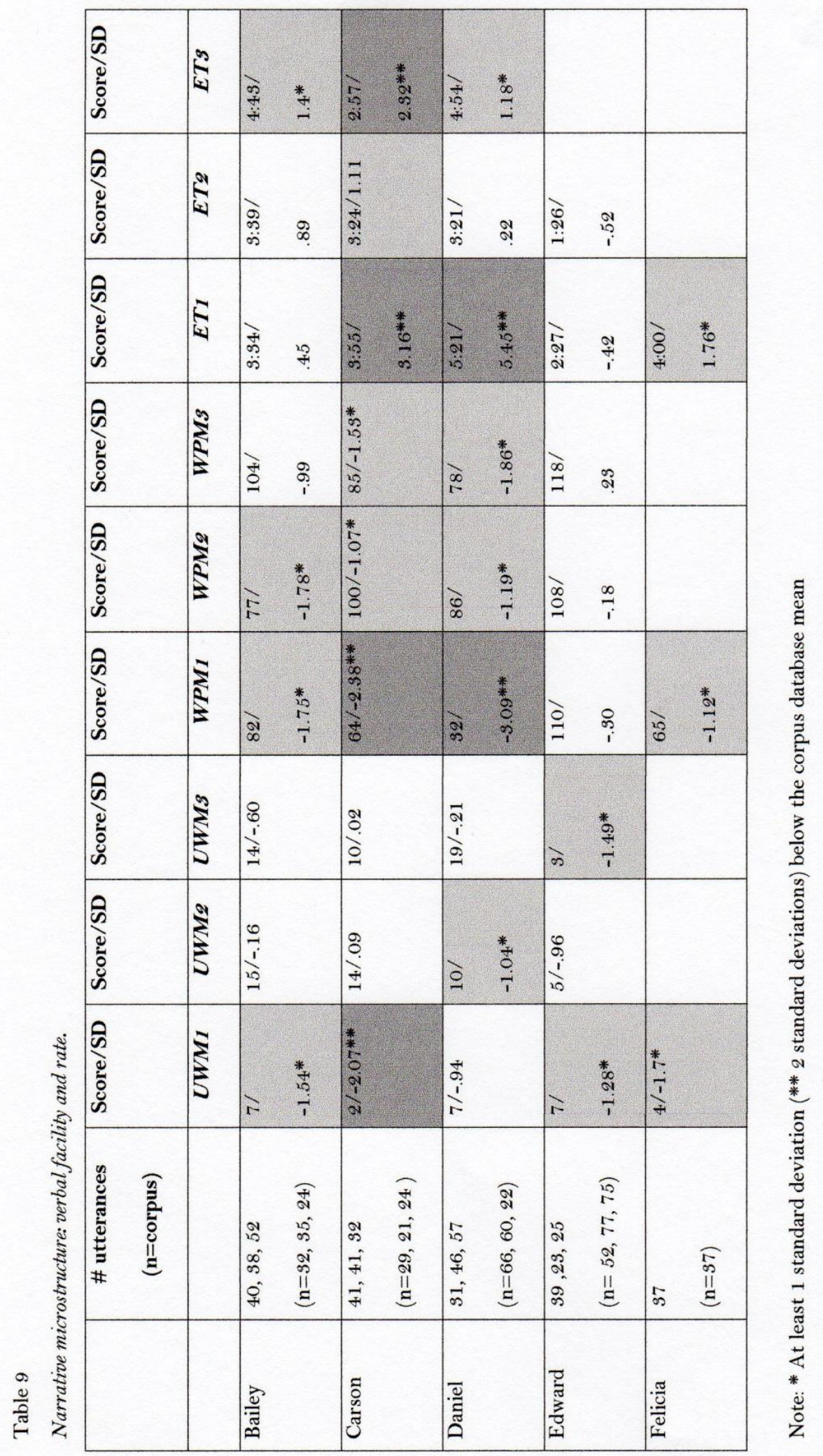


Utterance level errors, type of word level errors and maze type were important considerations when exploring patterns in the past tense narrative context of the language samples. Utterance level errors were coded using the standards for transcripts in SALT. If an utterance had more than one word-level error, was abandoned, or had an error in syntax, it was coded as an utterance level error. Word-level error classifications included omissions, non-specific word choice, incorrect word, and grammatical errors. In analysis, maze classifications included a) filled pauses; b) interjections; c) part-word repetitions; d) whole-word repetitions; e) phrase repetitions; and f) revisions.

According to Fiestas et al. (2005), typically developing monolingual and bilingual children can be expected to make a revision on up to $25 \%$ of utterances in a narrative language sample. They asserted that type of maze differentiated children with language impairment rather than overall percentage of utterances with mazes. To classify word level errors and mazes, a more detailed analysis indicated that grammar errors accounted for a large proportion of word level errors while repetitions accounted for the majority of coded mazes.

A classification of phonological revision, lexical revision, grammatical revision, syntactical reformulation, and orphans (a maze that does not have a relationship to other words around it) was used in analysis (Fiestas, Bedore, Peña, \& Nagy, 2005; Guo, Tomblinson, \& Samelson, 2008).

To support this analysis with examples, a summary of utterance level errors, word level errors, and mazes coded in a section of Bailey's first transcript is provided in Table 10. It includes a sample coding of errors and actual utterances. With the exception of 
Daniel, the first transcript for each participant had more coded errors than subsequent transcripts.

\section{Table 10}

Characteristics of utterances with error codes in Bailey's transcript \#1.

\begin{tabular}{|c|c|c|}
\hline \# Utterance & error & description \\
\hline 3. there and $>$ & utterance & abandoned utterance \\
\hline $\begin{array}{l}\text { 5. so not (um he was) he } \\
\text { was (he was) look/ing at the } \\
\text { pond. }\end{array}$ & maze & phrase repetition \\
\hline $\begin{array}{l}\text { 5. so not (um he was) he } \\
\text { was (he was) looking/ing at } \\
\text { the pond. }\end{array}$ & maze & phrase repetition \\
\hline $\begin{array}{l}\text { 6. and then (now um) he } \\
\text { and (then) the dog just look } \\
\text { [EW:looked] up and } \\
\text { [EW:at] the pond }\end{array}$ & maze & filled pause \\
\hline $\begin{array}{l}\text { 6. and then (now um) he } \\
\text { and (then) the dog just look } \\
\text { [EW:looked] up and } \\
\text { [EW:at] the pond }\end{array}$ & maze & word level repetition \\
\hline $\begin{array}{l}\text { 6. and then (now um) he } \\
\text { and (then) the dog just look } \\
\text { [EW:looked] up and } \\
\text { [EW:at] the pond }\end{array}$ & word level & $\begin{array}{l}\text { grammar error: past tense regular (look for } \\
\text { looked) }\end{array}$ \\
\hline $\begin{array}{l}\text { 6. and then (now um) he } \\
\text { and (then) the dog just look } \\
\text { [EW:looked] up and } \\
\text { [EW:at] the pond }\end{array}$ & word level & incorrect word \\
\hline 7. then he spot & utterance & fragment \\
\hline $\begin{array}{l}\text { 8. (from the a) from a frog } \\
\text { and he wants to (check) } \\
\text { catch it. }\end{array}$ & maze & lexical revision \\
\hline $\begin{array}{l}\text { 8. (from the a) from a frog } \\
\text { and he wants to (check) } \\
\text { catch it. }\end{array}$ & maze & lexical revision \\
\hline $\begin{array}{l}\text { 9. an* he have [EW:has] a } \\
\text { bucket and a net. }\end{array}$ & word & grammar error: past tense irregular \\
\hline
\end{tabular}


Results summarized in Table 11 show that as a proportion of speaking disruptions and error codes, grammatical errors and repetitions were more common than other word errors and maze types. Table 11 quantifies patterns in the transcripts from each participant for utterance level errors, word level errors, and maze types.

\section{Table 11}

Classification of word level errors, mazes, and total utterance level errors.

\begin{tabular}{|c|c|c|c|c|}
\hline codes & Bailey & Carson & Daniel & Edward \\
\hline word level errors & $\begin{array}{l}\text { omissions: } 3 \\
\text { non-specific } \\
\text { word choices: } 1 \\
\text { incorrect words: } \\
2 \\
\text { grammatical } \\
\text { errors: } 15\end{array}$ & $\begin{array}{l}\text { omissions: } 1 \\
\text { non-specific } \\
\text { word choices: } 0 \\
\text { incorrect words: } \\
1 \\
\text { grammatical } \\
\text { errors: } 4\end{array}$ & $\begin{array}{l}\text { omissions: } 0 \\
\text { non-specific } \\
\text { word choices: } 2 \\
\text { incorrect words: } \\
1 \\
\text { grammatical } \\
\text { errors: } 6\end{array}$ & $\begin{array}{l}\text { omissions: } 0 \\
\text { non-specific } \\
\text { word choices: } 1 \\
\text { incorrect words: } \\
2 \\
\text { grammatical } \\
\text { errors: } 7\end{array}$ \\
\hline mazes & $\begin{array}{l}\text { filled pauses: } 5 \\
\text { interjections: } 0 \\
\text { part word } \\
\text { repetitions: } 5 \\
\text { whole word } \\
\text { repetitions: } 7 \\
\text { phrase } \\
\text { repetitions: } 2 \\
\text { phonological: } 0 \\
\text { lexical: } 3 \\
\text { syntactic: } 1 \\
\text { orphan: } 2\end{array}$ & $\begin{array}{l}\text { filled pauses: } 1 \\
\text { interjections: } 0 \\
\text { part word } \\
\text { repetitions: } 0 \\
\text { whole word } \\
\text { repetitions: } 4 \\
\text { phrase } \\
\text { repetitions: } 6 \\
\text { phonological: } 0 \\
\text { lexical: } 2 \\
\text { syntactic: } 0 \\
\text { orphan: } 1\end{array}$ & $\begin{array}{l}\text { filled pauses: } 1 \\
\text { interjections: } 0 \\
\text { part word } \\
\text { repetitions: } 1 \\
\text { whole word } \\
\text { repetitions: } 23 \\
\text { phrase } \\
\text { repetitions: } 11 \\
\text { phonological: } 0 \\
\text { lexical : } 1 \\
\text { syntactic: } 10 \\
\text { orphan: } 1\end{array}$ & $\begin{array}{l}\text { filled pauses: } 2 \\
\text { interjections: } 0 \\
\text { part word } \\
\text { repetitions: } 0 \\
\text { whole word } \\
\text { repetitions: } 9 \\
\text { phrase } \\
\text { repetitions: } 1 \\
\text { phonological: } 0 \\
\text { lexical : } 2 \\
\text { syntax : } 2 \\
\text { orphan: } 0\end{array}$ \\
\hline $\begin{array}{c}\text { total utterance } \\
\text { level errors }\end{array}$ & 6 & 3 & 6 & 4 \\
\hline
\end{tabular}

With the exception of Daniel, participants had very few revisions at the utterance level. The maze types with the highest occurrences were word and phrase repetitions. The small number of revisions in Bailey's, Carson's, and Edward's transcripts, when 
compared to corpus means, indicated that using strategies to revise for meaning was difficult for participants. Word finding efforts in addition to processing time resulted in longer ET for the same number of utterances for participants. Participants did not, however, take more time because of a higher number of revisions at the utterance level. With the exception of Carson's second and third transcripts and Bailey's second transcript, total coded mazes were less frequent than corpus comparison groups.

A lack of revisions that contributed to the meaning-making function of narrative discourse had a negative impact on macro-narrative scores that will be discussed in the following section. Interjections and revisions were communication repair strategies that provided communication partners with enough information and clarify what was being said. Participants used very few of these language strategies. Data showed that participants had difficulty planning and coordinating what to say. According to Fiestas et al. (2005), children with language and learning difficulties had an over reliance on nonspecific language and garbage mazes when producing narratives due to word-finding difficulties. A garbage maze was a repeating of words or phrases, initial parts of words, or unattached fragments that do not contribute additional meaning to the language but was evidence of attempts to repair communication breakdowns and fill pauses to allow for processing time. Research has shown that speech hesitation rates in the narratives of children with language impairment have a negative impact on communication. Speech disruptions and hesitations for participants' data was affected by the narrative demands and therefore could be evaluated using WPM calculations as well as maze analysis. These findings were consistent with Finneran, Leonard, and Miller (2010), who found that high 
levels of word and phrase repetitions as a proportion of total mazes differentiated children with language impairment from their typical peers. Low levels of revision indicated difficulties with self-monitoring during the communication event. However, other research found a higher number of overall maze types in groups of children with language impairment when compared to control groups (Guo et al., 2008). A pattern of overall high numbers of utterances with mazes was consistent with Daniel's data. For Daniel, results showed that maze data should be interpreted as a developmental process in narrative discourse where Daniel was making revisions as he progresses toward a more normative MLU. In Daniel's case, syntactic reformulations accounted for the majority of revisions.

Maze data indicated two patterns in the language of participants. First, decreased speech disruptions (garbage mazes) in participants' transcripts had a relationship with normative MLU. Second, a low level of revisions that contributed meaning in narrative formulation indicated difficulties with self-monitoring.

Narrative macrostructure. Narrative macrostructure includes discourse organization, content, and language skills beyond the utterance level (Heilmann et al., 2010). Narrative discourse is required in the general education curriculum and formal and informal subjective evaluation has been shown to have a very high rater agreement when compared to other language content assessments (Morrow, Tracey, Woo, \& Pressley, 1999). Retelling and summarizing were reading comprehension measures used in curriculum-based assessments and running reading records. The NSS (2010) incorporated higher-level narrative features and the NSS (2010) scoring rules required 
judgments across seven domains of the narrative process. The NSS (2010) was aligned with many curriculum-based assessments and the CCSS (2010). The seven judgments included scoring for introduction, character development and mental states of the characters, referencing, conflict resolution, cohesion, and conclusion. See Appendix H for a description of the scoring schema in the NSS (2010).

NSS (2010) data for each transcript was analyzed using corpus data from the NSR (2010) database with a grade/transcript length matched comparison group. Grade level mean scores for kindergarten were reported in a range from 17-19, grade 1 range was 2325, and grade 2 means range from 24-26 depending on transcript length. Total NSS scores for each participant transcript, standard deviations, and mean scores reported in corpus comparison groups are summarized in Table 12.

Table 12

Narrative macrostructure: narrative scoring scheme total score.

\begin{tabular}{|l|l|l|l|c|}
\hline participant & $(\mathbf{n}=\mathbf{N S R})$ & Score/SD/Mean & Score/SD/Mean & Score/SD/Mean \\
\hline & & \multicolumn{1}{|c|}{ NSS1 } & NSS2 & NSS3 \\
\hline Bailey & $(\mathrm{n}=40,37)$ & $16 /-2.44 / 24.92 * *$ & $15 /-2.63 / 24.70 * *$ & $19 /-1.26 / 24.45^{*}$ \\
\hline Carson & $\begin{array}{l}(\mathrm{n}=40,29, \\
43)\end{array}$ & $17 /-1.90 / 24.63 *$ & $23 /-.41 / 24.72$ & $17 /-1.66 / 24.33 *$ \\
\hline Daniel & $\begin{array}{l}(\mathrm{n}=43,41, \\
37)\end{array}$ & $12 /-3.04 / 20.26 * *$ & $14 /-2.31 / 20.32 * *$ & $18 /-.84 / 20.27$ \\
\hline Edward & $\begin{array}{l}(\mathrm{n}=41,45, \\
32)\end{array}$ & $17 /-1.15 / 20.17 *$ & $14 /-2.27 / 20.04 *$ & $20 /-.15 / 20.41$ \\
\hline Felicia & $(\mathrm{n}=72)$ & $21 / .65 / 18.99$ & & \\
\hline
\end{tabular}

With the exception of Felicia, participants had narrative discourse content and organization NSS (2010) scores greater than 1.0 standard deviation below the mean when compared to grade/transcript length corpus comparison groups on the initial story retelling, qualifying them to participate in the full research study. Confirming a deficit in 
the language use components under study was a research convention in speech-language pathology used in the current study (Nippold, 2010).

Results showed that 7 of 12 scored transcripts were 1.5 standard deviations or more below the mean after analysis in SALT. The mean NSS (2010) score in the corpus for first grade was 20, indicating that a score of 20 or better represents demonstration of basic story grammar. Five of the NSS (2010) categories, including introduction, character development, conflict resolution, conclusion, and cohesion, were consistent with basic story grammar. Scores of three or better on the quality of story grammar and the overall cohesion of the narrative (i.e., linguistic devices used to connect the elements of the text, such as articles and conjunctions) were given to Carson's second and Edward's third retelling.

Carson's second transcript scored a 23 and Edward's third transcript scored a 20 on the NSS (2010). Carson, Edward, and Bailey demonstrated at least one language sample that took on the form of an adventure for the central characters. This included a structure of episodes that were presented in a logical sequence. According to Hedberg and Westby (1993), this emergent narrative stage was described as a focused chain and was descriptive of typically developing kindergarten children. The following transcript excerpt was an example of a focused chain.

"then their frog jump/ed in the salad.

then the waiter put it on non-specific language $\}$.

then the lady scream/ed.

it jump/ed into his drink.

then (he) he was $\mathrm{xxx}$ and then he was try/ing to catch the frog. 
then he cover/ed his mouth.

then he was going to throw away the frog.

then the little boy said "no that/'s my frog".

they got kicked out.

they went at home [EU].

and they was[EW:were] all mad at the little boy.

and (they) he got sent to his room with his frog and his little turtle and his little dog. Meyer)

then he was crack/ing up" (Edward, transcript 3, Frog Goes to Dinner, Mercer

Most transcripts scored below 20 on the NSS (2010), indicating that participants were not able to demonstrate basic story grammar in retelling a wordless picture book after a model. Transcripts that scored a one or two on the story grammar components had the quality of a list or an unfocused chain of events. The following is an excerpt from Bailey's second transcript. It was an example of an unfocused chain because it lacked a description of the central characters' physical characteristics, facial expressions, or internal thoughts or plans. Bailey's later transcripts demonstrated a focused chain or episodic narrative.

"OK[FP] the boy here is now UM[FP] sleep/ing.

but the frog (get) get*s out of (hi*) his jar.

there was an open window here that he climbs out.

the boy wak/ed[EW:woke] up and the jar was empty. the>

; :4

(the) $\mathrm{UM}[\mathrm{FP}]$ the boy here was try/ing to find the frog.

did we>

is it in his boot/s. 
nope.

the boy here (jus* jus*) UM[FP] say[EW:says] "froggie where are you"? "come back".

the fro*>

(the) the jar stuck to the dog/3s head.

the dog fall/ed[EW:fell] because the jar was heavy, very heavy" (Bailey, transcript 2, Frog Where Are You, Mercer Meyer.

Daniel's initial transcript lacked the necessary referencing needed to sequence events in the retelling. Daniel's narrative had the quality of a collection of unrelated ideas. However, he used intonation and pausing as he verbalized while turning the pages. His facial expressions and page turning demonstrated an understanding of the task. However, his words did not connect to one another or to the story episodes or chain, giving it the quality of a list. The following excerpt is an example of a list narrative style of speaking from Daniel's first transcript.

and the frog (crack/ed open the) crack/ed open.

\{sighed taps finger looking for word $\}$ (the the) the drum.

then the frog went hop onto the dish.

the frog is in the dish.

then the frog surpris/ed her.

the frog top[EW:hop] in>

the frog hopp/ed (into) (into thus the) \{ deep breath and then very deliberate in finishing the unit $\} \sim$

into the cup.

then he went all>

then he>

they hopp/ed out and he went right there [EU].

thee[EW:he] went here.

then the people ran away from the frog. 
the frog went to the fire exit" (Daniel, transcript \#1, Frog Goes To Dinner, Mercer Mayer).

For Daniel, severe utterance formulation difficulties had a negative impact on his ability to produce a narrative. However, Daniel had the strongest upward trend across measures for a global language deficit. Findings from narrative analysis suggest that the deficits in narrative micro- and macro-structure represent a narrative discourse domain deficit related to weak language skills for Bailey and Edward. Patterns suggest a specific narrative deficit for Carson, the oldest participant.

Table 13 summarizes category scores on the NSS (2010) across participants and across transcripts.

Table 13

Narrative scoring scheme: summary of category scores.

\begin{tabular}{|c|l|l|l|l|l|}
\hline $\begin{array}{c}\text { NSS } \\
\text { Category }\end{array}$ & \multicolumn{1}{|c|}{ Bailey } & \multicolumn{1}{|c|}{ Carson } & \multicolumn{1}{|c|}{ Daniel } & \multicolumn{1}{|c|}{ Edward } & Felicia \\
\hline Introduction & $3,4,4$ & $4,3,3$ & $3,3,1$ & $2,3,2$ & 3 \\
\hline $\begin{array}{c}\text { Character } \\
\text { Development }\end{array}$ & $2,2,3$ & $3,3,3$ & $2,2,3$ & $3,2,2$ & 4 \\
\hline $\begin{array}{c}\text { Mental } \\
\text { States }\end{array}$ & $3,2,3$ & $2,4,2$ & $1,3,3$ & $1,1,2$ & 1 \\
\hline Referencing & $1,1,2$ & $3,3,2$ & $1,2,2$ & $4,3,4$ & 4 \\
\hline $\begin{array}{c}\text { Conflict } \\
\text { Resolution }\end{array}$ & $2,2,2$ & $2,4,3$ & $1,1,2$ & $2,2,3$ & 3 \\
\hline Cohesion & $3,2,3$ & $1,2,3$ & $2,2,3$ & $3,2,4$ & 4 \\
\hline Conclusion & $2,2,2$ & $2,4,1$ & $2,1,4$ & $2,1,3$ & 2 \\
\hline
\end{tabular}

Patterns overall showed that Daniel's narrative attempts represented story retelling under improving micro-structural skills. Macro-narrative patterns from analysis of NSS (2010) category scores, summarized in Table 13, showed a pattern of difficulty imbedding the mental states of characters, referencing characters, and providing a 
conclusion in narrative discourse across participants. There were several explanations for this pattern. First, the vocabulary needed to convey the mental states of character emotions and the syntax needed to reference pronoun agreement were developing skills for participants, and they were not able to access these skills consistently. A second explanation was that the past tense grammar required in retelling, combined with the multiple characters in the elicitation stories, required participants to use linguistic and cognitive resources at the utterance level. A focus at the utterance level takes away from language strategies associated with stronger narratives, such as advanced emotion words and careful word choice in referencing a specific character to a particular episode in the story.

With the exception of Daniel, participants had stronger skills for introductions and character development than for conclusions. The NSS (2010) conclusion scores ranged from 1-4 for Carson and Daniel and 1-3 for Edward. Bailey scored a two for conclusion across transcripts. This pattern was tied to participants' difficulties retelling higher-level emotion words to describe the mental states of the characters. The stories "Frog Where Are You" and "One Frog Too Many" conclude with a reunion. Participants were more likely to conclude with appropriate statements such as "they walked home and they were friends again" (Carson transcript 1). In the story "Frog Goes to Dinner," the frog and the boy pretend shame when returning home from a restaurant dinner that was disrupted by the frog, but laugh at the fun when they are finally alone in their room.

In summary, each participant had a pattern of deficits in narrative micro- and macro-structure. Participants had deficits in word finding, grammar, and verbal facility 
and rate in the absence of deficits in productivity, including scores similar to corpus means for MLU, TNW, and NDW on at least one out of three language samples. Participants lacked revisions in their narratives when compared to corpus data age/transcript length peers.

Classroom observations. Based on classroom observations using the CLEP (2004) scoring guide, individual classroom scores for provisioning (p) and engagement (e) were as follows: Bailey $\mathrm{p}=4.0, \mathrm{e}=3.0$; Carson $\mathrm{p}=5.2$, e=4.66; Daniel $\mathrm{p}=4.4$, e=2.9; and Edward $p=5.55, e=5.13$. Results summarized in Table 14 indicated that overall scores for provisioning were higher than scores for engagement.

Classroom observations provided an added context to this dissertation research. Features of the classrooms' literacy products and engagement environments were consistently associated with one another as was evidence of student work. Results indicated that although participants' classrooms varied in the amount, type, and engagement in literacy practices, each participant was being educated in an adequate or enriched learning environment. Researchers have identified specific features of classroom literacy environments that facilitate language and literacy growth (Reutzel \& Clark, 2011; Guo et al., 2012) that were observed in the classrooms. These features centered on active teacher management of classroom spaces that encouraged reading, writing and speaking about interesting topics. There was evidence of these practices across classrooms. 
Table 14

Classroom observation scores.

\begin{tabular}{|c|c|c|c|c|}
\hline participant & & & & \\
\hline & impoverished & minimal & satisfactory & enriched \\
\hline \multicolumn{5}{|l|}{ Bailey } \\
\hline provisioning & & & 4.0 & \\
\hline engagement & & 3.0 & & \\
\hline \multicolumn{5}{|l|}{ Carson } \\
\hline provisioning & & & 5.20 & \\
\hline engagement & & & 4.66 & \\
\hline \multicolumn{5}{|l|}{ Daniel } \\
\hline provisioning & & & 4.4 & \\
\hline engagement & & 2.9 & & \\
\hline \multicolumn{5}{|l|}{ Edward } \\
\hline provisioning & & & & 5.55 \\
\hline engagement & & & 5.13 & \\
\hline $\begin{array}{l}\text { Provisioning } \\
\text { Interpretive } \\
\text { Descriptions }\end{array}$ & $\begin{array}{l}1.0-2.4 \\
\text { impoverished } \\
\text { An unacceptably } \\
\text { small number of a } \\
\text { few different types } \\
\text { of literacy tools } \\
\text { are present. }\end{array}$ & $\begin{array}{l}\text { 2.5-3.9 minimal } \\
\text { Several different } \\
\text { types of literacy } \\
\text { tools are present in } \\
\text { moderate amounts. } \\
\text { There are enough } \\
\text { literacy tools to } \\
\text { support the } \\
\text { number of students } \\
\text { in the classroom. }\end{array}$ & $\begin{array}{l}4.0-5.4 \text { satisfactory } \\
\text { An acceptable } \\
\text { number of literacy } \\
\text { tools or all types } \\
\text { are present. }\end{array}$ & $\begin{array}{l}\text { 5.5-7.0 enriched } \\
\text { The classroom is } \\
\text { abundantly } \\
\text { supplied with all } \\
\text { types of literacy } \\
\text { tools. The literacy } \\
\text { tools are complex, } \\
\text { elicit multiple } \\
\text { responses in varied } \\
\text { settings and are } \\
\text { developmentally } \\
\text { appropriate. }\end{array}$ \\
\hline $\begin{array}{l}\text { Engagement } \\
\text { Interpretive } \\
\text { Descriptions }\end{array}$ & $\begin{array}{l}\text { 1.0-2.4 } \\
\text { impoverished } \\
\text { The physical } \\
\text { environment } \\
\text { provides little } \\
\text { support to literacy } \\
\text { acquisition. } \\
\text { There was a bleak } \\
\text { or stark quality in } \\
\text { the classroom. }\end{array}$ & $\begin{array}{l}2.5-3.9 \text { minimal } \\
\text { The physical } \\
\text { environment } \\
\text { provides some } \\
\text { support to literacy } \\
\text { acquisition. The } \\
\text { classroom has a } \\
\text { neutral feeling and } \\
\text { does not capture } \\
\text { the observer's } \\
\text { interest. A narrow } \\
\text { range of literacy } \\
\text { tools and products } \\
\text { are present but not } \\
\text { featured. }\end{array}$ & $\begin{array}{l}\text { 4.0-5.4 satisfactory } \\
\text { The physical } \\
\text { environment } \\
\text { provides an } \\
\text { acceptable level of } \\
\text { support to literacy } \\
\text { acquisition. A } \\
\text { comfortable } \\
\text { classroom } \\
\text { atmosphere was } \\
\text { created by the } \\
\text { presence of many } \\
\text { literacy tools of } \\
\text { varying types and } \\
\text { the display of } \\
\text { some literacy } \\
\text { products. }\end{array}$ & $\begin{array}{l}\text { 5.5-7.0 enriched } \\
\text { The physical } \\
\text { environment } \\
\text { provides optimum } \\
\text { effectiveness in } \\
\text { support of literacy } \\
\text { acquisition. A } \\
\text { museum-like } \\
\text { quality and } \\
\text { pleasing ambience } \\
\text { was created by } \\
\text { prominently } \\
\text { featured literacy } \\
\text { tools and products. }\end{array}$ \\
\hline
\end{tabular}


Results also indicated that related classroom contexts specific to story retelling skills, including story reenactment props, documentation of repeated reading of favorite story books, and direct instruction in evaluative aspects of narrative, such as graphic organizers or sequenced drawings, resulted in a higher engagement score for Edward's classroom. Literacy environments with these products were shown to improve oral narrative skills over time (Reutzel \& Clark, 2011).

A typical structure for the participants' classrooms included tables rather than desks, and none of the classrooms had large amounts of technology available to the children or teacher. Each classroom had a library, but the number of books and quality of the organization varied greatly. The relative small size of Bailey's classroom was noted in field notes and had a negative impact on both provisioning and engagement scores. None of the classrooms was rated as impoverished.

Bailey's and Daniel's classrooms scored in the minimal range for engagement. These classrooms did not have well defined areas for communication or literacy events in the classroom and literacy tools were stored away on shelves or in bins rather than being organized in stations for the children to use in reading or writing. Small libraries resulted in lower scores overall in Bailey's and Daniel's classroom.

There was evidence of interventions to support Bailey's engagement in specific literacy events. A book collection in Bailey's classroom included books from the public library on desert animals and habitat. This temporary library was stored on the floor in boxes. The teacher had selected several high interest texts about rabbits for Bailey and at 
the time of the observation, a teaching assistant was preparing materials at Bailey's desk to support her use of the texts to produce a short report. In Daniel's classroom, literacy materials were organized in bins assigned to a particular classroom volunteer. Daniel's basket included leveled and high interest reading material, some simple writing, and a log of books read.

Edward's classroom received an enriched score for engagement. A score of seven was given on the three items scoring the classroom library. The classroom library covered over $25 \%$ of the entire classroom space. In Carson's and Edward's classrooms, children produced functional print literacy, such as jobs and schedules, which on the CLEP (2004) was scored higher than print literacy that is commercially or teacher produced.

In addition, there was no evidence of basal readers or didactic phonics instruction materials in any of the students' classrooms. There was evidence of balanced literacy practices such as reading strategies associated with practices such as The Daily Five (Boushey \& Moser, 2006) and student-selected texts and tracking of comprehension in logs and assessments. Classroom observation data provided a context of general idealness for participants' language development. Classroom observation data ruled out lack of opportunity to participate in classroom discourse as an explanation for participants' poor oral narrative skills. Participants' scores on the NSS (2010) indicated narrative macro-structure at the emerging stage on at least one transcript. This stage of narrative production supported interactive routines in the classroom. 


\section{Qualitative Results, Findings and Analysis}

Patterns in the qualitative data emerged after identifying key terms, dividing data into meaningful, paragraph length, units, labeling each unit with a code, and then cross coding some units. Coding was compared against quantitative findings and to the literature reviewed in chapter two. Coding, source analysis and cross-coding analysis of qualitative data resulted in seven major themes related to participants' functional communication and response to communication events. Table 15 lists each theme and provides an operational definition. Sources include teacher interviews, parent interviews, a review of assessment reports and current IEP documents, and quantitative findings. 
Table 15

Emergent themes and operational definitions.

\begin{tabular}{|c|c|}
\hline & Theme \\
\hline $\begin{array}{r}1 \\
\text { utterance } \\
\text { formulation }\end{array}$ & $\begin{array}{l}\text { Utterance formulation was difficult for this group of participants } \\
\text { with language impairment. They needed more time to communicate } \\
\text { ideas and had difficulty repairing communication. }\end{array}$ \\
\hline $\begin{array}{r}2 \\
\text { narrative skills }\end{array}$ & $\begin{array}{l}\text { Narrative skills include the ability to tell and write stories, talk } \\
\text { and write about upcoming and past events, and to be understood by a } \\
\text { variety of listeners when talking about topics outside of the immediate } \\
\text { context. These skills were difficult for participants at school and at } \\
\text { home. }\end{array}$ \\
\hline $\begin{array}{r}3 \text { social } \\
\text { communication }\end{array}$ & $\begin{array}{l}\text { Social communication was reported as a struggle for } \\
\text { participants. On top of difficulties using words, they were also reported } \\
\text { to have confusing facial expressions and gesture, difficulty } \\
\text { communicating emotions. They need adults in the school and home } \\
\text { environment to take extra time negotiating meaning. }\end{array}$ \\
\hline attention/ focus & $\begin{array}{l}\text { Focus and attention skills were mixed for participants with } \\
\text { language impairment. Participants were reported as distracted at times } \\
\text { and hyper-focused at other times. }\end{array}$ \\
\hline $\begin{array}{r}5 \text { social } \\
\text { skills }\end{array}$ & $\begin{array}{l}\text { Social skills for participants were a concern at school and at } \\
\text { home. Participants were described by their teachers and parents as } \\
\text { having strong friendship skills despite immature play skills and other } \\
\text { social skill deficits. }\end{array}$ \\
\hline $\begin{array}{r}6 \\
\text { conflict }\end{array}$ & $\begin{array}{l}\text { Verbal communication during conflicts was not always } \\
\text { available to participants. Participants were highly likely to shut down } \\
\text { during conflicts across settings. }\end{array}$ \\
\hline $\begin{array}{r}7 \\
\text { health } \\
\text { factors and } \\
\text { emotional } \\
\text { health } \\
\text { symptoms }\end{array}$ & $\begin{array}{l}\text { Early childhood health risks and ongoing emotional health } \\
\text { symptoms define quality of life concerns for children with language } \\
\text { impairment. }\end{array}$ \\
\hline
\end{tabular}


Themes. The following section provides the reader with a thick description of each theme and data to support its emergence. Thematic analysis using qualitative data supported finding patterns that extended the quantitative data findings.

Theme one: utterance formulation. Utterance formulation is difficult for young children with language impairment. They need more time to communicate ideas and have difficulty repairing communication.

There was agreement across the data that participants continue to struggle at the utterance level and that utterance level errors were part of a larger struggle with functional communication. Teachers and parents agreed that this makes participants more difficult conversation partners. "Bailey mixes up her words a lot more than other kids which is hard to listen to sometimes but she's a gen. ed kid. I wish she could have more help with comprehension and learning how to answer questions" (Bailey, teacher interview, May 16, 2012). Similarly, parents recognized the need to support utterance level language at home. "A lot of times if he says something and there's an incorrect problem with it, I will repeat it with the right way and he will repeat it back to me because he's had enough speech therapy to know. So we are trying to work on the little things" (Carson, parent interview, June 21, 2012). Each participant's IEP goals or shortterm objectives also reflected needs at the utterance level. An example from Daniel's IEP is "Daniel will demonstrate understanding and use of irregular past tense verbs, irregular plural nouns and pronouns in a) drill; b) structured utterances; and c) spontaneous speech with 90\% accuracy" (Daniel, IEP, September 27, 2011). An example 
from Carson's IEP is "Carson will use a variety of sentence types, moving from simple to compound/complex" (Carson, IEP, November 10, 2011).

Teachers and parents reported concerns that, in addition to finding it more difficult than their peers to communicate, participants were vulnerable to disapproval. One teacher observed, "Bailey has significantly fewer interactions than other kids because kids don't gravitate toward her and communication is a lot of work. Rather than raising her hand to ask a question or make a comment she gets very close to me and taps me. Getting through the communication takes several turns and a lot of give and take" (Bailey, teacher interview, May 16, 2012).

Edward's teacher also reported initiating proximity to manage difficulties understanding Edward's communication. "We both get that deer in the headlights look and then nod and smile. I try to use humor to get through it [communication with Edward] and I keep him close" (Edward, teacher interview, June 12, 2012).

Utterance formulation difficulties in qualitative data showed a pattern of deficits in word finding, grammar, a lack of revision, and difficulties with purposeful sequencing of events. There was congruence between qualitative and quantitative data related to utterance formulation difficulties based on direct observation and reported difficulties in conversation/discourse, pragmatic communication, and language used in social interactions in the classroom.

Theme two: narrative skills. Narrative skills included the ability to tell stories, talk about upcoming and past events, and be understood by a variety of listeners when talking about topics outside of the immediate context. Evidence that narrative discourse 
affects functional communication was found across participants and across data sources. One parent stated, “I don't think he uses past tense. He is so in the here and now I do not think he even communicates about what happened before. In addition, when he does, it is a struggle for him to do it right. Like he has to think about it. I think he will mess up when he's talking about the past. I don't think he really has the concepts of the past in his speech and at nine, he really should have that. He just doesn't know how to logically build a story" (Carson, parent interview, June 21, 2012).

During interviews and classroom observations, teachers spoke about difficulties with literacy assessments because of retelling requirements that were aligned to decoding, fluency and general comprehension text levels. Daniel's, Carson's and Bailey's teachers discussed specific reading skills and comprehension assessments. "He's more of a reader than a writer. He can read very well, but on Developmental Reading Assessment (DRA) (Beaver, 2003) testing he just gave very short, choppy snippets to tell the story back and he has a lot of trouble with order and time" (Daniel, teacher interview, May 18, 2012). Another teacher reported, "she's low at reading, I mean not special education low ... for comprehension she knows private think time and with lots of check ins she can get some things out" (Bailey, teacher interview, May 16, 2012). Narrative skills were addressed in IEP documents for participants. For example, "Edward will retell $75 \%$ of a grade 1 story" (Edward, IEP, November 8, 2011).

Document data indicated that each participant received services from a SLP aimed to remediate narrative deficits. Edward's evaluation report stated, "Edward was able to retell $30 \%$ of the story elements, including what happened and what the problem 
was, in the appropriate order. He did not include the characters, setting, solution or cohesion in telling the story" (Edward, evaluation report, March 15, 2010). Parents described how limitations in extended discourse affected communication at home. Bailey's and Edward's moms both described how at times their children talk about past events clearly and how at other times the communication is lost and ends in frustration. "I don't know if she hears herself and then sometimes she gets frustrated and is like 'you know' and I'm like 'no I don't”' (Bailey, parent interview, February 27, 2013).

Quantitative data strongly suggested that participants had narrative deficits that affected their ability to participate in communication events. According to Gerber, Brice, Capone, Fujiki, and Timler (2012), narrative deficits impacted global discourse skills including turn taking, repair of communication breakdowns, contingent commenting, and responding to questions as well as initiating questions to request more information or clarification, and other topic management skills. Bailey's and Carson's mothers reported that difficulty being understood in conversations put their children at risk for negative evaluation by their peers. This was not a concern for Daniel and Edward who were reported by their teachers and parents as highly social despite language difficulties. This finding was consistent with Gazelle (2006) who found that subtle deficits in language were associated with an increase in social impact as children got older. Younger participants had an easier time compensating with humor and shared interests with their peers.

Theme three: social communication. Social communication was a struggle for participants. On top of difficulties using words, participants were also reported to have 
confusing facial expressions and gestures, difficulty communicating emotions, and needing adults in the school and home environment to take extra time negotiating meaning.

This theme focused on functional language use and ongoing use of communication for academic and social learning both at home and in the classroom. Social communication with participants required more time to provide for repeated opportunities to practice within a communication event. Teachers and parents shared a similar belief that without special communication strategies participants were likely to shut down or abandon the communication. They reported that communication difficulties affected their own relationship with the participant.

“It's not just what Bailey says. Her face and her gestures are also hard to read. She fiddles and likes to draw. She will say 'I don't get it.' We have two adults all the time. We get kids a lot of materials because the classroom is small and it is hard to have the kids always moving around. She can get work done. She has to shush other kids when she is working or she'll get off track. Even with all this, I still don't know her very well. It's frustrating" (Bailey, teacher interview, May 16, 2012).

Another teacher reported, "I think it's going to help to ask him to say it again, but then he says it quieter and gets farther away from me. I say 'get over here you' and we talk about something else like their dog or his sister" (Daniel, teacher interview, May 18, 2012).

Teachers reported that planning around participants' interests and abandoning low interest activities was a useful strategy for sustaining more positive interactions in the 
classroom. Strategies included grouping a student with a friend even when those friends had very different academic skills, having the student work on longer term projects to replace several shorter assignments, and learning about the child's special interest area to engage in social conversations.

Parents were more likely to provide specific examples of social communication as it related to negotiation discourse. "I think with peers he wants to be friends, he will tell people when he doesn't like something. He wants to negotiate everything. He does try and he tries to negotiate with words, which is good. The words don't flow very easily for him, but he is always trying to make a different deal. Um, he can protest, but he will shut down verbally" (Daniel, parent interview, August 22, 2012). This report was consistent with Edward's teacher who stated, "When someone else is breaking the rules he feels "wronged," he really likes the justice piece but he doesn't know how to resolve conflict without crying or fake crying. He continues to argue until an adult comes in" (Edward, teacher interview, June 12, 2012).

Improving social communication with the participants appeared to be a goal for both teachers and parents. However, difficulties with social communication were reflected in IEP goals for Daniel only. Goals included "demonstrating the ability to take up to three conversational turns that maintain the topic" (IEP, Daniel, September 9, 2011). Quantitative data showed that each participant had marked difficulty on at least one elicitation in the areas of narrative content and verbal facility. According to Marton and Schwartz (2003), social communication requires simultaneous processing of social rules and language use. They go on to say that young children with language impairment 
have fewer resources for thinking and planning before problem solving, making social communication skills, such as negotiation, an area of need.

Theme four: focus/attention. Focus and attention skills, including the ability to attend to conversations and distractibility during instruction, were themes that emerged in qualitative data analysis. Participants were reported to be distracted at times and hyperfocused at other times. Focus skills were discussed in each teacher and each parent interview.

Distractibility was a concern specific to language-based classroom learning. Strategies to keep participants focused at school included modified work, such as shortened assignments, extra check-ins, writing down steps, explaining things a second time, and special seating. Knowing when to use focus strategies was a concern for teachers and parents.

Carson's teacher reported that she asks him as many questions as she can to keep up engagement because she believes that Carson is very smart and learning is quick and easy for him when he is engaged. "If he checks out and I call on him, he gets back to the whole group" (Carson, teacher interview, May 18, 2012). Edward's and Daniel's teachers reported that they use focus and engagement strategies in the classroom because they believe that these children were smart. "Academics are his gift. He loves geography and math. He's quick and as long as I don't lose him we're good" (Daniel, teacher interview, May 18, 2013).

Teachers and parents reported hyper-focus on topics of high interest and sustained attention with some activities. When describing what Edward did well, his teacher stated 
that he loves jokes and that he will study and read jokes. "He'll make up jokes that don't make sense" (Edward, teacher interview, June 12, 2012). His mother concurred, "He can play Legos or look at collections for hours. I don't see actual attention problems" (Edward, parent interview, August 22, 2012).

Teachers reported a variety of strategies for attention. "I check in to explain it a second time, re-teach with simple vocabulary" (Edward, teacher interview, June 12, 2012). "To keep Bailey focused and interested, she gets modified work sometimes, and extra check-ins. I use a white board with the steps and she likes that. In the end she can write and write and really bust out work" (Bailey, teacher interview, May 16, 2012).

The variety of strategies teachers reported using for engagement is consistent with Ratner (2006) who described the creation of classroom-based interventions as actively "taking advantage of being able to witness appropriate or inappropriate language use in context and then responding to it with suitable strategies that maximize the moment of learning" (p. 262). In IEP and evaluation documents, teachers reported attention as a concern for Bailey and Edward. However, attention difficulties and self-management were not evaluated as part of special education, and there were no attention or selfmanagement goals reflected on the IEPs of participants. Focus skills were a primary concern for Bailey's mother. When asked about dinner time conversation, Bailey's mother reported, "A lot of times she'll be lost ... she zones out and gets lost and then thinks of something else" (Bailey, parent interview, February 27, 2013).

Qualitative data on this theme helped to explain the lack of revisions in participants' narrative micro-structural data. In dissertation research studying stability in 
special education eligibility, Dunkle and Flynn (2012) stated, "Deficits in selective attention can account for the overall reaction time differences as well as the significant differences on tasks of conflict. This resulted in overall decreased efficiency of their attentional system, which results in unsuccessful completion of a task" (p. 47). According to Marton and Schwartz (2003), children with language impairment have a weakness in attentional control that has a negative impact on verbal and spatial processing and working memory. They go on to say that, reports of distractibility and inattention reflect multiple deficits that should be evaluated because children with language impairment were a heterogeneous group.

Theme five: social skills. Social skills for participants were a concern at school and at home. Participants were described by their teachers as having strong friendship skills despite immature play skills and other social-skills deficits. Parents reported concerns about friendship skills and peer relationships.

When asked how well participants got along with other children, teachers and parents reported generally immature skills across participants. However, some common terms included "never alone," "lots of friends," and "happy and silly" to describe participants. Several participants were described as having pro-social behavior in spite of difficulties with communication. For instance, one teacher stated:

She is always with a buddy at lunch or recess and likes to be silly with other girls in the hallway. She has one really good buddy and another friend, and they are always goofing off and enjoying the school day. She often engages friends in silly play, dancing, and drawing. (Bailey, teacher interview, May 16, 2012) 
A parent described similarly positive interactions at home for her son: "He has friends at school and we've had play dates this summer. There are kids he does really well with, some personalities not as well. He wants to be friends with kids; he likes to play with other kids. The kids he tends to be friends with are very smart, and kind of quirky and imaginative like he is, which is good because he gets along with them and they're nice" (Carson, parent interview, June 21, 2012).

At the same time, social skill differences were reported and concerns for Bailey and Carson were significant. When asked about concerns beyond communication difficulties, Bailey's mom stated, "I have to bring it back to her peers. I mean Bailey has a hard time making friends and I don't know if it's because she doesn't understand, or they don't understand her" (Bailey, parent interview, February 27, 2013).

Parents reported specific peer interactions that were a measure of social skills. One parent stated, "We had a play date here just the other day, and he sat down and played Chutes and Ladders all by himself. Even though he likes these kids and he would play with them too, but if they walked away he would be like, I'm still doing this" (Daniel, parent interview, June21, 2012).

IEP documents reflected humor as a strength for participants and social skills in groups as an area of weakness. Strong friendship skills across settings and evidence of friendship as a motivator to engage in school learning were clear strengths. However, extreme emotional outbursts for Bailey and Carson were reported as impacting social relationships. 
Theme six: shutting down during conflict. Participants were highly likely to shut down verbally during conflicts. Participants' behavior during conflict was reported as significantly different from that of other children. Parents reported that participants had negative emotional responses to communication events. One parent offered a list of cues that communication is becoming problematic for her son: "The minute he feels not competent, you can see it in his face. He's a bit of a perfectionist. He doesn't want to do something new that he won't be good at" (Daniel, parent interview, June 21, 2012).

The warnings mentioned above were commonly associated with frustration and were less of a problem for typical language young children who do not have difficulty formulating utterances to talk about their feelings or ask for a break. For some participants, frustration quickly becomes anxiety, making any communication difficult. One teacher explained it as: "He does that shut down thing. When he has troubles with other kids, he just points at them and can't talk. I leave him alone" (Daniel, teacher interview, May 18, 2012). Another teacher reported, “Then he screams and tears at his hair, he turns red and then goes into the corner. He'll even shut down like this if I redirect him in front of other kids" (Carson, teacher interview, May 18, 2012).

During teacher interviews, it was reported that Bailey, Carson, and Daniel had episodes of shutting down and that parents were called to the school when the child was not able to recover after a conflict. In each of these examples, an unfamiliar adult at school, outside of the classroom, reprimanded the participant. "It was a teacher who yelled at him for throwing bark, and she was mad because he wouldn't respond to her. 
She said come over here and he just wouldn't. He shut down and got so stuck. The school called me" (Daniel, parent interview, June 21, 2012).

When asked about recovery time for Bailey, her mother reported that it takes over 25 minutes for Bailey to recover at home and that her sister stated that Bailey has "anger issues" (Bailey, parent interview, February 27, 2013). Edward's teacher talked about "that shut down thing" and reported using humor to pull him back into the classroom learning. According to Kristensen and Torgersen (2008), children with language impairment feel scrutinized in stressful communication events and experience social anxiety that contributes to stress levels and risk for emotional health symptoms.

Theme seven: health and emotional health symptoms: To explore how health factors described participants, items were cross-coded for health, conflict, and attention and then were integrated to create health factors and emotional health symptoms as a theme. Early childhood health risks and ongoing emotional health symptoms define quality of life concerns for children with language impairment. Each parent was asked about known early childhood health risks that may help explain their children's language impairment. Bailey's mother described a combination of early childhood risks.

"So six years ago we were living in and remodeling a home and we had water coming in. They had to completely refinish the floors and re-drywall. I mean it was just a mess. So it's your home and you go check on the contractors. Well, I bring Bailey, and I put her on the ground and it was dusty and everything. So a friend of mine in church, who was a preschool teacher, said, 'I noticed Bailey doesn't speak, not like the other kids.'

When she did speak, she made up her own language, it was like *jargon* We used to think it was cute, but then we took her to the pediatrician, and she was like, well, that's not (cute)... let me get 
you a speech evaluation. It might sound cute, but something else is going on.

And then she decided to test her for lead, and she tested positive, and the guilt it went (pointed up to the sky)--I mean like awful. I had all the other kids tested, and they were like 2 and Bailey was like 5 .

That being said, I figured it's one thing. And then we had another test. The doctor said, 'I mean don't get guilty if you gave it. It's a gene from your mother that gives learning disabilities.' So I did have it. Because I have two girls who are similar, who have IEPs. I mean Bailey is starting to show ADD, but her sister is very hyper so I think that's the ADHD, so that was why I knew maybe it's something with me" (Bailey, parent interview, February 27, 2013).

Carson's mother described difficulties with asthma and difficulty with meals when Carson was very young. She also reported that Carson was a difficult baby. Each participant was described as a late talker, and Edward and Daniel were reported to be late at toilet training. None of the participants were premature and none of the participants were reported to have allergies. Physical health was not a significant concern for parents of participants. However, emotional health symptoms were a consideration for both parents and teachers.

According to Conti-Ramsden and Botting (2008), children with language impairment were at greater risk of having attention deficits, anxiety disorders, and more aggressive behavior at different times during childhood when compared to typically developing children. Carson and Bailey received community-based counseling for emotional health symptoms. Family history for attention disabilities was positive for four participants. According to Carson's mother, he was diagnosed with depression and anxiety. He took medication to support his emotional health. "Almost everything I do 
with him, unless it's super fun like going to the park, I get worried. Like if I need him to do something for me like practice the violin, it could be a big blow-up. There's no inhibition, just reaction" (Carson, parent interview, June 21, 2012).

Source analysis. Figure 1 illustrates a pattern that emerged from comparing the three sources of data against the seven emerging themes. This analysis showed that teachers and parents were concerned about how participants' focus skills affected their communication and learning in the classroom. With the exception of Daniel, IEP documents focused on structural language skills and narrative language skills only. Daniel's IEP had a social communication objective.

Figure 1

Source analysis.

\section{Individual Education Plan}

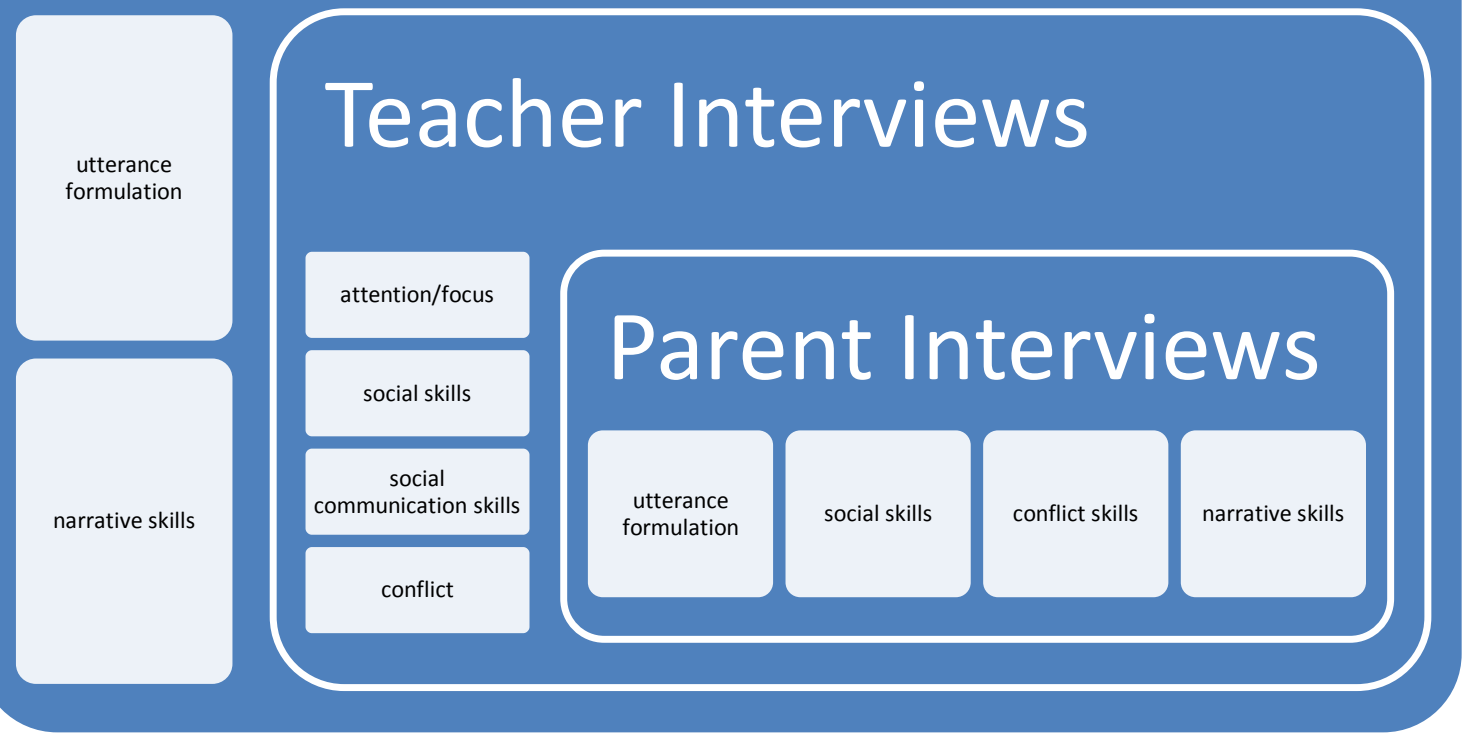


Source analysis indicated that attention/focus and social communication skills, particularly communication with the teacher, were a classroom area of need that was not addressed in the IEPs. Descriptions of participants as smart, creative, and imaginative were not reflected in IEP documentation. In addition, parents and teachers discussed social skill difficulties that were not addressed in the IEPs or evaluation reports.

Difficulty negotiating with peers was a teacher and parent concern that was not addressed in the IEPs. Analysis patterns were important because the IEP meeting was the only opportunity for parents to collaborate with their child's IEP team. There were two explanations for the lack of detail in participants' IEPs.

According to Goldberg (2005), services mandated by special education fell short of meeting young children's needs, and many primary children with very mild disabilities or delays in development went without services even when their parents and teachers were concerned. A second explanation was that observations by parents and teachers were treated casually when defining the special education needs of participants, because some needs were best addressed in the classroom and therefore were purposefully not documented in the IEP.

\section{Summary}

Results and analysis from the current research study provided data to support several findings. First, repeated practice with the elicitation context for narrative production resulted in an upward trend in MLU and higher scores on the NSS (2010). These trends did not result in a downward trend in errors at the word level or a greater number of revisions or interjections that might have contributed to the higher NSS (2010) 
scores. Secondly, with the exception of Daniel, participants as a group had limitations in using language strategies for story grammar when compared to their relatively average structural language skills. Immature story retelling resulted in lower NSS (2010) scores and fewer revisions, clarifications, and interjections when compared to corpus comparison groups overall despite any upward trends.

Daniel had difficulties at the utterance level that significantly impacted his scores in all areas. The youngest participant, he had significant limitations in vocabulary, completing intelligible utterances, and MLU. However, he also had the strongest positive trend in NSS (2010) scores. Lastly, participants had difficulties in common that were not directly related to linguistic markers of language impairment. Difficulty negotiating with peers, shutting down in difficult situations, and difficulty attending to verbal tasks in the classroom were areas of relative need while humor and likeability were relative strengths across participants. 


\section{CHAPTER FIVE}

\section{Discussion}

In this section, a discussion of the study results and an interpretation of the results in relation to the original research questions are provided. This study examined the patterns in oral narrative skills for young children with language impairment using a combination of case-based quantitative data and field research qualitative data. The discussion is divided into five sections. The first and second research questions are discussed followed by implications for assessment and implications for practice. In conclusion, limitations of the current research and contributions are presented.

Researchers long considered the pervasive nature of language impairment and the benefits of school-based services from a SLP, yet the results of school-based services in remediating young children with language impairment remains elusive. The current study presented a broad conceptual understanding of the patterns in communication skills and the concerns of teachers and parents to explain patterns in pervasive disability and special education eligibility.

Unlike the majority of previous research describing oral narrative skills as the result of specific linguistic resources, the current study explicitly targeted opportunities to produce multiple oral narratives under a controlled elicitation context to explore patterns in narrative communication. Qualitative data identified narrative language as a communication mechanism involved in classroom discourse, friendship skills, and sustaining communication following a setback for this group of participants. 
The current study presented a description of language impairment as a disability that explicitly affects school experiences. Data supported relationships between oral narrative deficits and social communication/social skills as well as emotional responses triggered by limitations in functional communication. This was particularly true during more stressful communication events. Other functional communication including discourse impairments, difficulty self-monitoring, and difficulty with attending to verbal tasks are discussed in detail.

In addition to contributing to an understanding of the patterns in pervasive language impairment, data supported a mismatch between teacher and parent concerns and IEP documentation. Implications for assessment strategies specific to data trends in attention/focus and emotional regulation and improving IEP documentation are offered. As a means of reducing the negative impact of specific linguistic processes identified in the qualitative data, clinical implications targeting word finding and designing multiple opportunities to produce short narratives in pull-out service models are recommended.

A mixed methods case and field research approach was used to answer the following original research questions as they related to a small group of young children with predetermined language impairment:

1. What patterns emerge between functional communication skills and context variables in the classroom environment for primary-grade children with identified language impairment?

2. Does health status contribute independently to variability in patterns of functional communication skills for target children? 


\section{Research Question \#1}

The first research question addressed patterns in functional communication and the classroom environment. To answer the first research question, the researcher collected data from direct observation of children's story retelling, teacher and parent interviews and classroom observations. Transcript data were compared to corpus means to identify participants' relative strengths and weaknesses in narrative production, complexity, and verbal rate and facility. Additionally, data from interviews were analyzed thematically using a mixed methods approach.

Language impairment. Language impairment was defined by a set of psycholinguistic markers present in the language of participants. The metaphor of a family was useful in understanding these classic markers of language impairment because family members, such as decreased mean length of utterance, may "move out" but can come back to visit based on the communication context. Based on language sample analysis from three elicitations, participants' data indicated a pattern of psycholinguistic markers of language impairment including narrative micro-structural deficits in the areas of word finding, past tense grammar, verbal facility and rate, and macro-structural deficits.

Each participant lacked language strategies, as scored on the NSS (2010), for story retelling when compared to an age and transcript length matched peer group from a corpus in the SALT (2010). Difficulty producing a narrative that included story grammar components was a classic marker of primary language impairment and contributed to pervasive disability. Participants' difficulties at the macro-structural level of language 
was evidence consistent with identified themes from functional linguistics. Difficulties planning, sequencing, and using linguistic behaviors to produce story retelling was the primary deficit for this group of young children with predetermined language impairment.

Deficits in verbal facility and rate across participants was attributed to needing more time to construct the retells and using garbage mazes to process the narrative task. In addition, participants made significantly fewer revisions and clarifications than typically developing comparison groups. Revisions and clarifications were fix-up strategies that contribute meaning to the narrative discourse. Upon further analysis, participants' data showed that they utilized garbage mazes to continue processing the oral narratives. In addition to these speech disruptions, participants' narrative productions were compromised by errors at the word level. Errors at the word level were markedly greater than typically developing comparison groups. This was primarily due to difficulties with the past tense verb (i.e. taked for took) requirements in retelling and word finding errors (i.e. turtle for frog). Word finding errors and language processing difficulties were classic markers of complexity deficits in language impairment and explain in part why participants qualified for school-based services from a SLP. Word finding and processing limitations impact communication success and can influence even basic communication attempts.

Discourse impairment. Mixed methods data analysis provided verification of findings from language sample quantitative data patterns. Confirmatory findings included reports of discourse impairments at home and at school, difficulty self- 
monitoring during communication events, and difficulty attending to verbal tasks. Interview data added an additional description of participants as having difficulty with initiations and failing to persist in communication following a setback. With the exception of Felicia, participants' language strategies for story retelling lacked conventions for providing enough information and connecting story episodes. Participants' meaning making in discourse is related to descriptions of their narrative profiles.

Participants in the current study represented three profiles of children with primary language impairment. The results of the case and field analysis indicated that there was a relationship between severity of narrative impairment and functional communication skills. Daniel, the youngest participant, presented with deficits at the utterance level that affected his ability to produce basic story grammar on the first and second elicitations. However, after practice with the process and familiarity with the researcher, Daniel produced basic story grammar on the third elicitation despite ongoing difficulties with utterance formulation including MLU limitations. Daniel's speaking was described by his teacher as "snippets". When asked how Daniel interacted, she reported that he was very affectionate with her and touched her hair. She reported that he often pointed and did not talk if he had problems with other children. However, she reported that he was very strong in demonstrating code-based skills in reading and math and that this overshadowed his communication disorder. Daniel's discourse profile was consistent with a listing style or unlinked chain because his narratives lacked episodic features and cohesive ties. Daniel's teacher reported that she and Daniel relied heavily 
on non-verbal communication. Daniel demonstrated deficits in productivity based on measures of lexical diversity, completing utterances, and being understood at the utterance level. Daniel's mean length of utterance in words and morphemes was below corpus means across transcripts indicating a deficit in narrative complexity.

In the area of micro-structural productivity, Daniel is the only participant who demonstrated deficits across transcripts. For Daniel, productive vocabulary and finishing verbal units made his narratives unconventional, giving them the quality of a list or set of unrelated events. Decreased MLU and limitations in the number of words used is a classic marker of productivity deficits in language impairment. Mean length of utterance was also a concern in Carson's first retelling. However, in subsequent transcripts MLU in words and morphemes was comparable to corpus data for Carson and remained relatively low for Daniel. This is evidence that Carson's MLU was sensitive to experience with the sampling context.

A second profile that emerged from the data for Bailey and Edward is consistent with sequenced events in episodes, or episodic narrative language. Episodic narratives lack consistent story grammar, cohesion, and an interpretive quality while maintaining a general quality of a story. With the exception of grammar and word finding errors, Bailey and Edward presented with productivity and complexity scores similar to the means reported in the corpus comparison groups. However, a more detailed analysis showed that they produced a large number of filled pauses and repetitions, or garbage mazes, resulting in a deficit in verbal facility and rate. They lacked revisions in their retellings and their first two language samples were greater than two standard deviations 
below the reported mean in SALT (2010). Edward's NSS (2010) score was similar to the mean in the corpus data on his third retelling. To facilitate communication in the classroom both Edward and Bailey's teachers sit them close and engage them in redirection and re-teaching. Teachers reported frustration in not "knowing" Edward's and Bailey's interests. Edward's and Bailey's teachers report that they struggle to have conversations without abandoning academic topics. Parents report a family history of ADD and ADHD and ongoing concern that their children get lost in conversations at home.

Carson, the oldest participant, presented with significantly more difficulty on the initial language sample compared to the second and third elicitations. With subsequent retellings, Carson's productivity and complexity scores were similar to means reported in SALT. In addition, Carson did not have a high proportion of garbage mazes, giving his speaking a more fluent quality. However, Carson did not revise his speaking for clarification, and he continued to have weaknesses in verbal rate and narrative content as scored on the NSS (2010). Carson's teacher reported that he "tells about what he knows and wants". She also was able to talk about Carson's interests in science and insects and stated, "He's proud of his imagination." Carson's teacher was able to provide a specific example of when his communication skills, including grammar, broke down. She reported that when he was embarrassed, he said "people are look at me". Carson's teacher is concerned about his writing. Carson's mother reported that her primary concern is Carson's emotional health and his responses in times of conflict. 
Carson's narrative skills were consistent with true narrative because he demonstrated episodic structures and basic story grammar with cohesion. Although Carson demonstrated oral narrative skills in retelling, his NSS (2010) scores were lower than corpus means because he did not describe the mental states of characters and cohesion in his retellings was scored at the emerging level. Interpretive qualities were important for academic narrative skills. Carson's difficulties with the subtleties of a more literate narrative style of speaking could explain his teacher's concern about writing. Carson's teacher reported meaningful understandings of what works for Carson, and she was able to describe her classroom-based interventions for him. Carson's teacher reports that writing skills were her primary concern.

The presence of a narrative impairment was associated with concerns about writing across all three profiles. Teachers were concerned about the transition to written discourse for each participant. Daniel's teachers said, “he's more of a reader than a writer," Bailey's and Edward's teacher both use paragraph frames (fill-ins) to support writing, and Carson's teacher reported that language problems occur "Not when he speaks, but in written language. His word choices were immature and he will not use the words the book uses" (Carson, teacher interview, May 18, 2012).

Difficulty self-monitoring and attending to verbal tasks. Based on qualitative data, participants had marked difficulty using communication repairs and accuracy in word choice. This revealed difficulties with self-monitoring and focusing on details when speaking. These findings indicated that participants' performance profiles were consistent with language processing difficulties. An upward trend in NSS (2010) scores 
was not consistent with a decrease in word level errors in the current study. This supported a hypothesis that primary language impairment with weaknesses in attention and information processing exacerbated communication difficulties at home and at school because word and utterance level errors remained problematic even when a message was communicated adequately.

These findings were consistent with research contending that elevated word level errors, particularly "unexpected variations" in tense-marking separated children with language impairment from children with primary attention problems (Redmond, 2004; Russell \& Grizzle, 2008). When describing language problems in children with ADHD, Redmond (2004) stated, “The presence of ADHD had compromised children's language performances but did so inconsistently and/or in subtle and specific ways that were different from the pervasive breakdowns in tense marking, emblematic of the SLI [specific language impairment] group" (p. 113).

It may be that difficulties initiating speaking and maintaining processing of language during extended discourse was misattributed to inattention in the classroom as reported by teachers of the participants in this study. Another explanation was offered by Kuntz (2012) based on her dissertation research on selective attention in children with language impairment. She found that inhibitory control, a cognitive skill, was significantly reduced in children with language impairment in a controlled experiment requiring word finding. The resulting longer reaction times and speaking mistakes found in the language impaired group gave them an inattentive appearance during language and reading tasks because, according to Kuntz (2012), the language impaired group paid too 
much attention to irrelevant information and failed to monitor their responses. She stated:

Deficits in selective attention can account for the overall reaction time differences as well as the significant differences on tasks of conflict. This results in a decrease in efficiency of their attentional system which results in unsuccessful completion of a [verbal] task. (p. 47)

This reasoning explained why some linguistic parameters such as NSS (2010) and MLU were sensitive to familiarity with the elicitation context. As the verbal task became familiar, it required less efficiency in attention; therefore, utterance formulation and narrative language was less problematic.

\section{Difficulty with initiation and failure to persist in communication following a}

setback. Participants in the current study were reported to have difficulty initiating communication with their classroom teachers. Difficulties with attention and processing stressful and novel communication events could explain in part why participants were described as having an oversensitivity to conflict in verbal exchange and why initiating verbally to their teacher in the classroom was reported to be difficult. Negative emotional responses to communication events also impacted social effectiveness and was likely to have an impact on persisting in some kinds of communication exchanges.

It was reported that Daniel and Bailey stood very close to their teachers and touched them rather than using verbal communication. Edward's teacher reported that she keeps him close and tries to read his need for her. Russell and Grizzle (2008) argue that there is strong evidence of a relationship between language functioning, psychiatric 
status, and emotional adjustment at different narrative stages for children with language impairment. They claim that children with mild to moderate developmental disabilities were at risk for emotional health symptoms. According to Beitchmann and Brownlie (2005), anxiety disorders were the most substantial co-morbid diagnosis in older children with language impairment rather than ADHD/ADD.

Based on the results of this research study, evidence of weaker language skills, when compared to corpus peer groups, and less amount of talk in the classroom influenced social communication and social skills across participants. Repeated reports during interviews and in IEP documentation of resistance to making social initiations and failures to persist in stressful communication events was prominent. Participants were described as socially helpless at times.

Practicing communication skills required during confrontation will be a useful future intervention for the participants in this study. More consistent practice with the discourse schema required during a conflict will support a more positive mode of thought through which episodes of conflict in the classroom, with peers, and at home can be understood as a discourse act or script. A better understanding of communication during conflict could result in fewer shut-down episodes for participants.

\section{Research Question \#2}

Early childhood health risks and emotional health symptoms beyond the early years of schooling were considered under-investigated areas of difficulty for children with primary language impairment. Data to answer the second research question in the current study was not as robust as the data used to answer the first research question. 
With the exception of Edward, the participants in the current study began receiving speech-language services prior to kindergarten. Bailey's mother reported lead exposure and a genetic predisposition to explain the etiology of Bailey's language impairment as a precursor to a learning disability. Carson's mother reported early childhood asthma and concerns about Carson's development from a very early age. Parents did not report early childhood health risks for Edward or Daniel. All participants were reported to be in good physical health at the time of the study.

Emotional health symptoms included shutting-down behavior following a stressful communication event, family history of ADD/ADHD, and concerns about confidence and anxiety were documented. Emotional health symptoms in the current research were associated in a pattern with age of the participants. Daniel, the youngest participant, was described in interviews as happy and engaged. Daniel's teacher had no concerns about his emotional regulation even when he shut down verbally. She reported feeling confident that with improved verbal communication skills Daniel's likelihood for school success was positive. However, his mother described him as preferring to play by himself even during play dates at his home, having negative self-talk, and putting nonfood in his mouth.

Edward and Bailey were described by their teachers as having immature relationships and friendship difficulties at school. Parents described concerns about confidence and anxious behavior specific to getting their children to school and doing homework. Negative self-talk was described as a significant concern by Bailey's and Carson's mothers. Carson, the oldest participant, was reported to have medical diagnoses 
of anxiety and depression. Anxious behavior and emotional outbursts were reported as a primary concern in Carson's qualitative data.

Edward was described in interviews as having a very strong sense of humor and generally positive attitude about himself. Concerns about Edward's social interactions centered on his need for adult support to resolve conflicts with peers and some shutting down at school. Edward's family history, like the other participants, was positive for ADD/ADHD and learning difficulties. Edward's good emotional health may have had a positive impact on his speaking rate and processing time for narrative formulation when compared to the other participants in the study. Edward took significantly less time to produce a similar total number of words (TNW) than the other children in the current study.

\section{Integrating Findings with Existing Research}

Of particular interest in this study was that deficits in oral narrative skills interacted with difficulties in social communication and written language and did not interact with basic reading and reading comprehension for this group of participants. During classroom observations and interviews, teachers were eager to report data that supported strong decoding skills for each participant. Carson and Daniel were reading above grade level at the time of the study, according to their classroom teachers. This was important because it situated this research study within the resurgence of subtype literature on language impairment.

Historically, language impairment subtypes included expressive language only, receptive language only, or mixed expressive/receptive language disorder. As discussed 
in the literature review, this classification system fell out of favor when children failed to maintain a profile over time. In addition, differences in responses to intervention for these three groups were weak. In general, all of the groups benefitted equally from interventions. The resulting practice was to provide similar interventions to all children with language impairment. This thinking explained why participants' IEPs lacked information about their friendship skills, behavior during conflict, written language skills, or emotional regulation/attention skills.

However, a resurgence in sub-type research in language impairment, due to the ngoing pervasiveness of language impairment in older children and adults, expanded our thinking about language impairment. In general, language impairment with and without reading disability, language impairment with and without ADD/ADHD, language impairment with and without anxiety, and language impairment with and without pragmatic language deficits provided a research foundation for profiles that contribute to the current research study. Figure 2 diagrams findings from the current research study as they related to the pervasive nature of language impairment.

Specific deficits that fit into these profiles of language impairment explain poor academic outcomes in different ways. In the current study, school success or failure was founded in social relationships at school and engagement in the classroom rather than in the generally accepted causal explanation that weak language skills result in learning disabilities. The current research challenges causal models that treat developmental language delays in young children as sufficient to explain learning disabilities in general. This was consistent with Greenhalgh and Strong (2001) who argue that higher-level 
language skills, such as literate narratives, were not a skill independent of children's

experiences using language socially to navigate the function, form, topics, and structures

of academic learning.

Figure 2

Pervasive language impairment.

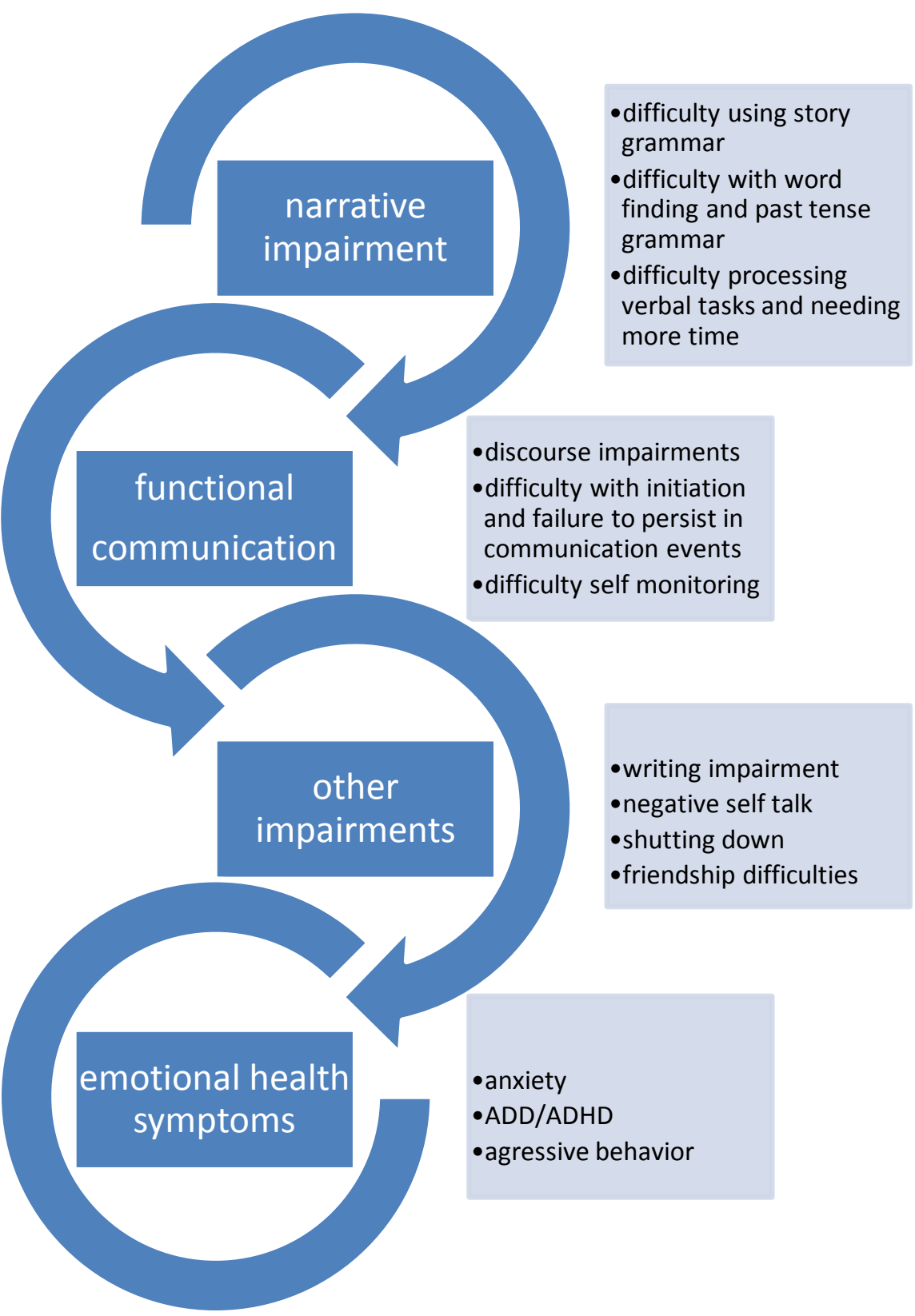


Implications for assessment. Research findings supported the hypothesis that focusing assessments on isolated linguistic deficits fails to explain the diverse and variable range of problems experienced by the participants in the current research. In addition to ongoing assessment of narrative skills under familiar and novel contexts, evaluation of problem-solving resources, such as working memory and planning strategies, such as those exposed in formal assessments of executive function, should be evaluated in children with pervasive language impairment. This type of comprehensive evaluation planning was reserved for older children or young children with more severe disabilities, such as autism, in the school setting. However, in community settings, developmental specialists have access to these assessments, and families can choose to share findings with school personnel.

Parents in this study who perceived their children as having emotional health symptoms reported accessing community resources for counseling and medication intervention. This data highlighted the need for communication among community service providers and school-based special education case managers. Data specific to health history and emotional health symptoms suggested that parents and teachers felt uneasy with the relatively abstract connection between services from a SLP at school and concerns about early health risks, ADD/ADHD, anxiety, and friendship skills. These developmental concerns seem less directly connected to participants' language impairment for individual stakeholders than this study would suggest. However, one limitation of the current research study is that teachers were the only school-based 
informants. Future investigations would benefit from multi-informant information from the school setting. Although results from the small sample size and limited informants should be interpreted with caution, the patterns in this study's results are particularly valuable in understanding how language impairment affects children in developing other important interaction skills. School and community partnerships should be reflected in students' IEP documentation and considered when designing classroom-based interventions.

Practice implications. The current research supported the need for improvements within stand-alone pull-out interventions from SLPs in school and private clinic settings. While advocating for ongoing pull-out services or a change in practice toward classroom based service delivery was beyond the scope of the current data, according to Sunderland (2004) current practice among school-based SLPs typically consisted of a 20-40 minute pull-out intervention once or twice a week. Research findings and analysis from the current study have resulted in three major implications for pull-out practice.

- Curriculum content pull-ins, such as providing young children with a purposeful overview of units of study from their general education classroom, including concept mapping and a basic understanding of key vocabulary.

- Word-finding practice and strategy instruction is a way to improve overall verbal facility and rate for young children with poor narrative skills. 
Word-finding practice as a linguistic warm-up is not unlike the oral motor warm-ups that have efficacy in articulation therapy.

- Short narrative practice within each session, as opposed to a single narrative retelling following a shared reading, supported young children with an opportunity to receive feedback quickly and use strategies such as 'act like a reporter'.

Curriculum pull-in. Collaborative models for meeting the needs of young children with disabilities focus on special education teachers and SLPs providing expertise and resources. Resources include an additional adult in the classroom for part of the day or special materials and texts to meet the needs of a specific child or small group of children. While not ideal, the IEP meeting itself served as the collaboration setting in the current study. An alternative approach situates the classroom teacher as the content and concept guide for intervention providers. This alternative to collaboration challenges the relationship to co-construct the priority learning and behavior goals in a way that highlights the most salient aspects of content learning and classroom experiences.

This is particularly helpful if a grade level is planning a unit of study consistent with the CCSS (2010). This can include practicing how to say key vocabulary terms, a chance to anticipate how the content will be learned and predict what makes the topic special or important. Collaborative effort on the part of the SLP to harmonize developmental aspects of communication skills, children's strengths and preferences, and 
target behaviors is relevant to the classroom teachers' goals. For children in full inclusion placements, this approach sponsors productive and meaningful collaboration.

Word-finding practice and strategies. Unlike articulation and fluency therapy, pull-out intervention for young children with language impairment often lacks structure. Warm-ups, not unlike preparations provided by a dance instructor prior to choreography, should focus on word finding for all children with language difficulties. Word finding warm-ups support the narrative dance. Examples include using a metronome to support rhythmic reciting of the days of the week or playing catch with a ball while having children name a sport (or other category) as they pass. Asking children to practice the foundations of discourse skills supports verbal facility and rate within therapy sessions by promoting a low-risk communication event as a warm-up. Word finding strategies such as re-stating, personal think time, having an adult cue semantic relationships, such as categories, and engaging background knowledge are strategies that translate well to discourse. Teaching, modeling, and reinforcing these skills in low-risk warm-ups simplifies feedback to support communication and emotional regulation during communication. Results from the present study provide a strong argument for encouraging repairs, such as re-stating, re-ordering, and choosing a different word. Face to face word finding activities are significantly different from word finding practice using a computerized intervention program because there is an aspect of co-construction to the task.

Short narratives. Aspects of quick retelling used in social and classroom discourse were hypothesized to be deficient in children with general deficits in narrative 
language. One purpose of this study was to explore narrative skill development in children with language impairment under best performance conditions, including using re-tell elicitation procedures, specific sampling criteria to select participants without special education needs, and evaluating participants' classroom environments and family backgrounds to rule out alternate explanations for poor narrative performance. Findings from this study resulted in a change in practice best described as a shift away from literate narrative elicitation toward short narrative discourse. This includes multiple opportunities to produce episodic narratives within each pull-out intervention. For example, providing young children with short video news clips about interesting topics and asking them how the producers built the story provides both a model and a schema. These short 'who, what, when, where, why' tellings requires many of the same elements of longer narratives but take less time. Providing a schema such as 'act like a reporter' is useful within the clinical session as well as during social communication events at school. Within a 20-minute pull-out session children can produce 10-20 short utterance tellings. While detailed retelling following a shared reading or experience remains a benchmark skill, the ability to produce a quick telling is a functional skill across discourse domains and across the lifespan.

\section{Limitations}

Findings from the current research were not generalizable to the population of children with language impairment. In addition, the descriptive statistics reported were not based on a representative sample comparison group. However, the case descriptions brought attention to important differences and likenesses among the participants as well 
as similar cases SLPs encounter in the school setting on a daily basis. From a feasibility standpoint, school-based SLPs are not able to build broad case examples over time in detail. Case-based patterns in this study provided school-based SLPs with data to support decision-making in their rushed professional environment. More specifically, the current research provided SLPs and other special education providers with thick descriptions of exemplars from a population of full inclusion young children eligible for special education under the category of a language impairment awakening them to patterns revealed in their daily work. For example, a small but meaningful upward trend in narrative skills data documented across participants was promising. Based on language sample data, participants showed significantly reliable improvements in mean length of utterance and scores on the NSS (2010) approaching mastery of basic story grammar on one or more story retelling transcripts. Though the direction of these trends is encouraging, the small number of participants limits population inferences, and given the limitation of corpus comparisons, results must be interpreted cautiously.

Secondly, the principal investigator conducted all transcription, coding, and analysis. Steps to control for investigator bias included a constant review of online training provided by SALT (2010) and CAT (2008) were referenced throughout coding and data analysis. In addition, data collection tools, including the CLEP (2004) and the NSS (2010) had existing validity research for use by a single rater. It is important to document the exploratory nature of this research and the goal of understanding patterns in the communication skills of a small group of young children with language impairment. The study used a small participant group and generalization of results beyond the data is 
outside the scope of this study. Three of five participants were receiving services from a private clinic SLP in addition to school-based services at the time of the study. Some of the participants' composite scores on standardized tests were above some districts' cut scores for eligibility criteria under the category of a communication disorder. The current study provided a documentation of potential areas of concern for young children with language impairment by describing patterns beyond classic psycholinguistic considerations in understanding the pervasive nature of this disability.

While the small number of participants limits any general conclusions that could be drawn from the data, this study's mixed methods approach contributed to broadening the scope of research methods that need to be utilized in the field of communication disorders to understand functional communication skills as a unique factor in special education eligibility. The present findings indicated that there was a substantial cooccurrence of social communication/pragmatic difficulties in this small group of young children with language impairment and that these co-occurrences impact communication at school, at home, and in the community. Future research is needed that defines meaningful school-based and community-based interventions for children with language impairment at risk for emotional health symptoms and social communication/social skills deficits.

\section{Contributions}

The present study contributed both confirmatory and original findings that described the functional communication patterns associated with language impairment. Confirmatory findings were consistent with extant literature that confirmed narrative 
formulation deficits did not resolve in a predictable pattern with other linguistic measures such as MLU or vocabulary. Original findings supported understanding a relationship between primary language impairment and social communication deficits, including significant difficulties with negotiation and conflict.

Confirmatory contributions. Data was consistent with findings reported by Greenhalgh and Strong (2001) who found that children with language impairment maintained deficits in narrative skills while producing sentence length and syntax similar to typically developing children. Data indicated that participants demonstrated deficits in word choice without deficits in functional vocabulary as measured using total number of words and total number of different words. Elevated word level errors were consistent with findings reported by Manhardt and Rescorla (2002). They go on to report that these patterns were consistent with $60 \%$ of children who were identified with language impairment in preschool which is consistent with participants in the current study. Additionally, research indicated that a lack of revisions and rewording and a disproportionate amount of garbage mazes in the speaking of children with language impairment (Fiestas et al., 2005) was confirmed in the present study. In general, data supported the assertion that children with language impairment maintained variations at the utterance level during narrative formulation even in the absence of deficits in MLU or vocabulary.

Original contributions. In the present study, oral narrative skills and functional communication deficits were situated as barriers to communication events. Failure to persist in communication events was related to emotional regulation and socially anxious 
behavior rather than language impairment alone. Data suggested that participants lacked language strategies or scripts for interactions, such as initiating verbal communication with the classroom teacher and maintaining verbal responsiveness during conflict. Quantitative and qualitative data supported the argument that communication events that were novel (vs. routine) or required negotiation skills had a negative impact on language use and functional communication skills. Language impairment was maintained by discourse impairments and poor self-efficacy that acted like sediment in a river system during communication events.

Previous studies from the field of public health found unique aspects of language development in populations of young children with primary health, attention, and social withdrawal disabilities. In the current research, data suggested that participants with primary language impairment had unique difficulties with social and emotional development.

Participants in the current study experienced different phases of their communication disorder and more challenging school experiences when the required discourse skills were sophisticated. Emotional responses to communication events reduced self-efficacy and influenced social relationships at school. It will be helpful to design intervention strategies that explicitly coach children with language impairment by using scripts during communication events a child finds stressful. Future research is needed comparing different intervention approaches for children with language impairment without reading disability to focus interventions toward the pragmatic and social skill profiles. Collaborations between school-based and community-based 
organizations were needed to address the emotional health symptoms described in the current research.

Typical language development is often described as a simple fan with form at the base guided by function and behavior. For children with pervasive language impairment, form, function and behavior became braided with communication events that limited linguistic conventions during communication. When participants avoided communication events such as communication during conflict and peer communication the braid tightened and it was difficult for participants to demonstrate socially desirable behavior such as paying attention and maintaining verbal communication following a setback. The resulting pattern of pervasive language impairment was therefore not unlike the braids and fans in a river system. Conventional language and disordered language joined together and divided in many places confirming the elusive nature of this disability. 


\section{References}

American Psychiatric Association (2000). Diagnostic and statistical manual of mental disorders (4th ed., text rev.). Washington, DC: Author.

Apel, K. (2001). Developing evidence-based practices and research collaborations in school settings. Language, Speech, and Hearing Services in Schools, 32, 196197.

Arnold, D. H., \& Doctoroff, G. L. (2003). The early education of socioeconomically disadvantaged children. Annual Review of Psychology, 54 (1), 517-545.

Bandura, A. (2001). Social cognitive theory: An agentic perspective. Annual Reviews of Psychology, 52, 1-26.

Bandura, A. (2003). Negative self-efficacy and goal effects revisited. Journal of Applied Psychology, 88 (1), 87-99.

Battery, J. (2008). Incidence and prevalence of communication disorders in children. Retrieved at http://www.asha.org/research/reports/children.htm.

Beaver, J. (2003). DRA: Developmental reading assessment. Celebration Press: Parsippany, NJ.

Beitchman, J. \& Brownlie, E. (2005). Language development and its impact on children's psychosocial and emotional development. In Encyclopedia on Early Childhood Development, [online]. Montreal, Quebec: Centres of Excellence for Children's Well-Being.

Biemiller, A. (2003). Vocabulary: Needed if more children are to read well. Reading Psychology, 24, 323-335. 
Bignell, S. \& Cain, K. (2007). Pragmatic aspects of communication and language comprehension in groups of children differentiated by teacher ratings of inattention and hyperactivity. British Journal of Developmental Psychology, 25, 499-512.

Bishop, D. M. V., McDonald, D., Bird, S., \& Hayiou-Thomas, M. (2009). Children who read words accurately despite language impairment: Who are they and how do they do it? Child Development, 80 (2), 593-605.

Bishop, D. V. M. (1994). Is specific language impairment a valid diagnostic category? Genetic and psycholinguistic evidence. Philosophical Transactions: Biological Sciences, 346 (1315), 105-111.

Bishop, D. V. M. \& Edmundson, A. (1987). Language impaired four year olds: Distinguishing transient from persistent impairment. Journal of Speech, Language, and Hearing Disorders (52), 156-173.

Bishop, D. V. M. \& Norbury, C. (2005). Executive functions in children with communication impairments, in relation to autistic symptomatology. Autism, 9 (1), 7-27.

Bond, M. \& Wasik, B. (2009). Conversation stations: Promoting language development in young children. Early Childhood Education Journal, 36 (6), 467-473.

Botting, N. \& Boucher, J. (2008). Language in autism and specific language impairment: Where are the links? Psychological Bulletin, 134 (6), 944-963.

Botting, N. \& Conti-Ramsden, G. (2008). The role of language, social cognition, and social skill in the functional social outcomes of young adolescents with and 
without a history of SLI. British Journal of Developmental Psychology, 26 (2), 281-300.

Boudreau, D. (2008). Narrative abilities: Advances in research and implications for clinical practice. Topics in Language Disorders, 28 (2), 99-114.

Boushey, G. \& Moser, J. (2006). The daily 5: Fostering literacy independence in the elementary grades. Portland, ME: Stenhouse.

Brinton, B. \& Fujiki, M. (2006). Social intervention for children with language impairment: Factors effecting efficacy. Communication Disorders Quarterly, 28 (1), 39-41.

Brock, L. L., Nishida, T. K., Chiong, C., Grimm, K. J., \& Rimm-Kaufman, S. E. (2008). Children's perceptions of the classroom environment and social and academic performance: A longitudinal analysis of the contribution of the Responsive Classroom approach. Journal of School Psychology, 46 (2), 129-149.

Brock, L. L., Rimm-Kaufman, S. E., Nathanson, L., \& Grimm, K. J. (2009). The contributions of 'hot' and 'cold' executive function to children's academic achievement, learning-related behaviors, and engagement in kindergarten. Early Childhood Research Quarterly, 24 (3), 337-349.

Bronfenbrenner, U. (1994). Ecological models of human development. In International Encyclopedia of Education, $2^{\text {nd }}$ Ed. (Vol.3). Oxford: Elsevier.

Bryan, T., Burstein, K., PenChiang, C., \& Ergul, C. (2006). The relationship between health status, language development, and behavior in young children. Physical Disabilities: Education and Related Services, 24 (2), 7-19. 
Burnstein, K., Bryan, T., Chao, P., Berger, K., \& Hirsch, D. (2005). Communication patterns of primary care pediatricians, parents, and children with and without special health care needs. Journal of Developmental and Physical Disabilities, 17 (3), 249-262.

Buyse, E., Verschueren, K., Doumen, S., Van Damme, J., \& Maes, F. (2008). Classroom problem behavior and teacher-child relationships in kindergarten: The moderating role of classroom climate. Journal of School Psychology, 46 (4), 367-391.

Campbell, W. \& Skarakis-Doyle, E. (2007). School-age children with SLI: The ICF as a framework for collaborative service delivery. Journal of Communication Disorders, 40, 513-535.

Castrogiovanni, A. (2008). Incidence and prevalence of speech, voice, and language disorders in adults in the United States: 2008 edition. Rockville, MD: American Speech-Language-Hearing Association.

Catts, H. W., Bridges, M. S., Little, T. D., \& Tomblin, J. B. (2008). Reading achievement growth in children with language impairments. Journal of Speech, Language and Hearing Research, 51 (6), 1569-1579.

Catts, H. W., Fey, M. E., \& Proctor-Williams, K. (2000). The relationship between language and reading: Preliminary results from a longitudinal investigation. Logopedics Phoniatrics Vocology, 25 (1), 3-11.

Catts, H. W., Fey, M. E., Zhang, X., \& Tomblin, J. B. (1993). Language basis of reading and reading disabilities: Evidence from a longitudinal investigation. Scientific Studies of Reading, 3, 331-362. 
Cazden, C. (1988). Classroom discourse: The language of teaching and learning. Portsmouth, ME: Heinemann.

Chafe, W. \& Tannen, D. (1987). The relation between written and spoken language. Annual Review of Anthropology, 16, 383-407.

Charmaz, K. (2006). Constructing grounded theory. London: Sage.

Chomsky, N. (1982). Language and the Study of Mind. Tokyo: Sansyusya Publishing.

Coleman, D. \& Pimentel, S. (2011). Publishers' criteria for the Common Core State Standards in English language arts and literacy, grades 3-12. Retrieved September 7, 2011, from http://www.corestandards.org/assets/Publishers_Criteria_for_3-12.pdf.

Conti-Ramsden, G. \& Botting, N. (2008). Emotional health in adolescents with and without a history of specific language impairment (SLI). Journal of Child Psychology and Psychiatry, 49, 516-525.

Corrigan, R. (2008). Beyond the obvious: Constructing meaning from subtle patterns in the language environment. Communication Disorders Quarterly, 29 (2), 109-124.

Craig, H. K., Connor, C. M., \& Washington, J. A. (2003). Early positive predictors of later reading comprehension for African American students: A preliminary investigation. Language, Speech, and Hearing Services in Schools, 34 (1), 31-43.

Craig, H. K., Evans, J. L., Meisels, S., \& Plunkett, J. (1991). Linguistic production abilities of 3-year-old children born premature with low birth weight. Journal of Early Intervention. 15 (4), 326-337. 
Curtain, H. \& Dahlberg, C. (2004). Languages and children: Making the match. Boston, MA: Pearson.

Delpit, L. (1995). Other people's children: Cultural conflict in the classroom. New York: New Press.

Dickinson, D. K., McCabe, A., \& Sprague, K. (2003). Teacher rating of oral language and literacy (TROLL): Individualizing early literacy instruction with a standardsbased rating tool. Reading Teacher, 56 (6), 554-564.

Diller, D. (2007). Making the most of small groups: Differentiation for all. Portland, ME: Stenhouse.

Downer, J., Rimm-Kaufman, S., \& Piñata, R. (2007). How do classroom conditions and children's risk for school problems contribute to children's behavioral engagement in learning? School Psychology Review, 36 (3), 413-432.

Dunkle, J. \& Flynn, P. (2012). Speech-language pathologists and the Common Core Standards initiative. Seminar in Speech and Language, 33 (2), 102-110.

Ebert, K. \& Kohnert, K. (2011). Sustained attention in children with primary language impairment: A meta-analysis. Speech, Language and Hearing Research, 54 (5), $1372-1384$

Evans, J. L. (2002). Variability in comprehension strategy use in children with SLI: A dynamical systems account. International Journal of Language and Communication Disorders, 37 (2), 95-116.

Feldman, D. H. (1976). Winner of second place, Kappan bicentennial essay contest: The child as craftsman. The Phi Delta Kappan, 58 (1), 143-149. 
Fiestas, C., Bedore, L., Peña, E., \& Nagy, V. (2005). Use of mazes in the narrative language samples of bilingual and monolingual 4-7 year old children. Somerville, MA: Cascadilla Press.

Finneran, D., Leonard, L. \& Miller, C. (2010). Speech disruptions in the sentence formulation of school-age children with specific language impairment. International Journal of Language and Communication Disorders 44 (3), 271 286.

Fountas, I. \& Pinnell, G. S. (2006). Teaching for comprehending and fluency: Thinking, talking, and writing about reading, $K-8$. Portsmouth, ME: Heinemann.

Fraser, B. J. \& Fischer, D. L. (1982). Effects of classroom psychosocial environment on student learning. The British Journal of Educational Psychology, 52 (3), 374-377.

Gazelle, H. (2006). Class climate moderates peer relations and emotional adjustment in children with an early history of anxious solitude: A child X environment model. Developmental Psychology, 42 (6), 1179-1192.

Gazelle, H. \& Ladd, G. (2003). Anxious solitude and peer exclusion: A diathesis-stress model of internalizing trajectories in childhood. Child Development, 74 (1), 257278.

Geoff, L., Dockrell, J., Letchford, B., \& Mackie, C. (2002). Self -esteem of children with specific speech and language difficulties. Child Language Teaching and Therapy, $18(2), 125-143$.

Georgakopoulou, A. (2006). The other side of the story: Towards a narrative analysis of narratives-in-interaction. Discourse Studies, 8 (2), 235-257. 
Girolametto, L., Wiigs, M., Smyth, R. Weitzman, E., \& Pearce, P. (2001). American Journal of Speech-Language Pathology, 10 (4). 358-370.

Glaser S. R. (1981). Oral communication apprehension and avoidance: The current status of treatment research. Communication and Education, 30, 321-41.

Goldberg, S. (2005). Ready to learn. New York: Oxford University Press.

Goorhuis-Brouwer, S. M. \& Knijff, W. A. (2002). Efficacy of speech therapy in children with language disorders: Specific language impairment compared with language impairment in comorbidity with cognitive delay. International Journal of Pediatric Otorhinolaryngology, 63, 129-136.

Green, S. \& Hogan, D. (2005) Researching children's experience. Los Angeles: Sage.

Greenhalgh, K. S. \& Strong, C. J. (2001). Literate language features in spoken narratives of children with typical language and children with language impairment. Language, Speech, and Hearing Services in Schools, 32 (2), 114-125.

Guilar, J. (2006). Intersubjectivity and dialogic instruction. Radical Pedagogy,8, ISSN: 1524-6345. Retrieved from http://www.radicalpedagogy.org/Radical_Pedagogy/Intersubjectivity_and_Dialog ic Instruction.html.

Guo, L., Tomblinson, B., \& Samelson, V. (2008). Speech disruptions in the narratives of English-speaking children with specific language impairment. Journal of Speech, Language and Hearing Research, 51, 722-738. 
Guo, Y., Justice, L., Kaderavek, J., \& McGinty, A. (2012). The literacy environment of preschool classrooms: Contributions to children's emergent literacy growth. Journal of Research in Reading, 35 (3), 308-327.

Hall, K. (2003). Listening to Stephen read: Multiple perspectives on literacy. Philadelphia, PA: Open University Press.

Halliday, M. A. K. (1974). A sociosemiotic perspective on language development. Bulletin of the School of Oriental and African Studies, 37 (1), 98-118.

Halliday M. A. K. (1975). Learning how to mean. London: Edward Arnold.

Hamre, B. K. \& Piñata, R. C. (2001). Early teacher and child relationships and the trajectory of children's school outcomes through eighth grade. Child Development, 72 (2), 625-638.

Hanushek, E., Kain, J. \& Rivkin, S. (1998). Does special education raise student achievement for students with disabilities?. NBER Working Papers \#6690. National Bureau of Economic Research, Inc. Retrieved from http://www/nber.org/papers/w6690.pdf.

Hedberg, N., \& Westby, C. (1993). Analyzing storytelling skills: Theory to practice. Tucson, AZ: Communication Skill Builders.

Heilmann, J., Miller, J., Nockerts, A. \& Dunaway, C. (2010). Sensitivity of narrative organization measures using narrative retells produced by young school-age children. Language Testing, 27 (4), 603-626. 
Hewitt, L., Hammer, C., Yont, K., \& Tomblin, J. (2005). Language sampling for kindergarten children with and without SLI: Mean length of utterance, IPSYN, and NDW. Journal of Communication Disorders, 38, 197-213.

Hoff, E. \& Naigles, L. (2002). How children use input to acquire a lexicon. Child Development, 73 (2), 827-838.

Hoff, E. (2006). How social contexts support and shape language development. Developmental Review, 26 (1), 55-88.

Hood, M., Conlon, E., \& Andrews, G. (2008). Preschool home literacy practices and children's literacy development: A longitudinal analysis. Journal of Educational Psychology, 100(2), 252-271.

Jackson, B. (2003). Education reform as if student agency mattered: Academic microcultures and student identity. Phi Delta Kappan, 84 (8), 579-585.

Jacoby, S. \& Ochs, E. (1995). Co-construction: An introduction. Research on Language and Social Interaction 28 (3), 171-184.

Johnson, R. B., Onwuegbuzie, A., \& Turner, L. (2007). Toward a definition of mixed methods research. Journal of Mixed Methods Research, 1, 112-133.

Jones, I. (2002). Social relationships, peer collaboration and children's oral language. Educational Psychology, 22 (1), 63-73.

Justice, L., Bowles, R., Kaderavek, J., Ukrainetz, T., Eisenberg, S., \& Gillam, R. (2006). The index of narrative microstructure: A clinical tool for analyzing school-age children's narrative performances. American Journal of Speech-Language Pathology, 15, 177-191. 
Kaderavek, J. \& Sulzby, E. (2000). Narrative production by children with and without specific language impairment: Oral narratives and emergent readings. Journal of Speech, Language, and Hearing Research, 43, 34-49.

Kirkland, L. D. \& Patterson, J. (2005). Developing oral language in primary classrooms. Early Childhood Education Journal, 32 (6), 391-395.

Kozulin, A. (1990). Vygotsky's psychology: A biography of ideas. Cambridge, MA: Harvard University Press.

Kratochwill, T., Brody, G., \& Piersel, W. (1979). Time-series research: Some comments on design methodology for research in learning disabilities. Journal of Learning Disabilities, 12 (4), 52-58.

Krauss, R. M. \& Glucksberg, S. (1969). The development of communication: Competence as a function of age. Child Development, 40 (1), 255-266.

Kristensen, H. \& Torgersen, S. (2007). Is social anxiety disorder in childhood associated with developmental deficit/delay? European Child \& Adolescent Psychiatry, 17(2), 99-107.

Kuntz, B. (2012). Selective attention in children with specific language impairment: Auditory and visual Stroop effects. City University of New York, ProQuest, UMI Dissertations Publishing.

Ladd, G. W. \& Birch, S. H. (1999). Children's social and scholastic lives in kindergarten: Related spheres of influence? Child Development, 70 (6), 1373-1400. 
Lasky, R. E., Jon, E. T., Rosenfeld, C. R., Priest, M., Krasinski, D., Heartwell, S., et al. (1983). Differences on Bayley's Infant Behavior Record for a sample of high-risk infants and their controls. Child Development, 54 (5), 1211-1216.

Law, J., Garrett, Z., \& Nye, C. (2004). The efficacy of treatment for children with developmental speech and language delay/disorder: A meta-analysis. Journal of Speech, Language, and Hearing Research, 47, 924-943.

Lu, C-J. \& Shulman, S. W. (2008). Rigor and flexibility in computer-based qualitative research: Introducing the Coding Analysis Toolkit. International Journal of Multiple Research Approaches, 2 (1), 105-117.

Luria, A.R. (2002). L.S. Vygotsky and the problem of functional localization. Russian and East European Psychology 40 (1), 26-54.

MacLure, M. (2003). Discourse in educational and social research. Buckingham, UK: Open University Press.

Manhardt, J. \& Rescorla, L. (2002). Oral narrative skills of late talkers at age 8 and 9. Applied Psycholinguistics, 23, 1-21.

Mantzicopoulos, P. (2005). Conflictual relationships between kindergarten children and their teachers: Associations with child and classroom context variables. Journal of School Psychology, 43 (5), 425-442.

Marshall, C. \& Rossman, G. (2006). Designing qualitative research. Thousand Oaks, CA: Sage. 
Marton, K. \& Schwartz, R. (2003). Working memory capacity and language processes in children with specific language impairment. Journal of Speech, Language and Hearing Research, 46, 1138-1153.

Marzano, R. (2007). The art and science of teaching: A comprehensive framework for effective instruction. Alexandria, VA: Association for Supervision and Curriculum Development.

McMahon, R., Richmond, M.G., \& Reeves-Kazelskis, C. (1998). Relationships between kindergarten teachers' perceptions of literacy acquisition and children's. Journal of Educational Research, 91 (3), 173-183.

McMurray, B. (2007). Defusing the childhood vocabulary explosion. Science, 317, 631. Meyer, L., Wardrop, J. Hastings, S., \& Linn, R. (1993). Effects of reading storybooks aloud to children. The Journal of Educational Research, 88 (2), 69-85.

Miller, J. \& Iglesias, A. (2010). Systematic analysis of language transcripts (SALT), Research version 2010 [Computer Software], SALT Software, LLC.

Morrow, L. M., Tracey, D. H., Woo, D. G., \& Pressley, M. (1999). Characteristics of exemplary first-grade literacy instruction. Reading Teacher, 52 (5), 462-476.

National Governors Association Center for Best Practices \& Council of Chief State School Officers. (2010). Common Core State Standards. Washington, DC: Authors.

Neale, M. \& Test, D. (2011). Effects of the "I Can Use Effort" strategy on quality of student verbal contributions and individualized education program participation 
with third- and fourth-grade students with disabilities. Remedial and Special Education, 31 (3), 184-194.

Nippold, M. (1988). Later language development: Ages nine through nineteen. Austin, TX: PRO-ED.

Nippold, M. A. (2009). School-age children talk about chess: Does knowledge drive syntactic complexity? Journal of Speech, Language and Hearing Research, 52 (4), 856-871.

Nippold, M. A. (2010). How to conduct quality research in the schools... on a limited budget. Language, Speech, and Hearing Services in Schools, 41, 231-232.

Nippold, M. A., Hesketh, L. J., Duthie, J. K., \& Mansfield, T. C. (2005). Conversational versus expository discourse: A study of syntactic development in children, adolescents and adults. Journal of Speech, Language and Hearing Research, 48 (5), 1048-1064.

Ok Seung Yang, K. (2000). Guiding children's verbal plan and evaluation during free play: An application of Vygotsky's genetic epistemology to the early childhood classroom. Early Childhood Education Journal, 28 (1), 3-10.

Ouellette, G. \& Beers, A. (2010). A not-so-simple view of reading: How oral vocabulary and visual-word recognition complicate the story. Reading and Writing, 23 (2), 189-208.

Parisse, C. \& Maillart, C. (2009). Specific language impairment as systemic developmental disorders. Journal of Neurolinguistics 22, 109-122. 
Peets, K. F. (2009). The effects of context on the classroom discourse skills of children with language impairment. Language, Speech, and Hearing Services in Schools, $40(1), 5-16$.

Pendergast, C. (2003). Literacy and racial justice. Carbondale, IL: Southern Illinois University Press.

Penrod, J., Preston, D., Cain, R., \& Starks, M. (2003). A discussion of chain referral as a method of sampling hard-to-reach populations. Journal of Transcultural Nursing, $14(2), 100-107$.

Piñata, R. C., La Paro, K. M., Payne, C., Cox, M. J., \& Bradley, R. (2002). The relation of kindergarten classroom environment to teacher, family, and school characteristics and child outcomes. Elementary School Journal, 10, 225-238.

Prizant, B., Wetherby, A., Rubin, E., \& Laurent, A. (2006). The SCERTS model: Volume I assessment; Volume II program planning and intervention. Baltimore, MD: Brookes Publishing.

Ratner, N. (2006). Evidence-based practice: An examination of its ramifications for the practice of speech-language pathology. Language, Speech, and Hearing Services in Schools, 37, 257-267.

Redmond, S. (2004). Conversational profiles of children with ADHD, SLI and typical development. Clinical Linguistics and Phonetics, 18 (2), 107-125.

Redmond, S. (2011). Peer victimization among students with specific language impairment, attention deficit/hyperactivity disorder, and typical development. Language, Speech and Hearing Services in Schools, 42 (4), 520-535. 
Redmond, S., Thompson, H., \& Goldstein, S. (2011). Psycholinguistic profiling differentiates specific language impairment from typical development and from attention-deficit/hyperactivity disorder. Journal of Speech, Language and Hearing Research, 54 (1), 99-117.

Reutzel, R. \& Clark, S. (2011). Organizing literacy classrooms for effective instruction. The Reading Teacher, 65 (2), 96-109.

Rimm-Kaufman, S., Early, D., Cox, M., Saluja, G., Piñata, R., Bradley, R. \& Payne, C. (2002). Early behavioral attributes and teachers' sensitivity as predictors of competent behavior in the kindergarten classroom. Journal of Applied Developmental Psychology, 23 (4), 451-470.

Rinaldi, C. (2006). In dialogue with Reggio Emilia: Listening, researching, and learning. New York: Routledge.

Rubin, K. H., Coplan, R. J., \& Bowker, J. C. (2009). Social withdrawal in childhood. Annual Review of Psychology, 60 (1), 141-171.

Russell, R. \& Grizzle, K. (2008). Assessing child and adolescent pragmatic language competencies: Toward evidence based assessments. Clinical Child and Family Psychology Review, 11 (1/2), 59-73.

Scarborough, H.S. \& Dobrich, W. (1990). Development of children with early language delay. Journal of Speech and Hearing Research, 33, 70-83.

Scarborough, H. S., Dobrich, W., \& Hager, M. (1991). Preschool literacy experience and later reading achievement. Journal of Learning Disabilities, 24 (8), 508-511. 
Schleppegrell, M. J. (2009). Language, knowledge, and pedagogy: Functional linguistic and social perspectives. Language in Society, 38 (4), 543-545.

Semrud-Clikeman, M. (2005). Neuropsychological aspects for evaluating learning disabilities. Communication Disorders Quarterly (26), 242-246.

Shankar, S. (2002). The generativist-interactionist debate over specific language impairment: Psycholinguistics at a crossroads. The American Journal of Psychology, 115 (3), 415-450.

Sideridis, G. D. \& Greenwood, C. R. (1998). Identification and validation of effective instructional practices for children from impoverished backgrounds and those with learning and developmental disabilities using ecobehavioural analysis. European Journal of Special Needs Education, 13 (2), 145-154.

Small, M. L. (2011). How to conduct a mixed methods study: Recent trends in a rapidly growing literature. Annual Review of Sociology 37, 57-86.

Snow, C., Burns, S., \& Griffin, P. (1998). Preventing reading difficulties in young children. Washington, D.C.: National Academy Press.

Somersalo, H., Solantaus, T., \& Almqvist, F. (2002). Classroom climate and the mental health of primary school children. Nordic Journal of Psychiatry, 56 (4), 285-290.

Spencer, M. \& Markstrom-Adams, C. (1990). Identity processes among racial and ethnic minority children in America. Child Development, 61 (2), 290-310.

Spernak, S., Schottenbauer, M., Ramey, S., \& Ramey, C. (2006). Child health and academic achievement among former head start children. Children and Youth Services Review, 28, 1251-1261. 
Stanton-Chapman, T., Chapman, D., Bainbridge, N., \& Scott, K. (2002). Identification of early risk factors for language impairment. Research in Developmental Disabilities, 23, 390-405.

Stipek, D. \& Byler, P. (2004). The early childhood classroom observation measure. Early Childhood Research Quarterly, 19 (3), 375-397.

Stojanovik, V. (2006). Social interaction deficits and conversational inadequacy in Williams's syndrome. Journal of Neurolinguistics, 19 (2), 157-173.

Stojanovik, V. \& Riddell, P. (2008). Expressive versus receptive language skills in specific reading disorder. Clinical Linguistics and Phonetics, 22 (4/5), 305-310.

Sunderland, L. (2004). Speech, language and audiology services in public schools. Intervention in School and Clinic, 39 (4), 209-217.

Tallal, P., Dukette, D., \& Curtis, S. (1989). Behavioral/emotional profiles of preschool language-impaired children. Development and Psychopathology, 1, 51-67.

Tomblin, J. B., Xuyang Zhang, P., Buckwalter, M., \& O'Brien, A. (2003). The stability of primary language disorders: Four years after kindergarten diagnosis. Journal of Speech, Language and Hearing Research, 46 (6), 1283-1296.

Tomblin, J. B., Records, N., Buckwalter, P., Xuyang Zhang, P., Smith, E., \& O'Brien, A. (1997). Prevalence of specific language impairment in kindergarten children. Journal of Speech, Language, and Hearing Research, 40 (6), 1245-1261.

Tunge, J. \& Hogan, D. (2005). An ecological approach to observations of children's everyday lives. S. Green and M. Hill (Eds.). Researching Children's Experience: Approaches and Methods. London: Sage. 
Usher, E. L. \& Pajares, F. (2008). Sources of self-efficacy in school: Critical review of the literature and future directions. Review of Educational Research, 78, 751-796. Valencia, S. W., Place, N., Martin, S., \& Grossman, P. (2006). Curriculum materials for elementary reading: Shackles and scaffolds for four beginning teachers. Elementary School Journal, 107 (1), 93-120.

Valencia, S. W. \& Sulzby, E. (1991). Assessment of emergent literacy: Storybook reading. Reading Teacher, 44 (7), 498-500.

Vaughn, S. \& Fuchs, L. (2003). Redefining learning disabilities as inadequate response to instruction: The promise and potential problems. Learning Disabilities Research and Practice, 18 (3), 137-146.

Vygotsky, L. S. (1978). Mind in society: The development of Higher Psychological Processes. Cambridge, MA: Harvard University Press.

Vygotsky, L. S. (1994). The problem of the cultural development of the child. R. Van der Veer and J. Valsiver (Eds.). The Vygotsky reader. San Francisco, CA: Blackwell.

Wolfersberger, M. E., Reutzel, R., Sudweeks, R., \& Fawson, P. (2004). Developing and validating the classroom literacy environmental profile (CLEP): A tool for examining the print richness of early childhood and elementary classrooms. Journal of Literacy Research, 36 (1), 211-272.

Wood, D., Valdez, R., Hyashi, T., \& Shen, A. (1990). Health of homeless children and housed, poor children. Pediatrics, 86 (6), 858-866. 
Zill, N. (1995). Approaching Kindergarten: A Look at Preschoolers in the United States. National Household Education Survey. Statistical Analysis Report. 
Appendix A

\title{
Exploring Patterns in Primary Classroom Environments and Narrative Language Skills For Children With Language Impairment
}

\author{
A Dissertation Research Project \\ Portland State University \\ Anna J. Waters, MS,CCC-SLP
}

Dear Speech-Language Pathologist,

You are invited to nominate families to participate in a research study conducted by Anna J. Waters, MS, CCC-SLP, a doctoral candidate in the Graduate School of Education at Portland State University. Anna has been a speech-language pathologist working with children for 18 years. She hopes to learn about how patterns emerge between children's language development and their current classroom environment this school year and how health status contributes to these patterns. The study being conducted is in partial fulfillment of the requirements for the Doctorate in Educational Leadership. The research is being conducted under the supervision of Dr. Emily de la Cruz, Graduate Teacher Education Program Coordinator in Curriculum and Instruction.

In order to participate, children must meet the following criteria.

1) Children must be between the ages of 5 years to 9 years with a language impairment identified in existing documentation of a score of 80 or below on a standardized test of expressive language development.

2) Children must attend a private or public school at least half day. Children ages 5 or 6 who attend a multi-aged classroom with younger children will be eligible to participate.

3) Children must spend less than one hour per day in a special education setting as documented in an Individual Education Plan (IEP) if the child receives publicly funded special education services including services from a school-based SLP.

4) Prior to the observations phase of data collection, children must meet criteria for normal hearing on a $20 \mathrm{~dB}$ pure tone screening.

5) Children who have a medical or educational diagnosis of autism, Asperger's 
syndrome, pervasive developmental disorder, or mental retardation will not be eligible to participate.

6) Children must speak English.

Disability in the area of oral narrative skills will be confirmed during the research using the Systematic Analysis of Language Transcripts (SALT Software, LLC) . Language sample analyses at four times during the research could be used for planning and goal setting. Each family will receive a $\$ 50.00$ gift card to a local bookstore as a token of appreciation for their time and participation.

Any information that is obtained in connection with this study and that can be linked to a family or a child will be kept confidential. With parent permission, the language sample analysis can be shared with teachers and/or speech-language pathologists.

Enclosed are several letters explaining the research and requesting parent consent for participation. Please provide these letters to families and thank you in advance for your expertise and support.

If you have any questions, concerns, or problems about your participation in recruiting participants for this study or your client's rights as a research subject, please contact the Human Subjects Research Review Committee, Office of Research and Sponsored Projects, 600 Unitus Bldg., Portland State University, (503) 725-4288/1-877-480-4400.

If you have questions about the study itself, contact Anna J. Waters at (503)314-1504, 1927 NW 25 ${ }^{\text {th }}$ Avenue, Portland, OR 97210.

Anna J. Waters, MS, CCC-SLP 
Appendix B

\title{
Exploring Patterns in Primary Classroom Environments and Narrative Language Skills For Children With Language Impairment
}

\author{
A Dissertation Research Project \\ Portland State University \\ Anna J. Waters, MS,CCC-SLP
}

Dear

Date

Your family is invited to participate in a research study conducted by Anna J. Waters, MS, CCC-SLP, a doctoral candidate in the Graduate School of Education at Portland State University. Anna has been a speech-language pathologist working with children for 18 years. She hopes to learn about how patterns emerge between your child's language development and their current classroom environment this school year and how health status contributes to these patterns. The study being conducted is in partial fulfillment of the requirements for the Doctorate in Educational Leadership. The research is being conducted under the supervision of Dr. Emily de la Cruz, Graduate Teacher Education Program Coordinator in Curriculum and Instruction. Your family was selected as a possible participant in this study because your daughter (son) has been identified as a child with language impairment.

If you decide to participate, you will be asked to schedule 4 times for your child to tell stories with Anna at your child's school or in your home and participate in a 60 minute interview. Each story telling session will be video and audio taped. While participating in this study, it is possible that you and your daughter (son) will be inconvenienced by the scheduled appointments and you may feel discomfort being associated with an increase in the amount of time your child spends with a speech-language pathologist. Alternate times and locations for story telling activities and parent interview are always available. You may not receive any direct benefit from taking part in this study, but the study may help other children with language impairment and their teachers in the future. You will be provided with 4 language sample analyses to use when planning and goal setting for your child as well as a $\$ 50.00$ gift card to a local bookstore as a token of appreciation for your time and participation.

Any information that is obtained in connection with this study and that can be linked to your family or identify your daughter (son) will be kept confidential. 
With your permission, the language sample analysis can be shared with your daughter's (son's) teacher and/or speech-language pathologist. This information will be kept confidential. All information will be translated into digital formats and stored on a password-protected computer accessible to the primary researcher. Converting real names to pseudonyms will protect the identities of all research participants, teachers, and families.

Your participation is voluntary. You do not have to take part in this study, and it will not affect your child's services at school or in the community. You may also withdraw from this study at any time.

If you have any questions, concerns, or problems about your participation in this study or your child's rights as a research subject, please contact the Human Subjects Research Review Committee, Office of Research and Sponsored Projects, 600 Unitus Bldg., Portland State University, (503) 725-4288/1-877-480-4400. If you have questions about the study itself, contact Anna J. Waters at (503)314-1504, 1927 NW 25 ${ }^{\text {th }}$ Avenue, Portland, OR 97210.

Your signature indicates that you have read and understand the above information and agree that you and your daughter (son) will take part in this study. Please understand that you may withdraw your consent at any time without penalty, and that, by signing, you are not waiving any legal claims, rights or remedies. Anna J. Waters will provide you with a copy of this form for your own records.

Signature

Date

Signature

Date 
Appendix C

Authorization to Use and/or Disclose Educational and Protected Health Information

1. I authorize the following provider(s) to use and/or disclose educational and/or protected health information regarding my child.

(Student/Child's Name)

(Date of Birth)

(Other Names Used by Student/Child) Name)

(School or Program

Name and address of health care provider authorized to:

Name and address of school/EI/ECSE program authorized to:

- Send/disclose protected health

- Send/disclose educational information information

a Receive/use protected health

․ Receive/use educational information information

2. I understand that this information will be used for the following purposes (check all that apply):

$\square$ Determining eligibility for Special Education, EI/ECSE, or other services

- Determining student/child's current levels of performance

․ Developing an individualized health plan

D Developing an appropriate Individualized Education Program or Individualized Family Service Plan

口 Other (specify):

3. By marking the boxes below, I authorize the use/disclosure of the following specific medical and/or educational records:

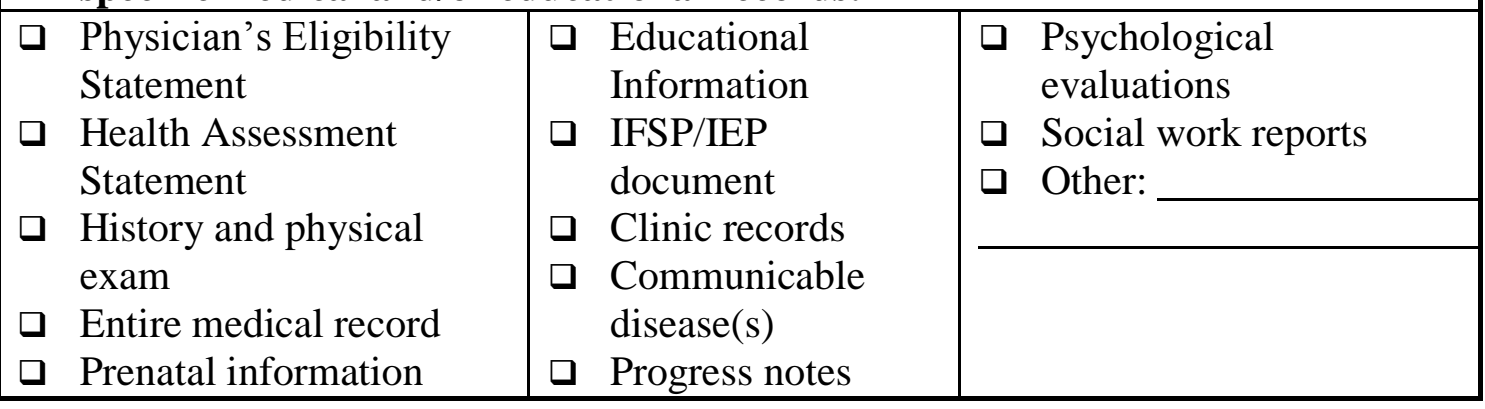


4. By initialing the spaces below, I authorize the use/disclosure of the following information. Specific records requested must be listed below, e.g., assessment, treatment plan, discharge plan.

Drug/alcohol diagnosis, treatment or referral information requested:

HIV/AIDS related records requested:

Mental health related information requested:

Genetic testing information requested:

\section{I understand that:}

a.This authorization is voluntary and I may refuse to sign it without affecting my child's health care.

b.I have the right to request a copy of this form after I sign it as well as inspect or copy any information to be used and/or disclosed under this authorization (if allowed by state and federal law. See 45 CFR $§ 164.524)$.

c.I may revoke this authorization at any time by notifying in writing. However, it will not affect any actions taken before the revocation was received or actions taken based on the previously shared information.

d.Federal privacy rules for protected health information apply only to health plans, health care clearinghouses or health care providers. If I authorize disclosure of medical information to other agencies or individuals the disclosed information may no longer be protected by federal privacy regulations.

e.Federal privacy rules for education information apply only to schools and EI/ECSE programs. If I authorize disclosure of educational information to other agencies or individuals the disclosed information may no longer be protected by federal privacy regulations.

6. I consent to the use/disclosure of the above information. I understand that the use of this information for any reasons other than the expressed reasons stated above is prohibited. This consent is subject to revocation at any time, except to the extent that action has been taken based on information that has already been disclosed.

(Signature of Parent, Legal Guardian, Student/Child)

(Relationship) 
This authorization expires on (Month/Day/Year) (not to exceed one year from date of signature above). 
Appendix D

To: Anna J. Waters

From: Todd Bodner, Chair, HSRRC 2012

Date: February 01, 2012

Re: $\quad$ Your HSRRC application titled, "Exploring Patterns in Primary Classroom Environments and Narrative Language Skills for Children With Language Impairment” (HSRRC Proposal \#111975)

In accordance with your request, the Human Subjects Research Review Committee has reviewed your proposal referenced above for compliance with DHHS policies and regulations covering the protection of human subjects. The committee is satisfied that your provisions for protecting the rights and welfare of all subjects participating in the research are adequate, and your project is approved.

Please note the following requirements:

Changes to Protocol: Any changes in the proposed study, whether to procedures, survey instruments, consent forms or cover letters, must be outlined and submitted to the Chair of the HSRRC immediately. The proposed changes cannot be implemented before they have been reviewed and approved by the Committee.

Continuing Review: This approval will expire one year from the approval date. It is the investigator's responsibility to ensure that a Continuing Review Report (available in ORSP) of the status of the project is submitted to the HSRRC two months before the expiration date, and that approval of the study is kept current.

Adverse Reactions: If any adverse reactions occur as a result of this study, you are required to notify the Chair of the HSRRC immediately. If the problem is serious, approval may be withdrawn pending an investigation by the Committee.

Completion of Study: Please notify the Chair of the Human Subjects Research Review Committee (campus mail code ORSP) as soon as your research has been completed. Study records, including protocols and signed consent forms for each participant, must be kept by the investigator in a secure location for three years following completion of the study. 
If you have questions or concerns, please contact the HSRRC in the Office of Research and Strategic Partnerships, Market Center Building, Suite 620, 1600 SW Fourth Ave, Portland OR 97207 (503)725-3423.

cc: Roxanne Treece, Emily de la Cruz 
Appendix E

English script for Frog Goes to Dinner by Mercer Mayer (1974).

\section{Page Script}

1

A boy was getting dressed in his bedroom. His pet dog, frog and turtle watched as he put on his best clothes.

2

While the boy was petting the dog, the frog jumped into his coat pocket. The boy didn't know he was there.

3

As the boy left with his family, he waved and said "Goodbye" to his pets. The frog waved goodbye too.

4-5

When the boy and his family arrived at a fancy restaurant, the doorman helped them out of the car. The frog peaked out of the boy's pocket but no one noticed him.

6-7

The boy and his family sat down at a table in the restaurant. While they were looking at the menus, the frog jumped out of the boy's pocket towards the band. 8

The frog landed right in the man's saxophone! "Squeak" went the saxophone. 9

The man looked inside the saxophone to see why it made that awful noise. 10

Then the frog fell out of the horn and landed right on the saxophone player's face!

11

The saxophone player was so surprised that he fell backwards into the drum. $12-13$

The drummer yelled at the saxophone player, "Look what you did to my drum- it's broken!" While they were arguing, the frog jumped away on a plate of lettuce salad.

14

The waiter didn't notice the frog. He served the salad to a woman. 15

Just as she was about to take a bite, the frog popped out of the lettuce. The woman was shocked to see the frog.

16

She screamed and fell back on her chair. The frog was frightened and he jumped away. 17

There was a man at the next table who was having a glass of wine with his wife. The frog landed right in his glass.

18

The woman complained to the waiter about getting a salad with a frog in it. She was very angry! 
Meanwhile, when the man went to take a sip of his drink, the frog kissed him right on the nose.

20-21

The angry waiter was about to grab the frog who was waving goodbye to the man and his wife.

$22-23$

The waiter, who had caught the frog, was going to throw him out of the restaurant. But the boy saw the waiter carrying his frog and shouted, "Hey, that's my frog!" The boy's mother told him to be quiet.

24

The boy asked the waiter to give him back his frog 25

The angry waiter told the boy and his family, "Take your frog and get out of this restaurant at once. Don't you ever bring that frog in here again!" 26-27

On the way home the boy's family was angry with him. The frog had ruined their dinner! 28-29

When they got home the boy's father scolded him, "You go to your room and stay there!" The dog and the turtle peaked around the corner to see what was going on.

30

When they got in his room, the boy and the frog laughed about everything that had happened at the restaurant. The more they thought about it, the more they laughed. 
Appendix F

Bailey transcript \#1.

+ Language: English

+ ParticipantId: 100alap

+ Name: Bailey

+ Gender: F

+ DOB:

+ DOE: 4/12/2012

$+\mathrm{CA}$ :

+ Grade: 2

+ Ethnicity: white

+ ParentEduc: 18

+ Context: Nar

+ Subgroup: SSS

+ Location: conference room

+ Collect: 1

+ Examiner: Anna

+ Transcriber: Anna

+ A Boy, A Dog, and A Frog

$-: 05$

\section{\$ Bailey}

B once upon a time.

B there was a boy (there and)>

$\mathrm{B}$ the dog was catch/ing something.

$\mathrm{B}$ (so now um[FP] he was he was) he was look/ing at the pond.

$\mathrm{B}$ (and then now um[FP] he) and then the dog just look/*ed[EW:looked] up and[EW:at] the sky.

$\mathrm{B}$ then he spot[F].

$\mathrm{B}$ (from the a) from a frog and he wants to (check)catch it.

$\mathrm{B}$ an* he have[EW:has] a bucket and a net.

$\mathrm{B}$ he was try/ing to catch the frog but he ran and then he trip[EW:tripped] on that log.

$B$ and then they fell on[EW:in] the pond.

B and the bucket just went high/er. \{eye contact and laugh with shoulder shrug to share humor\}

B the frog just smile/*ed[EW:smiled] at the boy.

B the frog look/*ed[EW:looked] at his eye/z.

$\mathrm{B}$ and then the dog was look/ing at his side of his butt [EU].

B (the frog) :2 the ugly little frog (um he) jump/*ed[EW:jumped].

$\mathrm{B}$ he leap over[F]. 
B (UM)[FP] he leap[EW:leaped] over his head.

$\mathrm{B}$ now he/'s on the log.

B just star/ing at him[F].

B (um) [FP] then the boy said "let's go over there".

$B$ and the frog is sad [EU].

$\mathrm{B}$ (and then now their) their sneak/ing to get it [EU].

$\mathrm{B}$ and he/'s gonna get the frog.

$\mathrm{B}$ (and then) now the frog just went in he hide [EU].

$B$ now the dog just got catched [EU].

$B$ the angry frog was very angry.

B then the boy was mad at him.

B I don't care if I get you (a*) again.

$B$ and then the frog got sad.

B let/s go home.

B the frog was sad still [EU]\{verb inflection error\}.

B the boy and the dog just walk/ed away.

B the frog was so sad and lone/ly.

B the frog follow/*ed[EW:followed] him with *THE boy/3s footprint/s and the $\mathrm{dog} / 3 \mathrm{~s}$ footprint/s [EU].

B now he just got in the house.

B now the frog see/*s[EW:sees] him when they/'re taking a bath [EU].

$\mathrm{B}$ and then the frog smile him and the dog [EU].

$\mathrm{B}$ now (the) the frog leap and get in the tub [EU].

B now they/'re friend/s.

$-3: 39$

+ Introduction: 3

+ CharacterDev: 2

+ MentalStates: 3

+ Referencing: 1

+ ConflictRes: 2

+ Cohesion: 3

+ Conclusion: 2 
Bailey transcript \#2.

+ Language: English

+ ParticipantId: 100alap

+ Name: Bailey

+ Gender: $\mathrm{F}$

+ DOB:

+ DOE: 6/13/2012

$+\mathrm{CA}$ :

+ Grade: 2

+ Ethnicity: white

+ ParentEduc: 16

+ Context: Nar

+ Subgroup: SSS

+ Location: elementary school conference room with parent

+ Collect: 2

+ Examiner: Anna

+ Transcriber: Anna Waters

$-0: 00$

\section{\$ Bailey}

$\mathrm{B}$ right here $[\mathrm{F}]$.

$\mathrm{B}$ and this frog and this dog were look/ing at the frog in a big jar in his (bedroom) bedroom.

$\mathrm{B}$ OK[FP] the boy here is now UM[FP] sleep/ing.

B but the frog (get) get*s out of (hi*) his jar.

$\mathrm{B}$ there was an open window here that he climbs out.

B the boy wak/ed[EW:woke] up and the jar was empty.

B the>

; :4

$\mathrm{B}$ (the) $\mathrm{UM}[\mathrm{FP}]$ the boy here was try/ing to find the frog.

B did we>

$\mathrm{B}$ is it in his boot/s.

B nope.

B the boy here (jus* jus*) UM[FP] say[EW:says] "froggie where are you"?

B "come back".

B the fro*>

B (the) the jar stuck to the $\operatorname{dog} / 3$ s head.

B the dog fall/ed[EW:fell] because the jar was heavy, very heavy.

B the boy here jus* jump out of the window and (th*) see the dog is ok[EU].

$\mathrm{B}$ and the glass break/ed[EW:broke].

B the boy here is (try) look*ing for him but he can/t hear him. 
B "froggie where are you"?

$\mathrm{B}$ "are you in that there"?

B (pe*) UM[FP] "oh ouch a bee UM[FP] bite [EW:bit] my nose ouch".

$\mathrm{B}$ the bee/s were angry because he dog (moosh) moosh/ed their houset[EW:house].

$\mathrm{B}$ the boy fall[EW:fell] there and the bee/s were chas/ing the dog.

B the boy was try/ing to find the frog but this bird was scar/ing him.

B now the boy says "froggie where are you still"?

$B$ (now) UM[FP] now the boy was on it/3s[EW:his] (stairs) UM[FP] face \{word finding errors may increase over the word antlers .

$\mathrm{B}$ and then the deer ran.

B "what is that"?

B the boy fell.

$\mathrm{B}$ and the deer (ma*) made them fall.

B the boy jump/ed in the water.

$\mathrm{B}$ (and hees)(and I) an* he fake \{meaning unknown .

$\mathrm{B}$ and he hears the frog in the that (bri* bri*) that $\log [\mathrm{EU}]$.

B the boy said "sh" (to that fro*) to that dog.

B the boy (look/ed) peek/ed at that log.

B the boy here say[EW:sees] the mother frog and the daddy frog.

$\mathrm{B}$ and he find[EW:found] baby frog/z.

B ANDS_UM[FP] he take/ed[EW:took] one.

B but they won/'t have the daddy frog anymore.

B they take a baby one.

$-3: 52$

+ Introduction: 4

+ CharacterDev: 2

+ MentalStates: 2

+ Referencing: 1

+ ConflictRes: 2

+ Cohesion: 2

+ Conclusion: 2 
Bailey transcript \#3.

+ Language: English

+ ParticipantId: 100alap

+ Name: Bailey

+ Gender: $\mathrm{F}$

+ DOB:

+ DOE: $3 / 6 / 2013$

$+\mathrm{CA}$ :

+ Grade: 3

+ Ethnicity: white

+ ParentEduc: 18

+ Context: Nar

+ Subgroup: PGHW

+ Location: speech office

+ Collect: 3

+ Examiner: Anna

+ Transcriber: Anna

+ Frog Goes To Dinner

- 3:04

$\$$ Bailey

$\mathrm{B}$ um [FP] there is a boy name [EW:named].

$\mathrm{B}$ what's his name? \{interjection

B :3.

B Bob. \{shook head implied 'Bob is a good name for him

$\mathrm{B}$ (Bob) Bob (Bob)was try/ing to put his tie on.

$\mathrm{B}$ and then he was try/ing to look nice.

$\mathrm{B}$ but um [FP] the frog turtle and the dog was[EW:were] like what are you do/ing.

$\mathrm{B}$ what are you dressing fancy [EU].

$\mathrm{B}$ and then um [FP] Bob said "I have to go for dinner".

B "I will play with you later after (my) my dinner with my family".

B "bye bye".

$\mathrm{B}$ and then um [FP] and then the frog jump [EW:jumped] up and um [FP] to his pocket [EU].

$\mathrm{B}$ when they'/re at the restaurant the door man was opening it/s [EW:the] car and um [FP].

B so now (they'/re) they find the table and they'/re looking at the menu to see what they'/re go/ing to eat.

$B$ and then the frog jump/ed on the saxophone.

B the sax* sko* um $[\mathrm{FP}]$ the sasks* ah $[\mathrm{FP}]>$ f frustration with the word saxophone

$\mathrm{B}$ it's hard to say it. \{interjection $\}$

$\mathrm{B}$ the saxihope [EW:saxophone] man (was) was like try/ing to um [FP] make some music but everyone was like aahh.

$\mathrm{B}$ and then he was try/ing to look at what there is[EW:was].

$\mathrm{B}$ (the sas* ah)the saxophone man> orphan maze $\}$ 
B um um[FP] the sasophone[EW:saxophone] man just look[EW:looked] deeper.

$\mathrm{B}$ and then the frog come[EW:came] to his face[EU].

$\mathrm{B}$ and then he just jump[EW:jumped] to (the) drum.

B the saxophone man and the drum man> \{orphan

B the saxophone man was so mad at him that it[EW:he] jump/ed in it/3s um[FP] drum (an*) (we we) they ruin/ed it.

$\mathrm{B}$ (and then) so now (the) the um[FP] frog just jump/ed in the salad but the waitress

did'/nt know.

B so (the) the waitress man[EW:waiter] put[EW:gave] the food to the lady.

$\mathrm{B}$ and then she/'s gonna take a big bite.

$\mathrm{B}$ and then she just saw (a big) a frog.

$\mathrm{B}$ she was about to faint.

$\mathrm{B}$ and then (the jog[EW:frog]) the frog just jump[EW:jumped].

$B$ and then now the frog just jump[EW:jumped] in a glass of wine.

$\mathrm{B}$ and $\mathrm{ah}[\mathrm{FP}]$ those people did/'nt notice.

$B$ the lady (was) was mad at that waitress because there was a frog and[EW:in] um[FP] my salad.

B "and this is the worst restaurant I[EW:I've] ever been to".

B "good bye".

$\mathrm{B}$ and then um[FP] the frog was kissing the man/3z ah[FP] nose.

$\mathrm{B}$ on the glass of wine[EU].

B the waitress was try/ing to caught[EW:catch] that frog.

$\mathrm{B}$ and then now um[FP] (that) the woman and that man was go/ing to say good bye.

$\mathrm{B}$ and then (the) the angry um[FP] waitress was pull/ing that um[FP] idious \{made up word for idiot $\}$ frog out.

B and then the um[FP] Bob was like "wait" "stop".

B "that/'s my frog".

B "well you have to leave if you want your frog back".

B "now get out of here".

$\mathrm{B}$ (the $\mathrm{pa}^{*}$ the) $\{$ revision $\}$ Bob/3z family was very mad at him right now.

B so they have[EW:had] to leave.

B so now their parent/s says[EW:say] "go to your room".

B "you/'re in big trouble".

$B$ and now the fo*[EW:turtle] the turtle and the dog look/ed in the peek[EU].

$\mathrm{B}$ and then he was laughing so hard at the restaurant.

$\mathrm{B}$ the end.

$-7: 30$

+ Introduction: 4

+ CharacterDev: 3

+ MentalStates: 3

+ Referencing: 2

+ ConflictRes: 2

+ Cohesion: 3

+ Conclusion: 2 
Carson transcript \#1.

+ Language: English

+ ParticipantId: 200fgb

+ Name: Carson

+ Gender: M

+ DOB:

+ DOE: 6/13/2012

$+\mathrm{CA}$ :

+ Grade: 2

+ Ethnicity: white

+ ParentEduc: 18

+ Context: Nar

+ Subgroup: SSS

+ Location: child's home, kitchen table

+ Collect: 1

+ Examiner: Anna

+ Transcriber: Anna J. Waters

- 0:05

\section{\$ Carson}

C frog on it/'s[EW:his] own.

$\mathrm{C}$ they were go/ing to the city park (with) with a frog and a turtle and a dog and a boy.

$\mathrm{C}$ the frog hopp/ed out of the pail he was carrying.

C he/'s[EW:he] wav/ed good_bye to them[EU].

$\mathrm{C}$ he saw a bug.

$\mathrm{C}$ he tri/ed to get the bug.

$\mathrm{C}$ he got the bug but he thought he tast/ed terrible.

$\mathrm{C}$ it was a bee.

C then they found other stuff.

C frog hopp/ed into the basket.

$\mathrm{C}$ and now the girl scream/ed.

$\mathrm{C}$ and the old man was like \%yeah and fainted.

$\mathrm{C}$ the girl/'s like \%ahh get out of here.

$\mathrm{C}$ the boy goes swimm/ing $\mathrm{xxx} \mathrm{xxx}$.

$\mathrm{C}$ he hopp/ed into the baby/3s bed.

$\mathrm{C} \%$ whaa \% whaa said the baby.

$\mathrm{C}$ put to rest here he $\mathrm{xxx} \%$ crash>

C "no I/'m gett/ing kill/ed"! \{\%err \%bab \%bab \%bab \}

$\mathrm{C}$ and now he got the frog.

C Frog_On_His_Own.

$\mathrm{C}$ (there/'s) there was a boy go/ing to the city park with his friend/s

$\mathrm{C}$ pet friend/s. 
C then the frog hopp/ed out \%bong \%ya_hoo.

$\mathrm{C}$ he waved good bye to his love/ly friend/z.

C "\%bye_bye".

$\mathrm{C}$ he found an insect.

$\mathrm{C}$ "\%zwip \%yum \%yowee that hurt"!

$\mathrm{C}$ it was a bumble bee.

$\mathrm{C}$ then he found an old man and a woman play/ing[EW:having] a picnic.

$\mathrm{C}$ then the frog climb/*ed into the basket.

$\mathrm{C}$ the girl/'s like "\%huh"?

$\mathrm{C}$ and the xxx like $\{$ whistled $\}$.

$\mathrm{C}$ hi \%eek \%ahoo \%pum he fainted.

$\mathrm{C}$ "get out of here".

$\mathrm{C}$ he spies a boat.

C "cannon ball"!

$\mathrm{C} \%$ woosh.

$\mathrm{C}$ he found a baby.

$\mathrm{C}$ ((Ryan may you be quiet)).

$\mathrm{C}$ he was about to give the baby food but then he accidentally gave him frog food.

$\mathrm{C} \%$ whaa \%whaa went the baby.

$\mathrm{C} \%$ whaa \%whaa.

$\mathrm{C}$ and the cat went after the frog.

$\mathrm{C}$ the cat caught him.

$\mathrm{C}$ but the cat is scar/ed of something else.

C \%eroof \%eroof went the dog.

$\mathrm{C}$ glad to have you back frog.

$\mathrm{C}$ the end.

$-4: 32$

+ Introduction: 4

+ CharacterDev: 3

+ MentalStates: 2

+ Referencing: 3

+ ConflictRes: 2

+ Cohesion: 1

+ Conclusion: 2 


\section{Carson transcript \#2.}

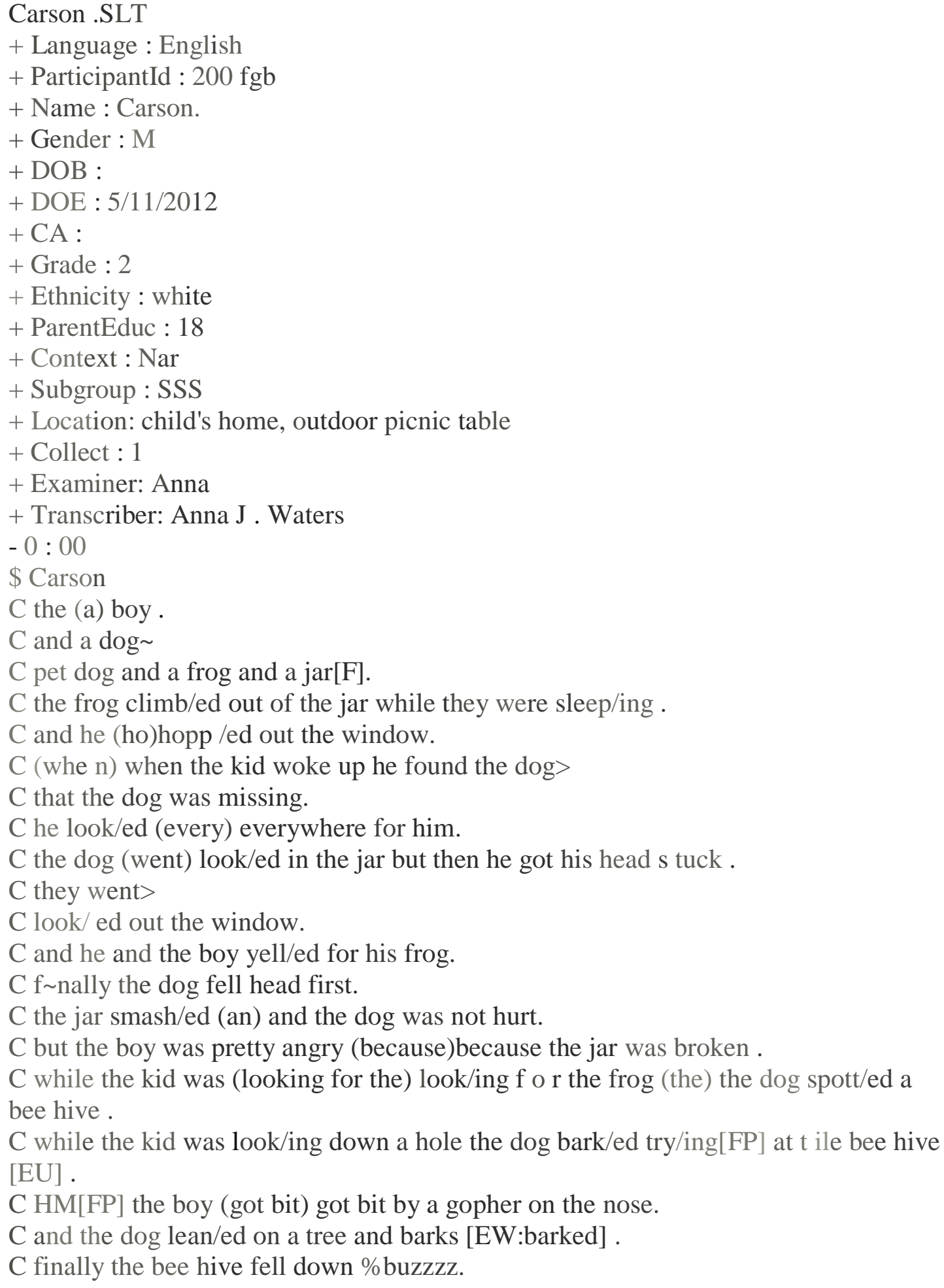


$\mathrm{C}$ a[EW : the $]$ boy look/ed inside a hole in a tree.

$\mathrm{C}$ it was an owl/3s nest (FP) .

$\mathrm{C}$ the owl kick/ed him to the ground.

$\mathrm{C}$ and the dog was runn / ing away from the bee/z.

$\mathrm{C}$ a [EW : an] owl chas / ed him .

$\mathrm{C}$ he climb/ed up some rock / s and hold[ EW:held] on to some branch/es (and ye*) and yell/ed for his frog .

$\mathrm{C}$ ( $\mathrm{t}$ h ey werenl ' $\mathrm{t}$ ) they weren/' $\mathrm{t}$ branch/es .

$\mathrm{C}$ (it[EW : they] was a [EW :an] antler/z an*) they were antler/ $\mathrm{z}$ on a deer.

$\mathrm{C}$ the deer ran toward a cliff with the boy on it.

$\mathrm{C}$ with the jog[EW : dog] f ollowing the (ba*) boy.

$\mathrm{C}$ then finally stoppled and put>

$\mathrm{C}$ and the kid and dog fell off the cliff.

C there / 's a pond be low .

$\mathrm{C}$ and $\mathrm{t}$ hen he splashled into the pond .

$\mathrm{C}$ he could hear the frog \% ribbit \%ribbit.

$\mathrm{C}$ he told the dog to be quiet .

$\mathrm{C}$ (he )they look/ed over the log and there was a mother frog (and his) and his frog .

$\mathrm{C}$ and there was baby/z .

$\mathrm{C}$ one of the baby/z leap/ed toward the boy to be his new pet .

$\mathrm{C}$ so they wa1k/ ed off saying bye to the frog framily[EW:family].

C \%I_wanna get_up \%I_wanna_get_up.

+ Introduction: 3

$; \sim+$ CharacterDev : 3

+ MentalStates: 4

+ Referencing: 3

+ ConflictRes: 4

+ Cohesion : 2

+ Conclusion : 4 
Carson transcript \#3.

+ Language: English

+ ParticipantId: $200 \mathrm{fgb}$

+ Name: Carson

+ Gender: M

+ DOB:

+ DOE: $8 / 2 / 2012$

$+\mathrm{CA}$ :

+ Grade: 3

+ Ethnicity: white

+ ParentEduc: 18

+ Context: Nar

+ Subgroup: SSS

+ Location: child's home, kitchen table

+ Collect: 3

+ Examiner: Anna

+ Transcriber: Anna J. Waters

- 0:02

\section{\$ Carson}

C A_Boy_A_Dog_A_Frog_A_Friend.

$\mathrm{C}$ the boy was fish/ing with a stick and a string.

$\mathrm{C}$ but then something tugg/ed on it and tugg/ed hard.

$\mathrm{C}$ it was pretty hard to get it out of the water.

$\mathrm{C}$ and then he fell into the (cr*) water \{may have been an attempt to use creek rather than water\}.

$\mathrm{C}$ and then he look/ed what had the hook \{awkward utterance, maybe intonation\}.

$\mathrm{C}$ it was a turtle.

C the dog was angry at the turtle.

$\mathrm{C}$ the turtle was angry at the dog.

$\mathrm{C}$ and then he bit his paw.

$\mathrm{C}$ (and then) and then the turtle bit the paw \{repetition of entire utterance\}.

C the boy tri/ed to get (the) him off.

C but finally (he) he lift/ed up the dog and the turtle.

$\mathrm{C}$ and he went back to the spot where his was[EU].

$\mathrm{C}$ and he let go of the turtle.

$\mathrm{C}$ which fell down into the water.

$\mathrm{C}$ the $\operatorname{dog}$ (was) was sitt/ing there with his tail in the water.

$\mathrm{C}$ an* then something yank/ed on the tail.

$\mathrm{C}$ it was a nasty old turtle again.

C he dragg/ed the dog into the water \%gurggle_gurggle_glub_glub. 
$\mathrm{C}$ the frog jump/ed into the water.

$\mathrm{C}$ and got the turtle off.

$\mathrm{C}$ he looked down in there (his) and the turtle was do/ing the backstroke.

$\mathrm{C}$ and then (he)he touch/ed the turtle.

$\mathrm{C}$ and then he thought it was dead!

$\mathrm{C}$ he was (ma*) angry at the dog.

$\mathrm{C}$ so he start/ed digg/ing a hole $\mathrm{AH}[\mathrm{FP}]$.

$\mathrm{C}$ and the hole was done but then the turtle*s eye/z open/ed up.

$\mathrm{C}$ (they're got)the boy pick/ed a flower and put it in the soil.

$\mathrm{C}$ but the turtle was about to (bite) bite the fish/ing hook.

$\mathrm{C}$ and then they were friend/z.

$\mathrm{C}$ and then they walk/ed home.

$-2: 59$

+ Introduction: 3

+ CharacterDev: 3

+ MentalStates: 2

+ Referencing: 2

+ ConflictRes: 3

+ Cohesion: 3

+ Conclusion: 1 
Daniel transcript \#1.

+ Language: English

+ ParticipantId: 300fgb

+ Name: Daniel

+ Gender: $\mathrm{M}$

+ DOB:

+ DOE: 6/13/2012

$+\mathrm{CA}$ :

+ Grade: $\mathrm{k}$

+ Ethnicity: white

+ ParentEduc: 18

+ Context: Nar

+ Subgroup: SSS

+ Location: child's home, kitchen table

+ Collect: 1

+ Examiner: Anna

+ Transcriber: Anna J. Waters

- 0:16

\$ Daniel

$\mathrm{D}$ (they/'re go/ing to dinner)they are go/ing to go to dinner.

$\mathrm{D}$ they/'re go/ing to a restaurant to get a thing[EU].

$\mathrm{D}$ they get menu/s.

$\mathrm{D}$ the people who are in the restaurant (pa) play music

D (when something) then some

$;: 4$

D thing happen/ed.

$\mathrm{D}$ (inside there) inside (in)inside the sax.

$\mathrm{D}$ in the>

$\mathrm{D}$ and the frog hopp/ed into it.

$\mathrm{D}$ the frog went on top of the face[EU].

$\mathrm{D}$ and the frog (crack/ed open the) crack/ed open.

$\mathrm{D}$ \{sigh/ed taps finger look/ing for word $\}$ (the the) the drum.

$\mathrm{D}$ then the frog went hop onto the dish.

$\mathrm{D}$ the frog is in the dish.

D then the frog surpris/ed her.

$\mathrm{D}$ the frog top[EW:hop] in>

$\mathrm{D}$ the frog hopp/ed (into) (into thus the) \{deep breath and then very deliberate in finishing the unit\}

D into the cup.

D then he went all>

$\mathrm{D}$ then he> 
D they hopp/ed out and he went right there [EU].

$\mathrm{D}$ thee[EW:he] went here.

$\mathrm{D}$ then the people ran away from the frog.

$\mathrm{D}$ the frog went to the fire exit.

$\mathrm{D} \times x x\{$ too quiet $\}$ (and then) and then they $\mathrm{ca}^{*}>$

$\mathrm{D}$ and then they bring their frog home.

$\mathrm{D}$ and they give>

$\mathrm{D}$ then they drive home.

$\mathrm{D}$ and they put the frog into his room.

$\mathrm{D}$ and he>

$\mathrm{D}$ then he slept.

$-5: 37$

+ Introduction: 3

+ CharacterDev: 2

+ MentalStates: 1

+ Referencing: 1

+ ConflictRes: 1

+ Cohesion: 2

+ Conclusion: 2 
Daniel transcript \#2.

+ Language: English

+ ParticipantId: 300fgb

+ Name: Daniel

+ Gender: $\mathrm{M}$

+ DOB:

+ DOE: $6 / 13 / 2012$

$+\mathrm{CA}$ :

+ Grade: $\mathrm{k}$

+ Ethnicity: white

+ ParentEduc: 18

+ Context: Nar

+ Subgroup: SSS

+ Location: child's home, kitchen table

+ Collect: 2

+ Examiner: Anna

+ Transcriber: Anna J. Waters

- 0:03

\$ Daniel

D the boy found a present.

D they found (an*) another frog!

$\mathrm{D}$ the frog climb/ed out of the box.

$\mathrm{D}$ they have two frog/s.

D (and they) and they were not friend/s.

D they them>

$\mathrm{D}$ (the) the old frog (was)was not nice to the new frog.

$\mathrm{D}$ he bit/ed[EW:bit] him on the foot.

$\mathrm{D}$ they were all mad at (the the) the first frog.

D (the other frog was)the two frog/s (were) were rid/ing on a turtle.

$\mathrm{D}$ the first frog push/ed him off of the turtle.

$\mathrm{D}$ and \%splat him onto the floor.

D the frog cri/ed.

D those three are angry at the first frog.

D the first frog was>

D out at>

$\mathrm{D}$ (in) in the land \{very deliberate again here to finish the utterance .

$\mathrm{D}$ and the other frog was on the board with the new frog.

$D$ the other $\mathrm{f}^{*}>$

$\mathrm{D}$ the first frog was mean to the other frog.

$\mathrm{D}$ the first frog push/ed him off of the board. 
$\mathrm{D}$ and splash/ed him into the pond.

$\mathrm{D}$ (then) then it was HM>

$\mathrm{D}$ then he splash/ed.

$\mathrm{D}$ (then it was)then the (then the) (the) first frog was UM>

$\mathrm{D}$ the first frog smil/ed.

$\mathrm{D}$ and the other frog was out there.

D then splash/ed : without him.

D (everybody foun*)everybody looked and looked and looked and they did/n't find (them) him.

$\mathrm{D}$ those three are $[\mathrm{FP}]>$

$\mathrm{D}$ (they're fxx) they/'re fxx>

$\mathrm{D}$ the two of them are sad.

$\mathrm{D}$ and one of them is in the (at) at the first frog [EU].

$\mathrm{D}$ these two the first one those two cried[EU].

D so as him[EU] \{maybe was trying to say so does him \}.

D they/'re daughter look/ed HM[EU].

$\mathrm{D}$ and then they heard a sound.

D \%ribbit \%ribbit \%ribbit \{laughs\}.

$\mathrm{D}$ (the fro*)(the new fra* the)the other frog jump/ed (out a) out of the window.

D those three were surpris/ed.

D (so was) so was the first frog.

$\mathrm{D}$ then he \%splat/ed on top of him!

$\mathrm{D}$ the ter*>

D the three were happy.

D so was the new frog.

$\mathrm{D}$ then they were friend/s.

$-3: 24$

+ Introduction: 3

+ CharacterDev: 2

+ MentalStates: 3

+ Referencing: 2

+ ConflictRes: 1

+ Cohesion: 2

+ Conclusion: 1 
Daniel transcript \#3

+ Language: English

+ ParticipantId: 300fgb

+ Name: Daniel

+ Gender: $\mathrm{M}$

+ DOB:

+ DOE: $8 / 2 / 2012$

$+\mathrm{CA}$ :

+ Grade: 1

+ Ethnicity: white

+ ParentEduc: 18

+ Context: Nar

+ Subgroup: SSS

+ Location: child's home, kitchen table

+ Collect: 3

+ Examiner: Anna

+ Transcriber: Anna J. Waters

- 0:00

\$ Daniel

$\mathrm{D}$ he had a new>

D (f*) "yeah" he had a new frog.

$\mathrm{D}$ (his his) his frog.

D (his frog) \{tight eye blink (his frog) his frog.

D (hism his) frog her[EW:his]>

D his old frog had a new friend.

D xxx Xxx.

D the new frog was mad at>

D the old frog was (mad) mad at the new frog.

$\mathrm{D}$ and he bit him in the leg.

$\mathrm{D}$ (he) the boy was surpris/ed.

$\mathrm{D}$ he is *A naughty frog.

$\mathrm{D}$ he/'s gonna take a ride on the turtle \{note increase in eye blinking\}.

$\mathrm{D}$ the old frog push/ed him off.

$\mathrm{D}$ the old frog is not very nice.

$\mathrm{D}$ then the old frog stay/ed there.

D (HUM[FP]) then he sail/ed off.

$\mathrm{D}$ and then he push/ed him off of the boat \{prolongation on pushed\}.

$\mathrm{D}$ and splash/ed him (in) in the pond.

$\mathrm{D}$ and they were mad.

D (they're) they were surprised of[EW:at] the new (fr*) frog. 
D (they)they search/ed everywhere (for the) for the little turtle[EW:frog].

D but they could not find him.

$\mathrm{D}$ (but) but there was a noise!

D xxx.

$\mathrm{D}$ an* then (it was) it was the new frog.

$\mathrm{D}\left(\right.$ he $\left.\mathrm{pu}^{*}\right)$ he $\mathrm{pu}^{*}>$

D (he/'s) he bonk/ed on the old frog/3s head. 
Edward transcript \#1.

+ Language: English

+ ParticipantId: 100jeh

+ Name: Edward

+ Gender: $\mathrm{M}$

+ DOB:

+ DOE: $6 / 7 / 2012$

$+\mathrm{CA}$ :

+ Grade: 1

+ Ethnicity: white

+ ParentEduc: 12

+ Context: Nar

+ Subgroup: SSS

+ Location: elementary room speech office

+ Collect: 1

+ Examiner: Anna

+ Transcriber: Anna J. Waters

- 0:00

\section{\$ Edward}

$\mathrm{E}$ in the morning a boy found a frog in a jar in the pond.

$\mathrm{E}$ (and) and then the dog look/ed at it.

E he was star/ing it (for) for all day[EU].

E when he went to sleep the dog sneek/ed[EW:snuck] out of the jar.

E he went away.

E in the morning he woke up.

$\mathrm{E}$ in $\mathrm{xxx} \mathrm{xxx}$.

E his frog was gone.

E the boy went to search for it with his dog.

E the boy was gett/ing dressed.

$\mathrm{E}$ and the dog got his head stuck in the jar.

E them was look/ing and the dog fall/ed out and smash/ed his head on the ground[EU].

E the jar broke.

E but the boy pick/ed him up.

E and :2 the dog (was)was barking at stuff.

$E$ the bees>

$\mathrm{E}$ and the boy call/ed the frog.

$E$ and the bees>

E and the dog was jump/ing up the tree look/ing for a bee.

$\mathrm{E}$ and the bee/s smash/ed.

$\mathrm{E}$ and the bee/s was[EW:were] chas/ing the dog. 
E the boy climb/ed up the tree and look/ed in the hole and saw the frog.

E the owl was come/ed out and push/ed him out of the tree[EU].

E the owl was chas/ing him and the bee/s was[EW:were] chas/ing the dog.

E he clim/ed up a very (big) big tree branch and hold[EW:held] onto it.

E then his dog was sneek/ing away.

E it was a deer.

$\mathrm{E}$ and it was gone.

E it was runn/ing.

E and (and) the deer stopp/ed.

E an* the boy and the dog fall/ed[EW:fell] off the cliff.

$\mathrm{E}$ and them[EW:they] smash/ed into the pond \{awkward utterance\}.

$\mathrm{E}$ and them[EW:they] heard a (noise) noise over the log.

$E$ (them said) oh them>

$\mathrm{E}$ (the) the boy frog has a mother and a bunch of baby/s.

E "I can keep this frog".

E "great".

E "bye".

E done.

$-2: 27$

+ Introduction: 2

+ CharacterDev: 3

+ MentalStates: 1

+ Referencing: 4

+ ConflictRes: 2

+ Cohesion: 3

+ Conclusion: 2 
Edward transcript \#2.

+ Language: English

+ ParticipantId: 100jeh

+ Name: Edward

+ Gender: $\mathrm{M}$

+ DOB:

+ DOE: $6 / 15 / 2012$

$+\mathrm{CA}$ :

+ Grade: 1

+ Ethnicity: white

+ ParentEduc: 12

+ Context: Nar

+ Subgroup: SSS

+ Location: elementary school speech office

+ Collect: 2

+ Examiner: Anna

+ Transcriber: Anna J. Waters

- 0:29

\$ Edward

E once there was a little boy walk/ing.

E he had his net, bucket, and his dog.

$\mathrm{E}$ he was try/ing to catch the frog.

E he tripp/ed over a log.

E he fall[EW:fell] in the pond with a bucket on his head.

E and frog jump/ed over him.

$\mathrm{E}$ and the frog was on the log.

$\mathrm{E}$ and the kid had his net.

E and the bucket on his head try/ing to catch the log UM[FP][EW:frog].

E I mean frog.

E the frog was fall/ing into the pond.

$\mathrm{E}$ and the dog was try/ing to get him.

$\mathrm{E}$ (and the) the boy just caught the dog.

E UM[FP] the frog did something xxx xxx.

E (the boy screa*) the boy scream/ed "no".

$E$ the boy just walk/ed away.

E the boy was walk/ing with his net, dog, and the bucket.

$\mathrm{E}$ (he) the frog was all alone.

$\mathrm{E}$ and the frog follow/ed the track/s. 
E and outside (the) the house[EU].

E even in the bathtub.

$\mathrm{E}$ (the dog) the frog jump/ed into the bathtub.

$E$ the end, done.

$-1: 55$

+ Introduction: 3

+ CharacterDev: 2

+ MentalStates: 1

+ Referencing: 3

+ ConflictRes: 2

+ Cohesion: 2

+ Conclusion: 1 
Edward transcript \#3.

+ Language: English

+ ParticipantId: 100jeh

+ Name: Edward

+ Gender: $\mathrm{M}$

+ DOB:

+ DOE: $9 / 6 / 2012$

$+\mathrm{CA}$ :

+ Grade: 2

+ Ethnicity: white

+ ParentEduc: 12

+ Context: Nar

+ Subgroup: SSS

+ Location: elementary room speech office

+ Collect: 3

+ Examiner: Anna

+ Transcriber: Anna J. Waters

- 0:00

\section{\$ Edward}

E a boy is gett/ing dress/ed.

E then he said good bye (to his) to his pet dog and his pet turtle and frog.

$E$ then he went to dinner with his family.

$\mathrm{E}$ and they got to the restaurant by the taxi [EU].

$\mathrm{E}$ then they sat down and ate.

E and then the frog jumped in the taxphone[EW:saxophone].

E then something was wrong with his horn.

$\mathrm{E}$ then he lift/ed it up and the frog com/ed[EW:came] out right on his face.

$\mathrm{E}$ and then they was[EW:were] laugh/ing.

E then one guy was mad.

E then (they) they almost got kick/ed out.

E then they did.

E then their frog jump/ed in the salad.

$\mathrm{E}$ then the waiter put it on \{non-specific language\}.

$E$ then the lady scream/ed.

E it jump/ed into his drink.

E then (he) he was xxx and then he was try/ing to catch the frog.

$\mathrm{E}$ then he cover/ed his mouth.

E then he was going to throw away the frog.

E then the little boy said "no that/'s my frog".

E they got kicked out. 
E they went at home [EU].

$\mathrm{E}$ and they was[EW:were] all mad at the little boy.

$\mathrm{E}$ and (they) he got sent to his room with his frog and his little turtle and his little dog.

$E$ then he was crack/ing up.

$-1: 38$

+ Introduction: 2

+ CharacterDev: 2

+ MentalStates: 2

+ Referencing: 4

+ ConflictRes: 3

+ Cohesion: 4

+ Conclusion: 3 
Felicia transcript \# 1.

+ Language: English

+ ParticipantId: 200jeh

+ Name: Felicia

+ Gender: $\mathrm{F}$

+ DOB:

+ DOE: $6 / 7 / 2012$

$+\mathrm{CA}$ :

+ Grade: $\mathrm{k}$

+ Ethnicity: Chinese/white

+ ParentEduc: 18

+ Context: Nar

+ Subgroup: SSS

+ Location: elementary school speech office

+ Collect: 1

+ Examiner: Anna

+ Transcriber: Anna J. Waters

- 0:08

\section{\$ Felicia}

F there was a little boy that had a pet dog *AND a pet frog.

$\mathrm{F}$ dog and frog rhyme $\{$ interject $\}$.

$\mathrm{F}$ at night the frog ran away.

F the next morning when he woke up the frog was not in the jar.

F they look for the frog.

F the dog got his head stuck in the jar.

F he looked out the window.

F and the boy said "oh frog where are you"?

$\mathrm{F}(\mathrm{dog})$ the jar was so heavy that the dog fell off[EW:out] of the window.

$\mathrm{F}$ and bonk/ed his head and broke the jar.

F dog wasn/'t pay/ing attention.

$\mathrm{F}$ the dog saw bee/z.

$\mathrm{F}$ the dog bark/ed at them.

F xxx the tree.

$\mathrm{F}$ the boy wouldn/'t[EW:wasn't] \{note type of word error paying attention to dog and look/ed down in the hole.

$\mathrm{F}$ then (in $\mathrm{xxx}$ ) bee came up and slapp/ed him.

$F$ the dog knock/ed *THE bee/z down.

$\mathrm{F}$ and the boy wasn/'t pay/ing attention to the dog $\{$ note repetition of this idea $\}$.

F boy yell/ed "little frog". 
F in an old old tree from a hole[EU].

$\mathrm{F}$ an owl came $\left(\mathrm{u}^{*}\right)$ went and knock/ed him over.

$\mathrm{F}$ and the dog came runn/ing from all the bee/s[EU] \{unique syntax?\}.

F look behind branch/es[EU].

$\mathrm{F} * \mathrm{IT}$ wasn/'t branch/es but *IT was deer.

$\mathrm{F}$ (from the) it was antler/s from a deer.

$\mathrm{F}$ and it keep[EW:kept] runn/ing.

$\mathrm{F}$ and the dog and the boy fell at the bottom into the middle of a pond.

F look behind the log.

F they saw two mom frog/z.

F they/'re some baby frog/z.

F I think that his frog is right there behind the log.

$\mathrm{F}$ because that frog wants to be on the log.

F I think.

F right $\{$ note gaze away from me $\}$ ?

F "I want to be your new pet" the frog said.

F he wav/ed bye_bye.

F and he went home with his dog \{smiled and closed the book\}.

$-4: 08$

+ Introduction: 3

+ CharacterDev: 4

+ MentalStates: 1

+ Referencing: 4

+ ConflictRes: 3

+ Cohesion: 4

+ Conclusion: 2 
Appendix G

\section{Directions for Responding to the CLEP \\ Purpose of the CLEP}

The CLEP is an instrument that can be used by teachers, administrators, and researchers to assess the "print richness" of kindergarten and elementary school classrooms (K-6).

\section{General Directions}

This instrument may be used with or without the teacher and students present in the classroom. No feedback is needed from anyone to respond to the items. All judgments are made based on the observable literacy tools, materials, arrangements in the classroom.

Time schedule

30 min. - Completing rating scale in classroom

10 min. - Scoring rating scale and interpreting score

$40 \mathrm{~min}$ - Total time required

\section{Directions for Responding to the Rating Scale}

The descriptors for each item evidence increased implementation of a "print rich" classroom environment. A rating of 1 is the lowest level of implementation and 7 represents the highest. Therefore, it is imperative to read all descriptors for each item progressing from 1 through 7 before selecting a rating.

Descriptors at $1,3,5$, and 7 on the rating scale are explicitly stated. Circle one of these numbers if the description accurately matches the environment. If 1, 3, 5, or 7 is not a match, then select 2, 4, or 6 which are implied descriptors indicating degrees of implementation between two descriptors. Circle the selected number above the rating scale.

For example, to select a rating for item \# 4, you might follow these thought processes. If about 200 books are present, circle a rating of 3 . If about 75 books are present, circle a rating of 2 . If about 275 books are present, circle a rating of 4 .

\section{Definition of Terms}

Literacy event

A communicative act in which reading, writing, speaking, and/or listening are integral to the participants' interactions and interpretive processes. 
Literacy products

A concrete object or a demonstratable event that occurs as the result of interaction with literacy tools.

\section{Literacy tools}

Physical objects present in the environment which support the acquisition of literacy (e.g., paper, pencils, professionally published books and magazines, adult- and childauthored materials, computers, and bookshelves).

\section{QUANTITY OF LITERACY TOOLS}

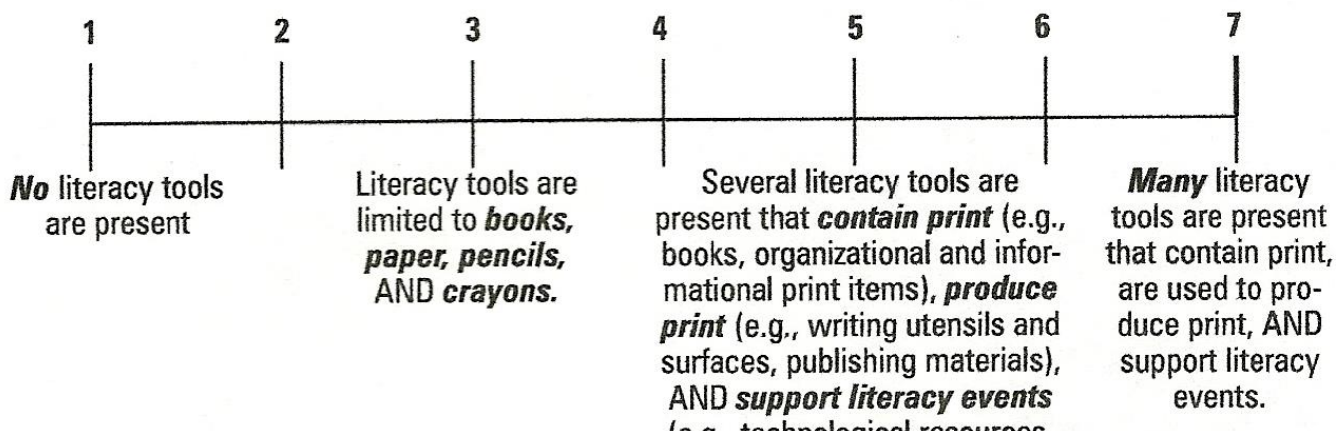

(e.g., technological resources,

furnishings, storage and display

containers, accessories)

2. UTILITY OF LITERACY TOOLS

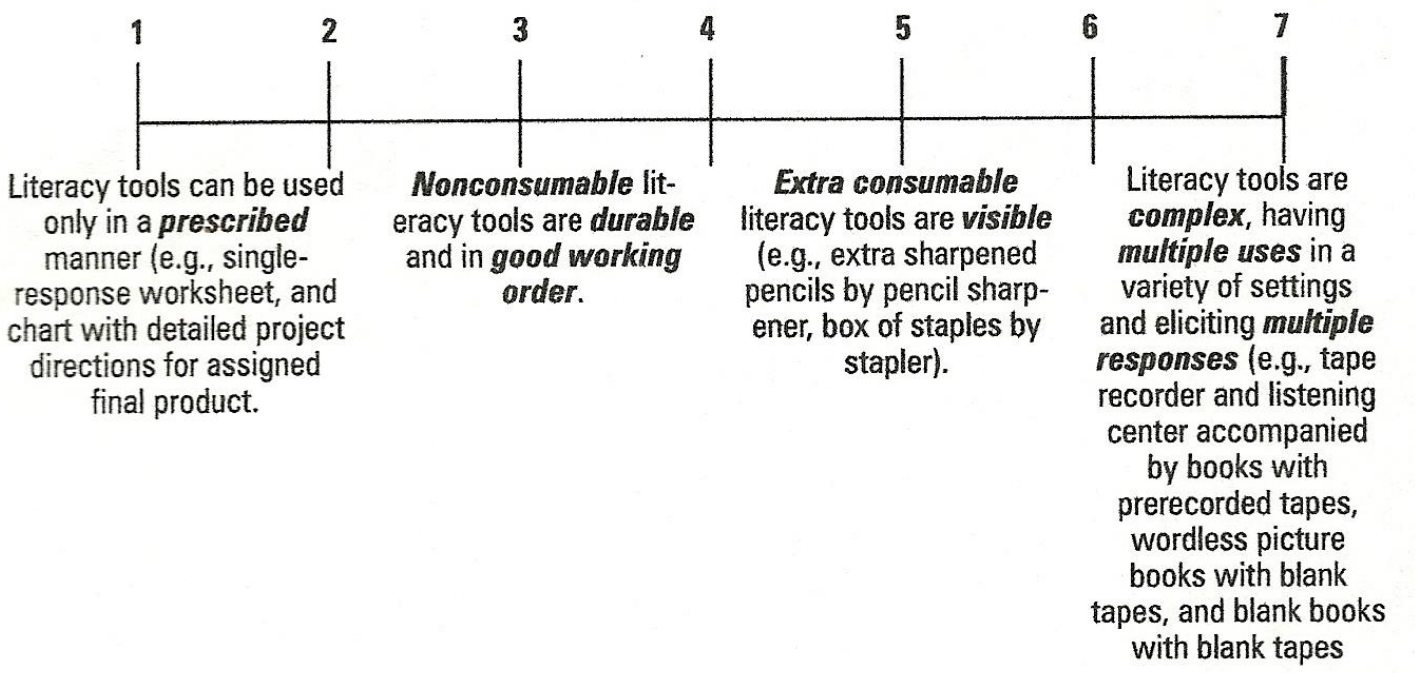


3. APPROPRIATENESS OF LITERACY TOOLS

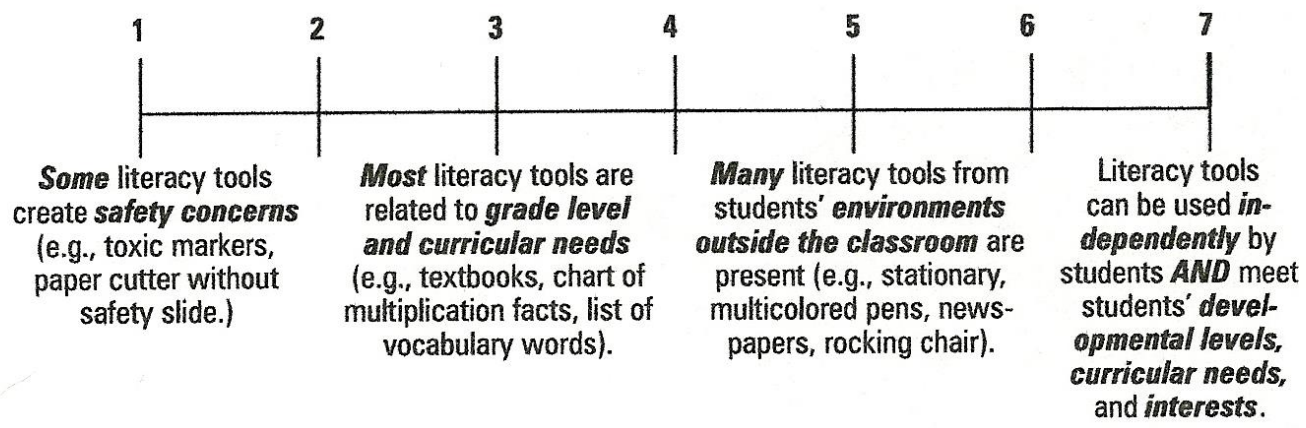

4. QUANTITY OF TEXT MATERIALS (including books, magazines, newspapers, etc.; count multiple copies as one)

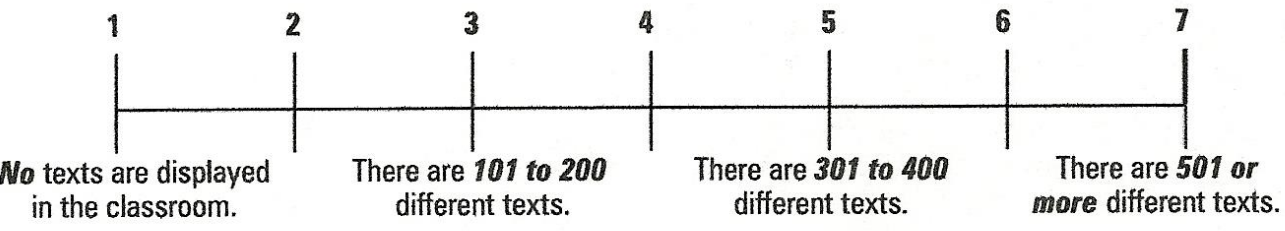

5. GENRES OF TEXT MATERIALS

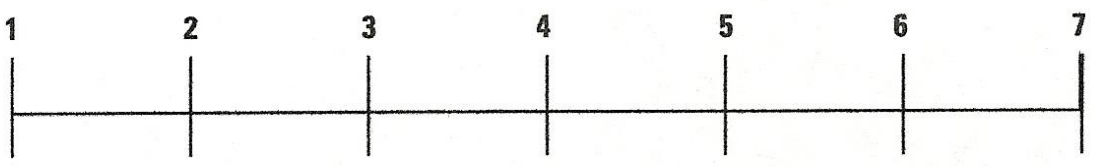

The text collection includes mainly one genre (e.g., fiction, nonfiction, poetry, contemporary, or classic).
The collection includes mainly texts of three genres.
The collection includes mainly texts of five genres.
The various genre are equally represented le.g., fiction, nonfiction, poetry, contemporary, and classic).

6. LEVELS OF TEXT MATERIALS

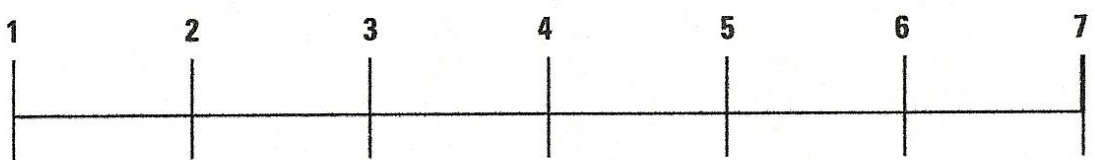

The level of most of the The levels of the texts texts is less than one grade level.

\section{typically span two grade} levels.
The levels of the texts typically span three grade levels.
The level of most texts spans four or more grade levels. 
7. FORMAT AND CONTENT OF TEXT MATERIALS

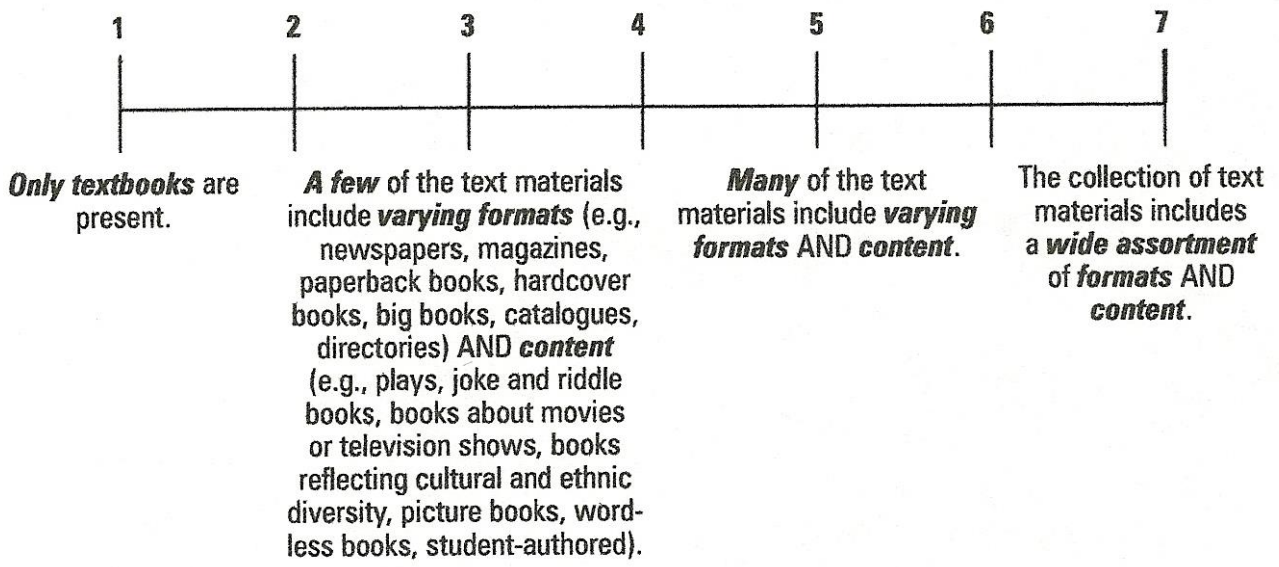

8. PRINT USED FOR CLASSROOM ORGANIZATION

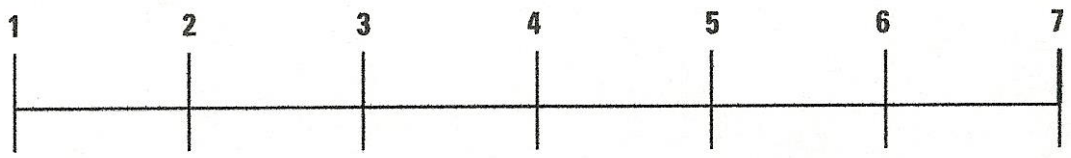

No printed directions, schedules, OR labels are visible.
Some displayed print is used for organizational (e.g., class rules and expectations; daily, weekly or monthly assignments; school lunch menus) AND

labeling (e.g., contents of shelves and storage containers) purposes.
Some displayed print is associated with literacy tools and events (e.g. timetables for use of materials and areas, project guidelines, sign-up sheets for reading/writing conferences).
A wide assortment of print in the form of directions, schedules, AND labels is clearly visible.

9.

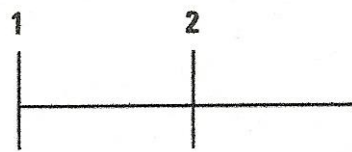

Several of the displays of student or class activities include print AND most of the print is teacherm produced.

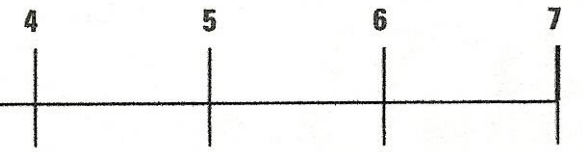

Many displays of student or class activities include primt AND most of the print is student produced.
Both teacher and student produced print is included in displays of student or class activities with the majority of the print being studentproduced. 
10. REFERENCE MATERIALS

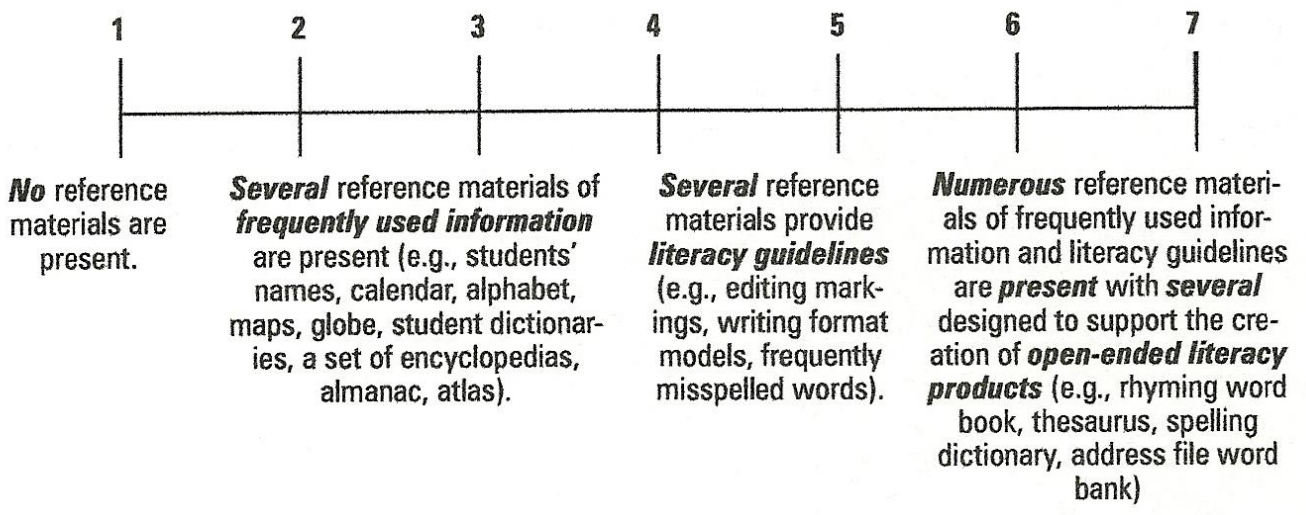

11. WRITTEN COMMUNICATIONS

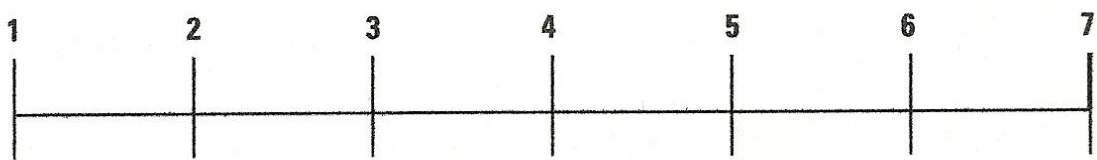

No written communica- Most written communications are present

tions are commercially published (e.g., books, posters, charts).
Some adult-authored

(e.g., school or classroom announcements, teacher-written directions on chalkboard) AND student-authored (e.g., books, notes, bulletin board titles) written communications are present.
There are about equal numbers of commercially published AND adult and studentauthored written communications.

\section{WRITING UTENSILS}

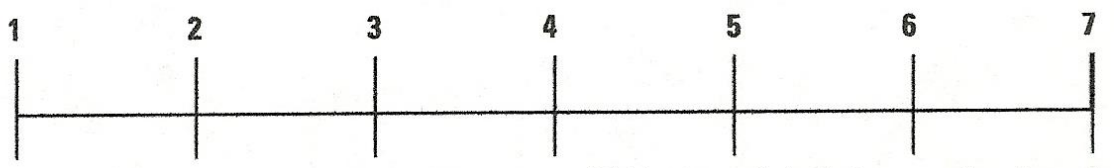

No writing utensils are present.
Writing utensils are limited

to crayons, \#2 lead pencils, white or yellows chalk, AND dry erase pens.
Writing utensils include several different types of pens and pencils AND a computer with a word processing program.
A variety of many difference types,

sizes, shapes, and colors of writing utensils are present (e.g., lettering stencils, alphabet stamps with assorted colors of inkpads). 
13.

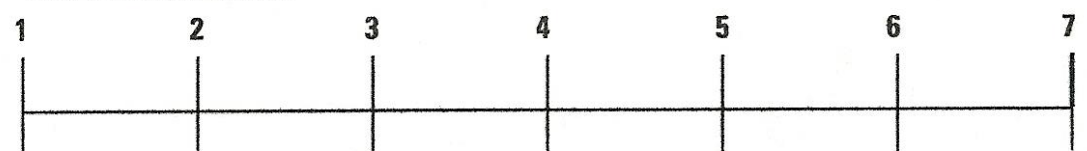

No writing surfaces

Writing surfaces are limited

Writing surfaces include

A variety of different are present. to wall-mounted chalk or marker boards AND lined writing paper. individual chalk or marker boards AND different types of paper (e.g., chart, story, unlined, butcher, newsprint, construction) types, sizes, shapes, AND colors of writing surfaces are present (e.g., a computer printer, stationary, graph paper, post-it notes, postcards, blank books).

14.

\section{PUBLISHING MATERIALS}

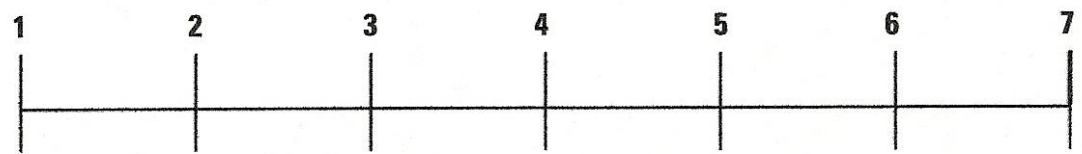

No literacy tools to use in publishing literacy products are available.
Several literacy tools are available to edit (e.g., revised draft, date rubber stamps and stamp pads; correction tape and erasers; paper clips), assemble (e.g., tape, glue, stapler, brads, plastic covers, stencils, stickers), OR decorate (e.g., fabric, ribbon, yarn, lace, buttons, pictures) literacy products.

\section{Many literacy tools are available to edit, assemble, AND decorate literacy products.}

About an equal number of a wide variety of literacy tools are available to edit, assemble AND decorate.

\section{TECHNOLOGICAL RESOURCES TO SUPPORT LITERACY EVENTS}

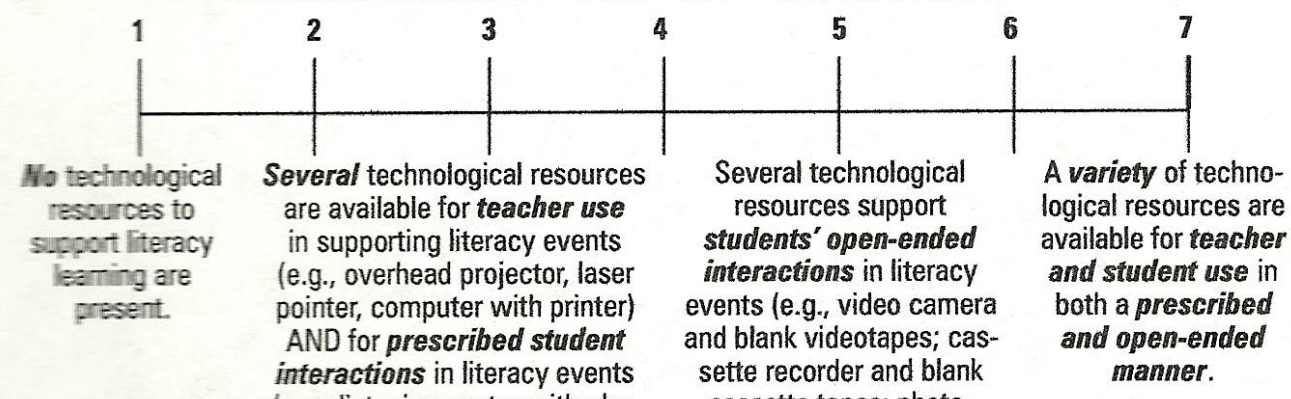
(e.g., listening center with phonograph, cassette or CD player and books with text recorded on records, tapes, or CDs; television and VCR with recorded stories on video tapes; computer with literacy-learning programs). cassette tapes; photographic camera with film; computer printer, and word processing program) 
16.

FURNISHINGS TO SUPPORT LITERACY EVENTS

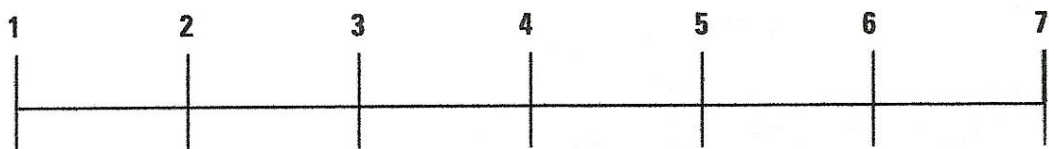

Furnishings are inad-

Standard classroom

furnishings are present equate (e.g., size of chairs is inappropriate,

height of desks and tables not adjusted properly).
Comfortable, home-like furnishings are present (e.g., rocking chair, throw rugs, bean bag chair) AND at least one is labeled as supporting literacy learning (e.g., a sofa placed in the "Cozy Corner" library, an "author's chair").
A variety of standard and comfortable, home-like furnishings are present AND several are identified as supporting literacy learning.

17. STORAGE AND DISPLAY CONTAINERS TO SUPPORT LITERACY EVENTS

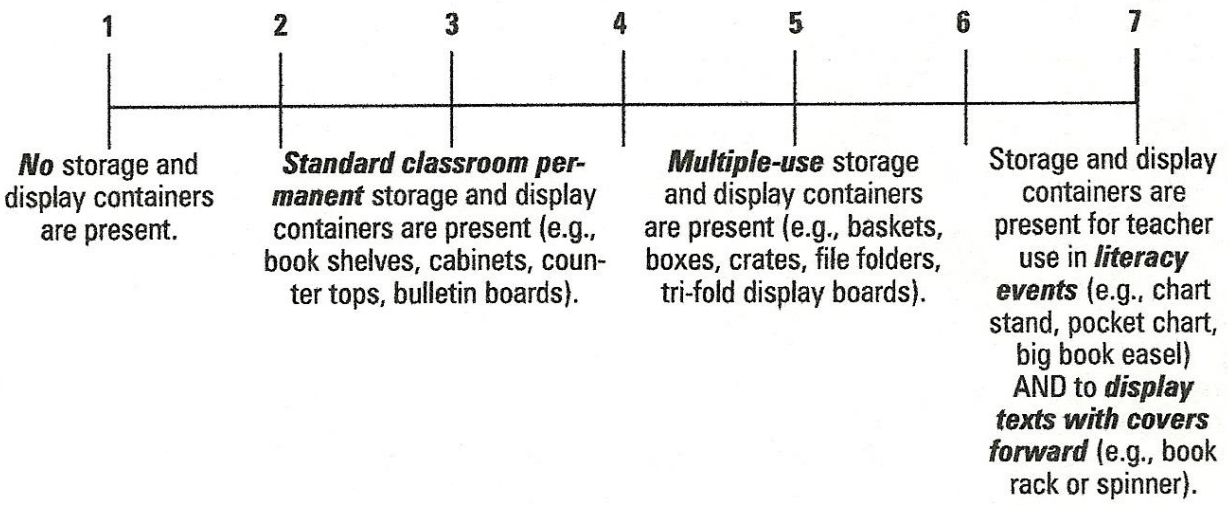

18. ACCESSORIES TO SUPPORT LITERACY EVENTS

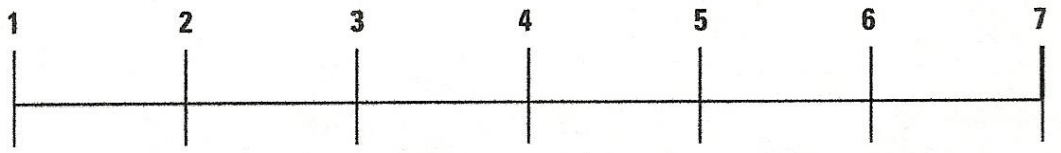

No accessories are present to support literacy events.
Accessories are present to support reading (e.g. text pointer, bookmarks, and pillows), support writing (e.g., mailboxes, clipboards, and collection of pictures), AND display literacy products (e.g., clothespins and fishing or clothesline).
Accessories are present from nature (e.g., artificial or live plants and trees, an aquarium, small animals) AND to use in reenactments or original dramatizations of literacy events

(e.g., a puppet stage with puppets, costumes, masks, flannel board with cutouts).
There is about equal representations of many accessories to support reading and writing, display literacy products, AND present reenactments or original dramatizations of literacy events. 
19. LOCATION OF CLASSROOM AREAS

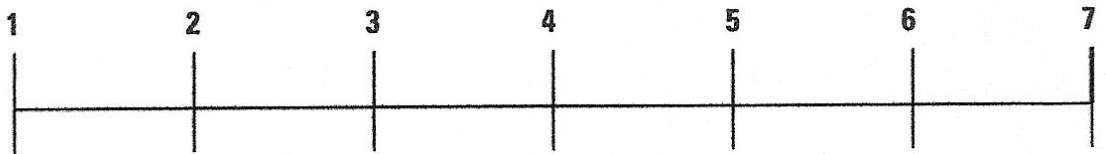

The large block of classroom space is not divided into smaller areas.
One-fourth of the classroom is divided into smaller areas which make use of fixed physical properties (e.g., windows, lights, electrical outlets, shelves, counters, bulletin boards).
One-half of the classroom is divided into smaller areas which are easily visible for teacher monitoring AND incompatible areas are separated (e.g. a library and a wet area).
The entire classroom is divided into smaller areas which are dispersed throughout the classroom AND grouped based on compatibility (e.g., a literacy center including a library, publishing area, listening center, and conferencing area).

20. BOUNDARIES OF CLASSROOM AREAS

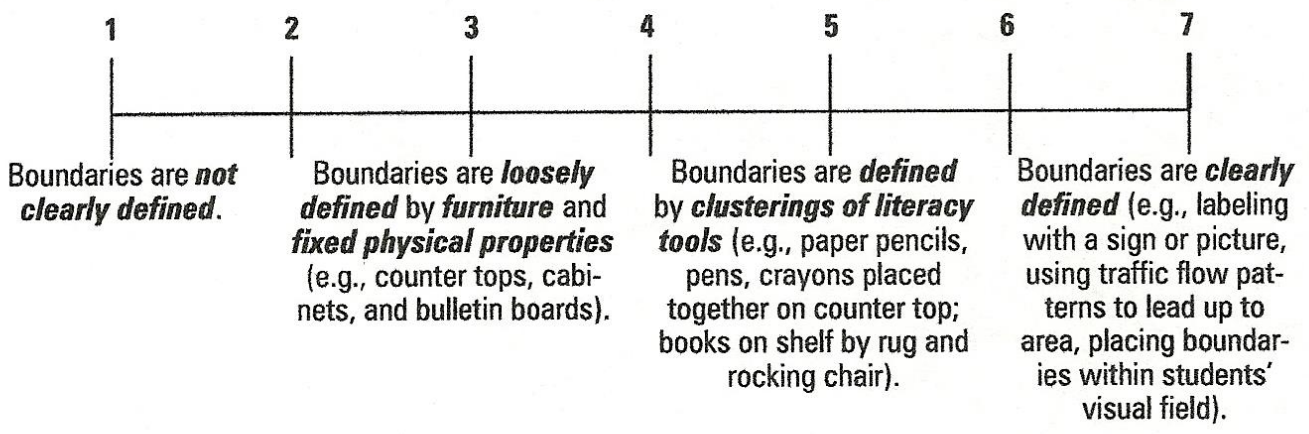

21. SIZE OF CLASSROOM AREAS

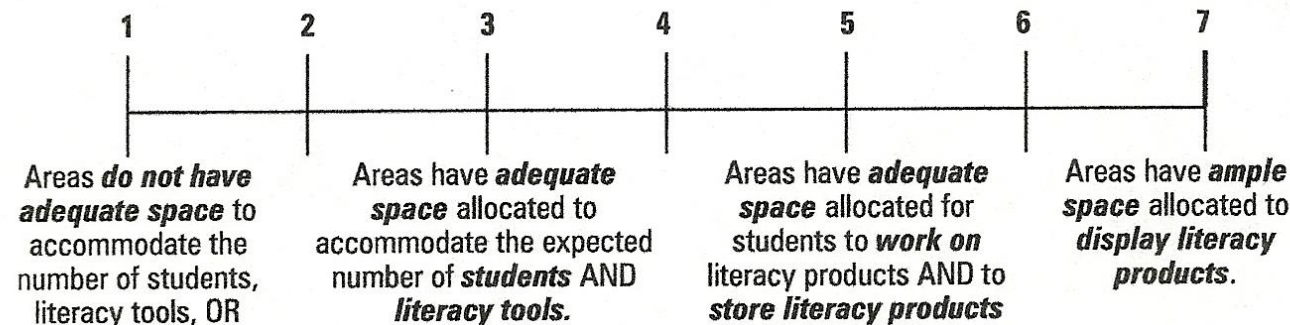

literacy tools, OR

literacy products

occupying the space.

in progress. 
22. TYPES OF CLASSROOM AREAS

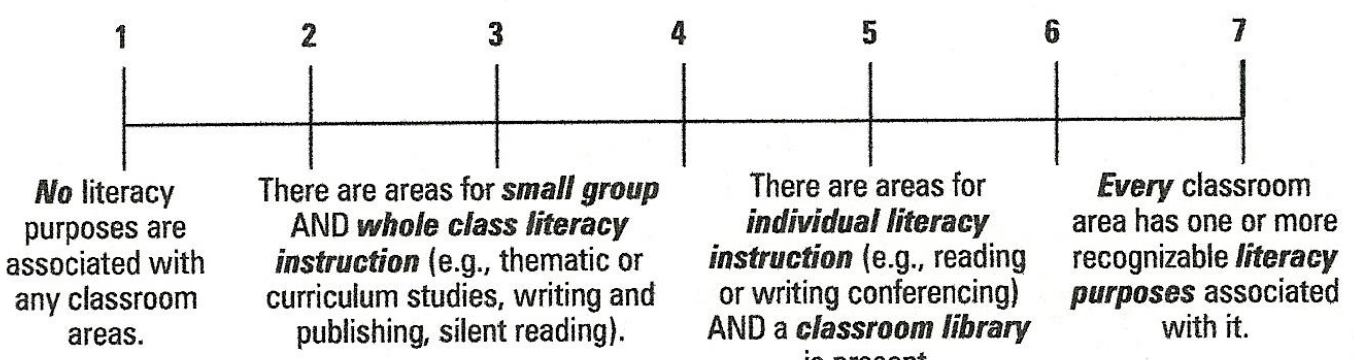

is present.

\section{CLASSROOM LIBRARY}

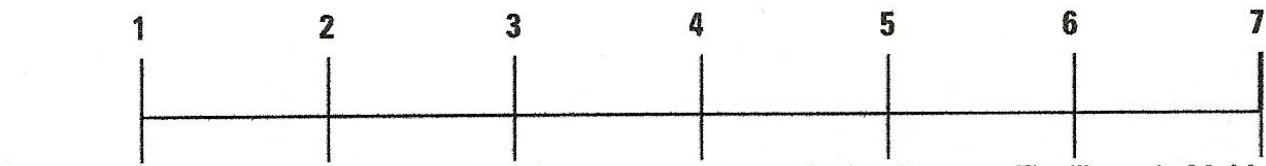

No part of the classroom functions as a library. A small collection of books is placed at one location.
A clearly identifiable area is labeled as the library. Bookshelves or furniture are used to establish boundaries and create privacy.

The library is located in a quiet area outside the general traffic pattern and accommodates at least 5-6 students.
The library is highly visible and occupies up to $25 \%$ of the wall space. It contains literacy-oriented displays and props which encourage reading and participation in extension activities. Books are displayed both spine and cover forward and include a variety of genres and reading levels. The book collection includes duplicate copies of favorite books and a total of 5-6 books per studemt. The library is furnished with comfortable seating and is well lighted.

24. GROUPING OF LITERACY TOOLS

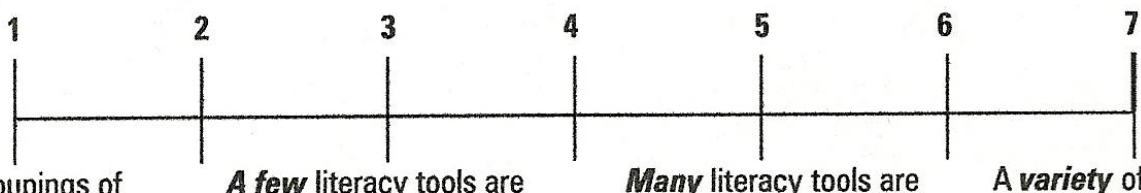

No groupings of literacy tools are evident.
A few literacy tools are neatly arranged in several areas.
Many literacy tools are organized thematically in several areas (e.g., by science, math, or social studies topics).
A variety of many literacy tools, including boxes of leveled books, are grouped in all areas of the classroom. 
25. ACCESSIBILITY OF LITERACY TOOLS

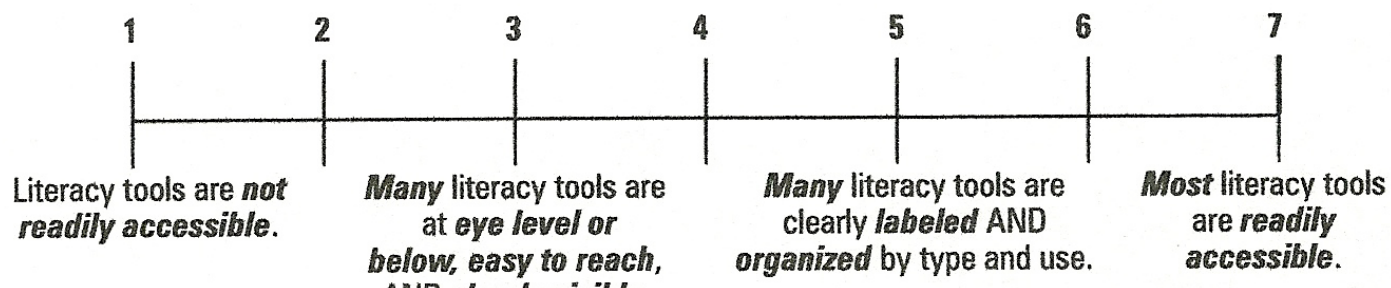

AND clearly visible.

26. PARTICIPATION IN LITERACY EVENTS IN ENCOURAGED

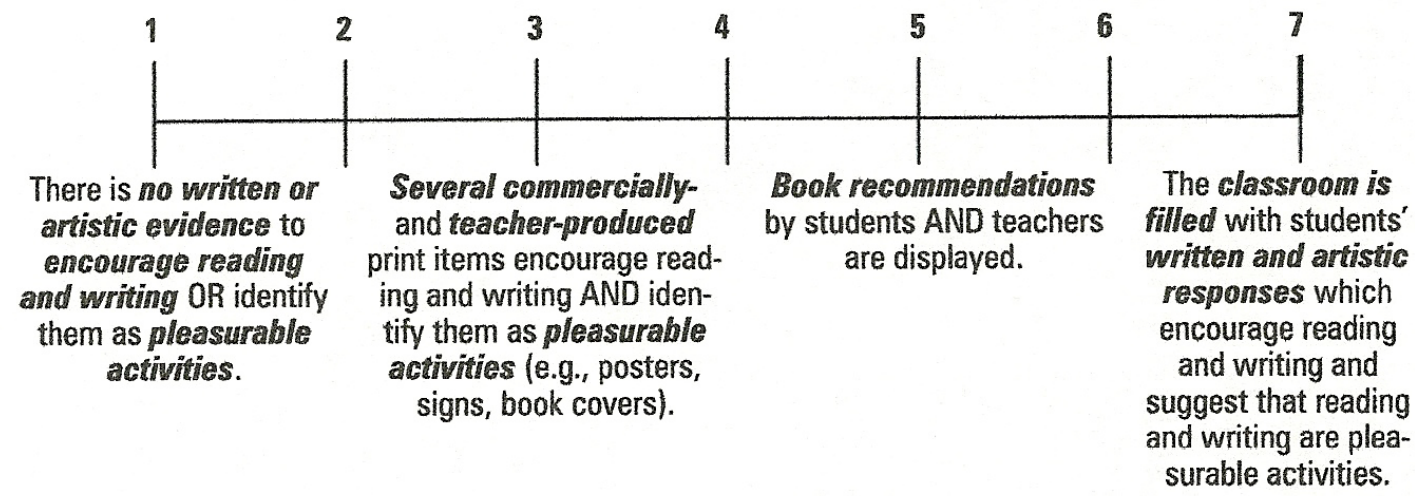

27. PARTICIPATION IN LITERACY EVENTS IS INVITING

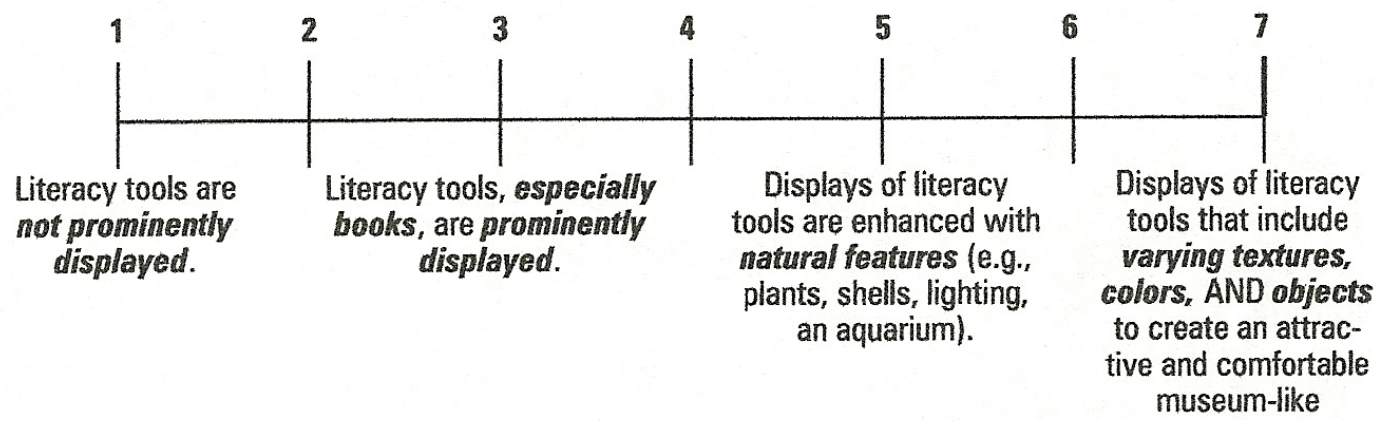


28. AUTHENTIC LITERACY SETTINGS

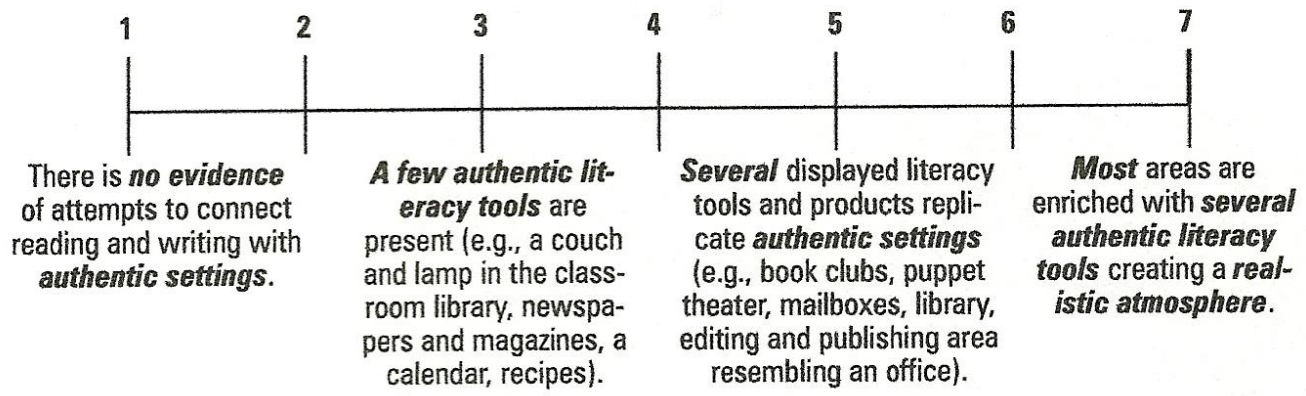

29. AUTHENTIC LITERACY EVENTS

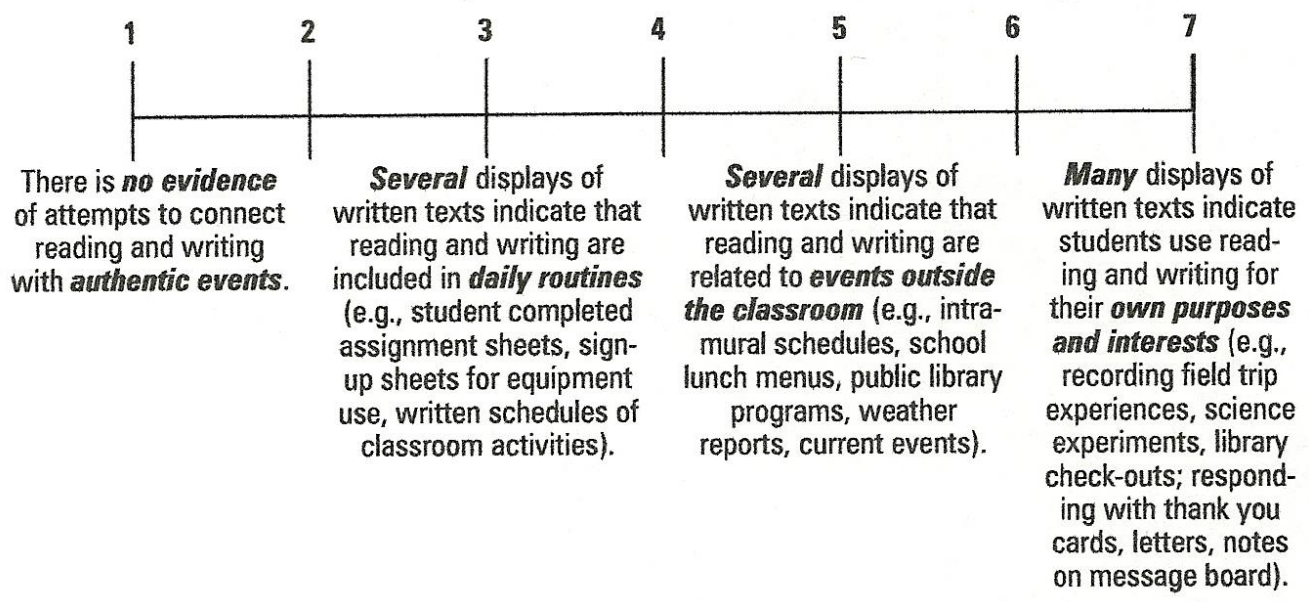

30. INTERACTIONS WITH LITERACY TOOLS

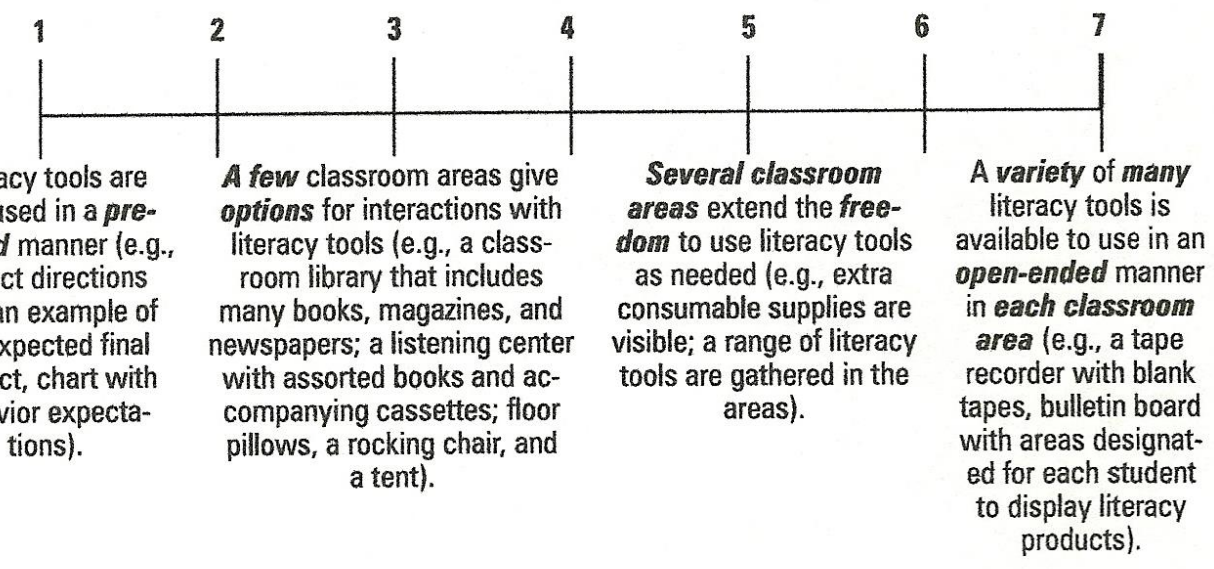




\section{RECORD-KEEPING OF LITERACY INTERACTIONS}

\begin{tabular}{|c|c|c|c|} 
There is no visible & & & \\
record keeping of class \\
OR individual students' \\
participation in literacy \\
events.
\end{tabular}

\section{VARIETY OF LITERACY PRODUCTS}

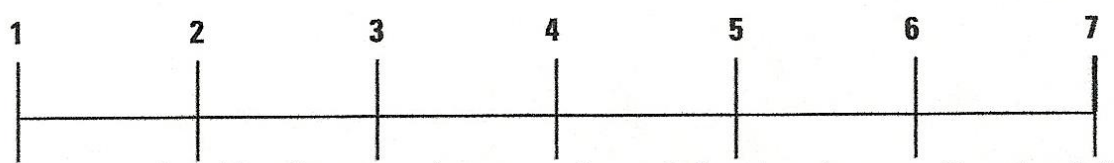

Displayed literacy products follow the same format (e.g., worksheets with identical responses in each blank).
Most literacy products are curriculum related; long term, taking more than one school day to complete; AND in a formal format (e.g., final copy, published)
Several short term le.g., completed in one school day) AND informal (e.g., personal messages, homework lists) literacy products are present.
There is a balance between many short term/long term AND formal/informal literacy products. Literacy products include students' original content in both creative (e.g., story extensions, dioramas, poems) AND functional forms le.g., thank you notes, letters, school/ class newspapers).

\section{SHARING LITERACY PRODUCTS}

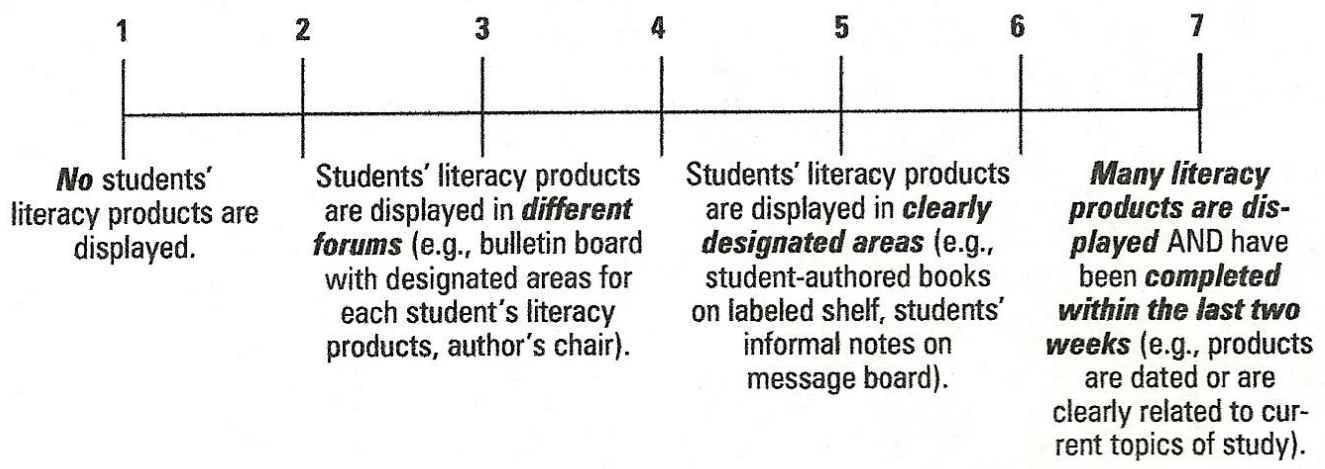




\section{CLEP Scoring Guide}

1. Enter each rating in the spaces below and total Subscale 1 and Subscale 2.

Subscale 1

1.

2.

3.

4.

5.

6.

7.

8.

9.

10.

11.

12.

13.

14.

15.

16.

17.

18.

$\longrightarrow$

$-$

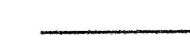

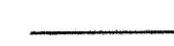

6.

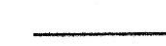

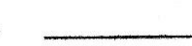

0.

.

.

.

.

8.
$-$
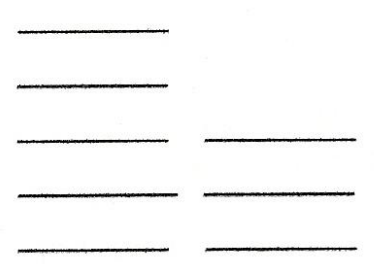

Subscale 2

19.

20.

21.

22.

23.

24.

25.

26.

27.

28.

29.

30.

31.

32.

33.

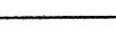

-

.

3.

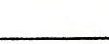

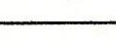
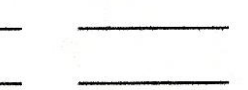

5.

6.

7.

.

.
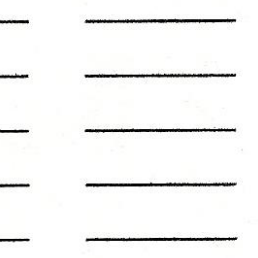

$-$

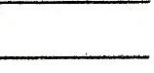

$+x^{2}$
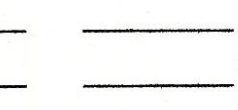

TOTAL: Subscale 1 TOTAL: Subscale 2

2. Complete each equation for Subscale 1 and Subscale 2.

SUBSCALE 1

- divided by $\quad 18=$

Subscale 1 Total divided by $18=\underline{\text { Subscale } 1 \text { Score }}$

SUBSCALE 2

$\begin{array}{lll} & \text { divided by } & 15= \\ \text { cale 2 Total } & \text { divided by } & 15=\text { Subscale 2 Score }\end{array}$


3. Enter the score for each Subscale on the scale below.

Subscale 1

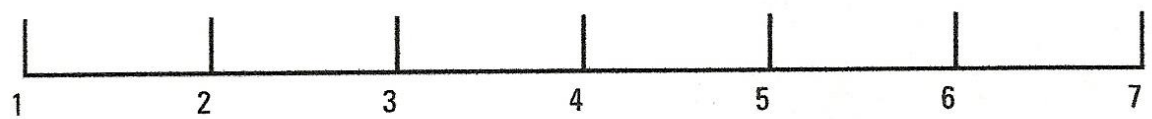

Subscale 2

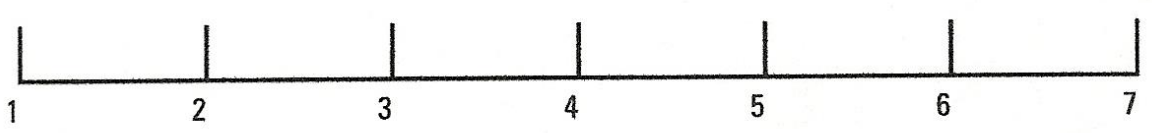

\section{Interpretive descriptions}

\section{Subscale 1: Provisioning the classroom with literacy tools}

\section{0-2.4 = Impoverished}

An unacceptably small number of a few different types of literacy tools are present. Some of the literacy tools are of low utility being damaged, outdated, or undersupplied.

\section{5-3.9 = Minimal}

Several different types of literacy tools are present in moderate amounts. There are enough literacy tools to support the number of students in the classroom.

\section{0-5.4 = Satisfactory}

An acceptable number of literacy tools of all types are present. The literacy tools are in good working order.

\section{5-7.0 = Enriched}

The classroom is abundantly supplied with all types of literacy tools. The literacy tools are complex, elicit multiple responses in varied settings, and are developmentally appropriate.

Subscale 2: Arranging classroom space and literacy tools, gaining students' interest in literacy events, and sustaining students' interactions with literacy tools

\section{0-2.4 = Impoverished}

The physical environment provides little support to literacy acquisition. There is a bleak or stark quality in the classroom atmosphere due to the random placement of only a few literacy tools. Literacy tools or products are not featured. Literacy is not identified as a valued goal. 


\section{5-3.9 = Minimal}

The physical environment provides some support to literacy acquisition. The classroom atmosphere has a neutral feeling and does not capture the observer's interest. A narrow range of literacy tools and products are present but not featured. Literacy is not identified as a valued goal.

\section{0-5.4 = Satisfactory}

The physical environment provides an acceptable level of support to literacy acquisition. A comfortable classroom atmosphere is created by the presence of many literacy tools of varying types and the display of some literacy products. Literacy is identified as one of several curricular goals.

\section{5-7.0 = Enriched}

The physical environment provides optimum effectiveness in support of literacy acquisition. A museum-like quality and pleasing ambience is created by prominently featured literacy tools and products. Literacy is easily identified as a valued, life-long goal. 
Narrative scoring schema rubric.

Appendix $\mathrm{H}$

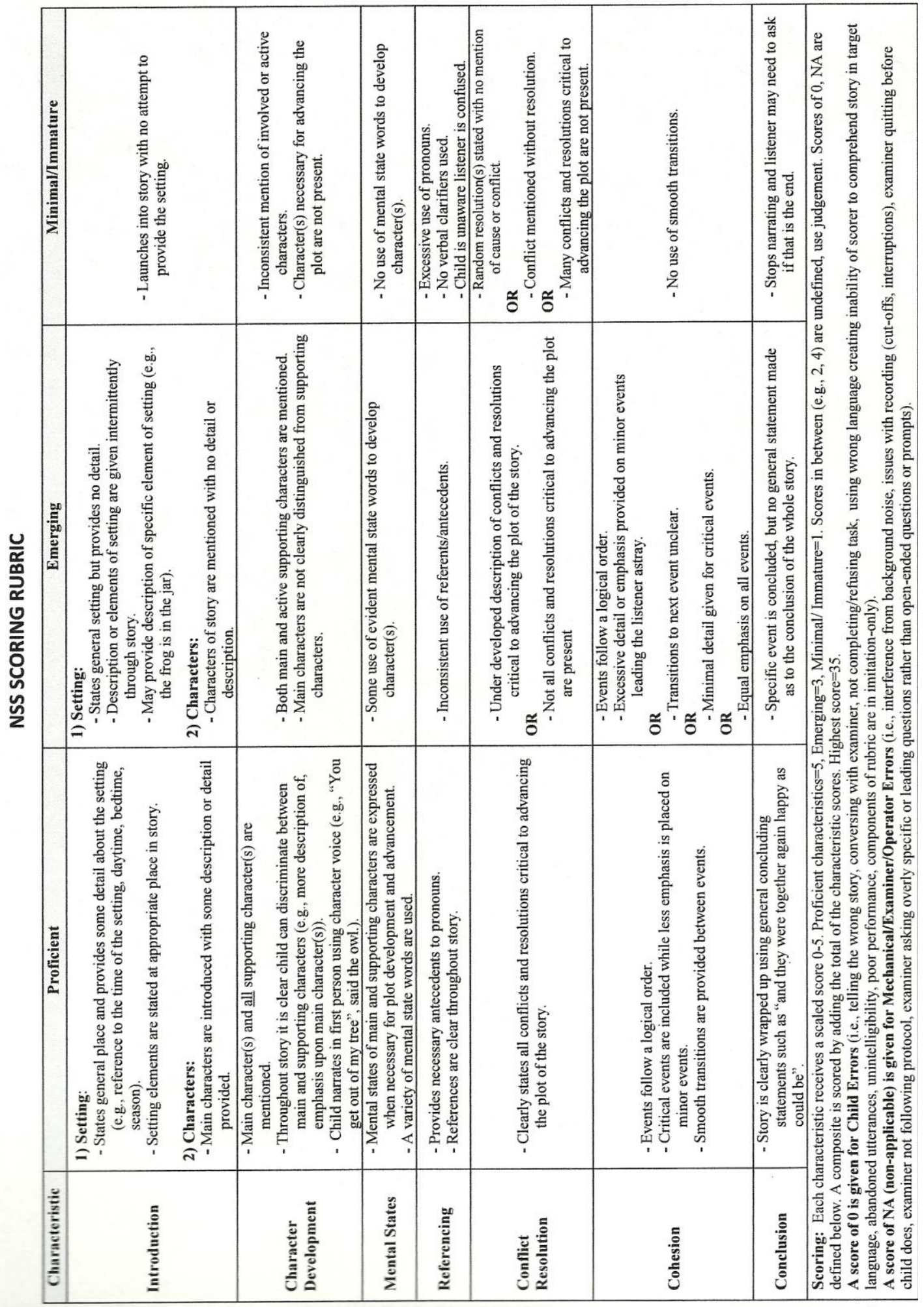




\section{Appendix I}

\section{S.C.E.R.T.S. assessment profile: Conversation partner.}

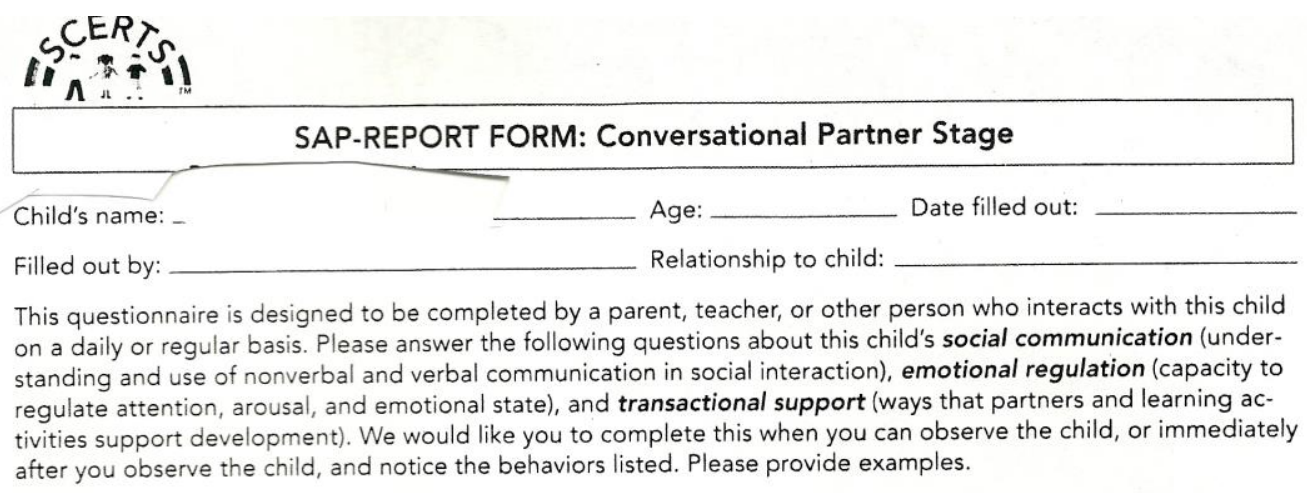

\section{SOCIAL COMMUNICATION}

1. Describe how the child interacts with others. For example, does the child monitor what a partner is attending to? Get a partner's attention before talking? Take many turns that follow a shared attentional focus?

2. Which of the following reasons does the child communicate for in conversation? Check all that apply and give examples.

_ To request desired objects or help

_ To request a break

_ To protest/refuse an undesired activity

_ To greet

_ To request permission

_. To express empathy

_ To comment on immediate and past events

_ To request information about immediate and past events

_ To express feelings and opinions.

_ To plan ahead and discuss what will happen

3. What happens if you can't figure out what the child is asking for or talking about? What does the child do?

4. Which of the following types of words does the child use regularly in sentences? Check all that apply and give examples.

—Wh-words (e.g., what, where, who)

- Words describing time (e.g., before, now, later, when)

_ Words describing size or number (e.g., small, many)

_. Words describing location (e.g., next to, between, under)

_- Pronouns (e.g., l/you, he/she, we/they)

__ Verbs (e.g., past, present, or future tense [e.g., ate, ran, will go])

_ Conjunctions that link (e.g., and, or)

_.. Conjunctions that imply cause (e.g., but, so, because, if) 
5. Which of the following "rules" of conversation does the child follow regularly? Check all that apply and give examples.

_ Initiates a variety of topics

_ Initiates topics frequently

_ Talks about things of interest to others

_ Takes turns as a speaker and listener appropriately

_ Provides needed information based on what others know

_ Requests relevant information

_ Adjusts length of turn based on partner's behavior

_ Shifts topics smoothly

_Ends conversations politely

6. Which of the following nonverbal behaviors does the child use appropriately during conversation? Check all that apply.

_ Facial expression__ Gestures__ Body posture__ Proximity or physical distance to partner

_ Volume or loudness of voice _ Intonation or melody of voice

7. What are the child's favorite toys, games, or recreational activities? How does he or she play or have fun?

8. Who are the child's favorite friends? What kinds of things do they do like to do together or talk about?

9. How does the child learn in group situations?

$$
\text { seldom or not at all sometimes often }
$$

Does the child imitate behaviors in new situations?

Does the child learn rules modeled by adults?

Does the child collaborate and negotiate with peers?

10. Which of the following meanings or nonverbal cues does the child consistently understand? Check all that apply.

_ Nonverbal cues of turn taking

- Nonverbal cues of emotion _ Humor

_Figures of speech _ Teasing__ Sarcasm _ Deception

\section{EMOTIONAL REGULATION}

1. How does the child respond to people and things in his or her environment? For example, does the child show interest in a variety of situations, show intense interest in a few things, express different emotions, keep to him- or herself, respond to and seek interaction, inhibit actions and behaviors, and/or persist during tasks appropriate for his or her abilities?

2. What activities or situations are the most fun or interesting to the child?

3. What activities or situations create the most distress or are boring to the child? 
4. Does the child use strategies to stay focused, interested, calm, or engaged during familiar activities (e.g., mouthing or chewing on clothing or other items, fidgeting, rocking, verbally repeating schedule sequences, using checklists to monitor task progress)? If so, please describe.

5. Does the child use strategies to stay focused, interested, calm, or engaged during new and changing situations, or situations that are otherwise challenging (e.g., saying, "I'm finished with writing," and checking schedule to see what's next; expressing emotion or asking for information to ease stress when having to wait)? If so, please describe.

6. Does the child express positive and negative emotions verbally or nonverbally? If so, how?

Positive emotions

Happiness

Contentment

Silliness

Excitement

Interest

Pride

Hope

\section{Negative emotions}

Sadness

Anger or frustration

Fear

Sickness or tiredness

Anxiety, stress, or worry

Boredom

Embarrassment

7. Does the child respond to feedback and guidance offered by others about regulating emotion? If so, how?

8. What strategies do you use to help the child stay focused, interested, calm, and engaged?

9. How do you know when the child is overwhelmed or upset? What signs does the child show?

10. How do you know when the child is bored or uninterested? What signals does the child show?

11. When the child is extremely upset or distressed,

... how does the child recover by him- or herself? How long does this usually take?

.. how does the child recover with support from partners? How long does this usually take?

\section{TRANSACTIONAL SUPPORT}

1. What people does the child interact with or see on a regular basis (i.e., daily or weekly)?

2. What places does the child go to on a regular basis (i.e., daily or weekly)? 
3. Which of the following are easy for you to read, follow, and respond to? Rate all that apply using the following key: 0 , can read or respond rarely or not at all; 1 , can read and respond some of the time: 2 , can read and respond most of the time.

- The child's focus of attention _ What the child is trying to communicate

_ How the child is feeling _ The child's preferred pace (fast or slow)

When the child needs a break _Whether the child is interested

Whether the child is frustrated _ Whether the child is overwhelmed

4. What strategies are the most helpful to encourage the child to initiate and stay on topics in conversation (e.g., offering choices, waiting and encouraging initiations, following the child's topic, requesting information)?

5. How do you usually react if the child uses problem behaviors when very stressed, such as screaming, bolting, or incessantly reciting certain phrases? Is this reaction effective?

6. What strategies are the most helpful to secure the child's attention (e.g., moving closer to or farther from the child, calling the child's name, introduce motivating topics into conversation)?

7. What strategies are the most helpful to keep interactions going with the child (e.g., allowing the child to initiate interactions, allowing the child to take breaks and move about, following the child's interest)?

8. How do you usually communicate to the child to ensure that your message is understood?

9. Do you use visual supports to help the child communicate, understand language, express emotion, and/or flow with the day better? If so, which supports do you use (e.g., pairing language and written cues; defining steps of a task with pictures or written words, schedules, or calendars; using video modeling; using a feelings diary)?

10. What features of the physical or social environment help the child stay engaged (e.g., limiting the number of people the child interacts with, limiting the amount of background noise and/or visual stimulation, adding more opportunities for movement and rhythm, using specific places consistently for specific activities)?

11. What features of the physical or social environment help the child communicate better (e.g., smaller group size, motivating topics or activities that the child prefers, practicing social activities prior to an event)?

\section{ADDITIONAL COMMENTS}

1. List the top strengths or assets you observe in the child.

2. List your major concerns about the child's development.

3. What information would be most useful to you in planning or updating the child's program?

4. Is there anything else about the child that you think is important to share with us?

5. Do you have any questions for us?

6. What is the best time and way to contact you? 
Bailey, parent interview.

\section{Appendix J}

Having blended classrooms, when you separate the grades I can see how ... it was like 'no there's $8^{\text {th }}$ graders in there.

It's rich and it's definitely classic. It's like even the principal, I can't even tell you how he said it.

He associated, so his training was in dance, and he formulated this whole classic of how ballet, the steps in ballet are like the processing in writing. Of how like paragraphs, and how literature, and how writing like I can't even explain it but it like made so much sense.

I'm trying to find, you know, have you ever heard of XL? Because that's where they both they have similarities, I mean not that I'm a speech-language person, but I mean that if you have a speech impediment or learning (difference) sometimes story problems are hard for you. Because there are words like, take away, and for Bailey to understand it's like really hard, I could definitely see how if you have a speech or language you are like oh that's a minus.

What does minus mean? And what does take away 2 mean. It was really hard for her and it was as well for (older sister).

So if you know any tutoring I have to get Bailey extra help?

They need a lot of special education teachers because of burn out. I mean they only last so long.

I think so. It has nothing to do with pregnancy I don't think. So six years ago we were living in a how and remodeling a home, I mean fixing it to flip, and roofers took off the roof but they didn't tarp and we had water coming in. I mean even out insurance said it was the worst case. They had to completing refinish the floors and re-drywall I mean it was just a mess. So it's your home and you go check on the contractors. Well I bring Bailey, and I put her on the ground and it was dusty and everything. So a friend of mine in church, who was a preschool teacher said, "I noticed Bailey doesn't speak, not like the other kids."

And when she did speak she made up her own language, it was like *jargon* We used to think it was cute, but then we took her to the pediatrician and she was like well that's not ... let me get you a speech evaluation, but it might sound cute but something else is going on.

And then she decided to test her for lead and she tested positive, and the guilt it went (up) I mean like awful, I've lost my house and all my things. And then I had all the other kids tested and they were like 2 and Bailey was like 5. So then I got very knowledgeable about lead and infant and breathing it in.

That being said, I figured it's one thing. And then we had another test, the doctor said I mean don't get guilty if you gave it. It's a gene from your mother that gives learning disabilities. So I did have it or I didn't. Because I have two girls who are similar who have IEPs. 
I mean Bailey is starting to show ADD, but her sister is very hyper so I think that's the ADHD so that was why maybe it's something with me.

I was diagnosed (with ADHD) and take medication. When I got in to all of this with my kids it was like there's a test, and I went to my doctor and my doctor's like I was moderately ADHD, and then my friend was like "I could have told you that".

Her health is good. But sometimes, like I said in IEP meetings, her confidence is not good. She takes things literally, and if someone says 'I don't want to play with you.' She thinks they hate her and will never be her friend ever again.

You know the expression, are you kidding. Well, Bailey is like, "no I'm not". Sometimes I think that she just really doesn't understand, I mean she gets lost a little bit. But her health is good.

It's just her challenges or her IEP.

Um, a lot of times she'll be lost, or I see that she's the third child or I feel like she has to fight for attention or to be or have her say or something. A lot of times we have to explain to her. But now she's asking questions, but sometimes I just don't think she's on the same page.

She zones out and gets lost and then thinks of something else.

We have to explain to her and some things she's getting.

She has like tantrums. She'll get drama like "what, I don't wanna" or she knows how to push my buttons or whatever or she'll just react or react with frustration. Like "oh my God this is so terrible."

She won't do that ( have a tantrum) with a teacher.

Sometimes she's really good about (telling past events) or she just won't talk about it and I'll have to ask her. Then she'll like remember.

A lot of times when she talks about something that was fun, she'll keep talking about it. She will just not let it go.

When she get's well, she's like, I want to go to sky high with a couple of friends, that's where I want my party. That's what I want to do this weekend.

Even today, she came in, please mom it was my birthday, and she had an ice cream cake. And she said, it was my birthday, please don't give the last piece to brother, or to sister, or to daddy. It's my birthday so please tell them. So she's thinking that later tonight I have dibs on that. It's planning, but it also gives her confidence.

Sometimes I'll be like, what, I don't understand Bailey, try to say it differently, And a lot of times she switches words, so a lot of times I will say it back correctly just to help her and sometimes I'm like say it this way.

I don't know if she hears it, and then sometimes she get frustrated and she's like "you know" and I'm like 'no I don't'

I have to bring it back to her peers, I mean Bailey has a hard time making friends, and I don't know if it's because she doesn't understand or they don't understand her. Or she doesn't know (how to be a friend) or she's trying too hard. If she doesn't understand she'll drop it or be "yeah, yeah, yeah." I don't know if she doesn't know or if she's faking it. 
She loves talking, seeing, I mean she has a really great voice. I mean she really excelled at acting, she was a totally different person.

If I say to do it, she won't memorize it, but if someone else says it she'll do it. I said, "why don't we take voice lessons" and she said, no mom I won't be good. I said, everybody needs to practice and she just doesn't have any confidence.

She knows how to use her gestures and she's pretty funny and she likes to laugh a lot. She loves to talk about princesses and American doll, and Makena. She'll definitely have certain subjects that she always wants to talk about. She gets so excited about that. That's funny, she was bored today, and she said, "I'm bored" they come to me and they just hang out with me and then I get funny and I'm like "we can clean" and their like "no mom".

She'll do that, I'll give suggestions and nothings good or else it is good and she'll go do it.

She wants me to sit down, even before, it's like a crutch. I'm like Bailey you haven't even read it. You have to try it and then do it. She's like "no school work is so hard for me."

That's one thing (homework) we talked about and so now their modifying her homework, because their saying it shouldn't be something that's hard for her, that's a struggle. It should be an extension of school but not like "oh my gosh these pages"

She get's excited and does stuff with her hands. And shakes or like she talks in a funny voice she'll really funny, so she does thing like that to show she's excited.

Either that she's afraid (in a new situation) or she's not good enough, or I'll try it. I don't know if I should say and be so candid, but bribery, which is like Bailey, if you get that I will take you to Fred Meyer and you can like get for like $\$ 10.00$ toy, or I'll get you a piece of candy, of I'll take you to Roses, and we'll get a milkshake.

She usually has a high voice, and recently we call them anger issues, because she gets very mad at sister. I mean they're so close, they had different rooms but not their back together because they sleep together. They're so close as sisters but they fight like cats and dogs.

I had to grab Bailey because I saw (sister) going out the door with something of her's on and going out the door to the carpool and she started hitting her like that. And I was like no Bailey, and she was like why did you grab me. I said, hands are not for hitting, their like to holding and hugging, you tell mom and she like was pounding at her and (sister) was like Bailey has anger issues, and the whole house while I'm like (waving) "hi, yeah just be a minute there". And my friend yells, "we've all been there", But then I don't see it (meltdowns) at school so much, I don't know if it's family dynamics or just a competitiveness.

She's like so afraid of messing up in school. That she's like (tight face). When we did her IEP I talked about friends and building her confidence better, and their 
like Well we think she's turning into a student, and I said I feel like we're talking about two different people. Sometimes I wish, or I don't know, I ask, "do you act like this in school."

I hear them, like "I need a break" and they have language, like scripts, I've taught them to use certain language, like words that I hear that I can say and they say. Is that why their behavior.

A long time. A really long time, she felt sad because I sent her up to her room, and then this is where we learn, because I talked to the counselor, is that because when she came down stairs, she said like mommy I'm so sorry, and I said, it's ok, I gave her an extra big hug and I was holding her and she goes You don't want me in the family anymore and you wouldn't care if I died, and I was like Bailey, where did you hear that from or I think Bailey with her IEP and her challenges she's like with a friend, she had this incident with a friend, and now she thinks that friend hates her now, she doesn't understand I care about you or I love you, just because I'm upset with you does not mean I want to give you away.

So she's very literal. And then I just pretended with her that I was falling asleep and she was like, "Mom" and then she was ok but she was still sad.

In second grade if she had episodes of sadness I would be able to tell the teacher and if she seems a little bit sad it's because of something that happened at home. 


\section{Carson, parent interview.}

Social emotional health is not good. He is on Fluroxamine $75 \mathrm{mg}$ from a Dr. at Mind Matters. It's for depression and anxiety. But a different guy works with our pediatrician on Wednesdays so we are going to switch over to him. He's a psychiatrist. He does a clinic on Wednesdays with Westside pediatrics. I mean the other guy only sees him once a month, so I mean how do you evaluate, it's not really therapy once a month its more of a med check.

Concerns about attention are not as much as we used to have. I think Carson's much better than that now.

His interactions are pretty good. He can get very stressed out when things don't go his way. He'll yell and get to an emotional extreme around other kids in his peer group. Which, he's going into third grade so that is going to be less and less tolerated.

$\mathrm{He}$ has friends at school and we've had play dates this summer. There are kids he does really well with. Some personalities not as well. He wants to be friends with kids, he likes to play with other kids. The kids he tends to be friends with are very smart, and kinda quirky and imaginative like he is which is good because he gets along with them and they're nice about him getting upset. I couldn't believe how nice the kids were about him being upset. They are always like 'it's ok Carson'. The kids are nicer than the adults. He doesn't tell me anything about school. The only reason I knew that kids were being nice to him was because I saw that. I think the teachers think no one wants to know anything unless they're in the priniciapal's office. Which is, I agree if the teacher can handle it I'm fine. It's better for Carson to not have me involved in working out his social problems.

He likes to plan things and we had our grand plan of studying different things each week this summer but then we went on vacation. He likes to get books and learn about something. We were doing plants and then we were going to do the Olympics and they (Carson and Daniel) weren't to jazzed about the Olympics. I think if I did more science-y stuff they would be very interested in that kind of stuff. I try to get it more historical and stuff because I know science is they're strength. They didn't say this is boring they just wouldn't pay attention. They were like 'what'.

$\mathrm{He}$ (Carson) is good at planning things, but if it doesn't happen he doesn't care. He doesn't have any follow through himself. If it doesn't happen, it's just gone. He might say something once in a while. But if I say something is going to happen he will never hold be accountable for that. He just doesn't remember those things which is weird because Daniel remembers everything I say.

He's supposed to get an allowance every Saturday but the deal is he has to tell Steve and they have to sit down together but it has to be him (Carson). Maybe he's gotten it once. I mean that's a big motivator for kids, you'd think he would remember.

I think he's (Carson) in the moment, but I think he also has trouble with memory. I think that's why he has trouble with writing. Because he may have all of these ideas but to 
take the time to write them in order by the time I'm thinkin' short term memory. It's weird. It's not like he's not smart and doesn't know the days of the week. The ideas are all there, but the follow through is nothing.

I don't think he uses past tense. He is so in the here and now I don't think he even communicates about what happened before. And when he does it is a struggle for him to do it right. Like he has to think about it. I think he will mess up when he's talking about the past. I don't think he really has the concepts of the past in his speech and at 9 he really should have that.

He (Carson) just doesn't know how to logically build a story.

Almost everything I do with him (Carson) unless it's super fun like going to the park. I get worried. Like if I need him to something for me like practice the violin it could be a big blow up. There's no inhibition just reaction. Oh and it also if he does something like math and then we have to go back and check it. If there's mistakes then he just crumbles. He'll say 'I'm stupid'. He doesn't know that his math is above grade level. He makes a mistake and everything's bad. If one thing goes wrong in a game it's like every time. Emotional disregulation when other kids do things wrong, like we were at the park and he was worried about a kid falling down or if Daniel walks away from me. We went to T-creek trail and there was a 9 year old girl and they have been in a play group together for years so they treat each other like siblings, they can get really nasty. She's a daredevil and Carson's worried that she's doing all these things they had a huge blow up because he's telling her not to do those things and she's like you can't tell me what to do and she said 'you're not my friend anymore' which girls say but boys don't say that and he could not get over it and just kept wailing crying that he had lost his friend no matter what I said. 
Daniel, parent interview.

I think Daniel has a good idea of some of the social things. He'll go up and say Hi, he'll try to make friends with people.

He works together.

He's still struggling with not getting his own way. He's struggling with compromise. In play situations sometimes his spontaneously generated sentences can be confusing to other kids. But kids are nicer about it than grownups are. So he manages to play with them.

But I do know at school he told me that at least some of the time he plays by himself. So he's very content playing by himself. We had a play date here just the other day and he sat down and played shoots and latters all by himself. Even though he likes these kids and he would play with them too but if they walked away he would be like, I'm still doing this.

I think with peers he wants to be friends, he will tell people when he doesn't like something.

He wants to negotiate everything. He does try and he tries to negotiate with words; which is good. The words don't flow very easily for him, but he's always trying to make a different deal. Um, he can protest, but he will shut-down verbally. If he thinks something is really wrong and I'll ask him what's wrong he does not answer. He's actually done this at school that I know of. It was a teacher who yelled at him for throwing bark and she was mad because he wouldn't respond to her. She said 'come over here' and he just wouldn't. He shut down and got so stuck. The school called me and said we know he's a good kid and she's just a really yell-y teacher.

He will shut down, so then when he's shut down or he's asking for something from me over and over he will gesture instead of talk. And Carson does that too. They'll come in and something will have happened and I'll be like 'use your words' but it doesn't really work because saying 'use your words' all the time they probably don't even process it anymore. It is an annoying thing to hear over and over so I try to say 'when you talk I will ..." He's pretty good if you talk to him he will respond back which is good because that is something Carson struggles with. If you say 'Daniel will you do this?' he will answer me.

Oh he always has ideas about what we want to do. Just this morning he was like, because we go out to eat a lot, not that I don't cook, I cook, we just like food. He always wants to decide where we'll go. So this morning now he wants to go to IKEA to eat, he doesn't want to eat he wants to play in the play place but he knows that if we eat there because Jon loves the meatballs then he knows (he'll get to play), I think he's working it which is good. More sophisticated than I would expect with his verbal ability but he can work it in 'what's the best way to get what I want'. So he definitely does try to negotiate. (when you don't understand) Usually what I try to do is redirect them. So this morning he wanted this book about the world and he said it was my book so we went upstairs and he just said 'it's a book about the world' so I thought well is it an atlas he said 'I've never read this book before' so we couldn't figure it out so I just said how about we look at one 
of these books my favorite comic books I'll show you I'll read it to you. When I brought it over he said that's not the book about the world. So he doesn't re-direct easily but usually I just say to him 'I don't know what you mean, I'm sorry." He doesn't freak out or anything, I mean socially he's like 'all right'.

Mostly he wants to talk about what he wants to. The one game we did play that he stayed on topic that I was surprised because I thought it would be almost impossible was apples to apples. He had little reasons why he chose different things and he would tell us why. It was all on the same topic and it was surprisingly good for him. Normally, most of the time he just wants to talk about what he wants to talk about. (when asked about typical development) I think my reference is confused because him (Carson) at 7 struggled to communicate to so I don't know if Daniel's topic communication is normal for 7, $\mathrm{I}$ hope it is.

He did well in swimming lessons. It depends on what the situation is but he likes to learn new things. He adjusted really well to kindergarten and to even full day kindergarten so I think his adjustment is pretty easy. He's pretty easy going.

He's getting better at persisting at difficult things. I think with that he is typical. He is a little bit of a pleaser in a teacher situation.

I think he is good at recovering from a tantrum at least when he feels that he is listened to and that it is loving. With peers I think he does all right. He may go and be by himself because we've taught that to Carson a lot.

If somebody has done something wrong or if he's blamed for something he didn't do (he gets distressed) if there is some injustice involved, but in general not to, he's not as upset about things compared to Carson. If he tries really hard at something and if some criticism like your bad or you did bad he'll have some, because he learned it from Carson, some negative self-talk, he'll verbalize it.

If he really doesn't get his way and if there's something else going on like it isn't what we planned it can get to a tantrum level.

He's doing really well (using what we are teaching at home about emotions). He will tell me why he's sad or why he's scared not just mad. With focus he does well. Like with a puzzle he can focus for a long time as long as he feels competent at it. I don't see any ADHD markers with him at all. The minute he feels not competent he shuts down a bit. You can see it in his face, he's not a blow up in your face kind of kid. You can see him getting more and more upset. He's a pretty happy kid but then you can see it he gets this little $\mathrm{mm}$ on his face and I've known him long enough that I just stop and say something. He's a bit of a perfectionist. He doesn't want to do something unless he does it well. There are lots of things as a kid that you don't do well so that can be frustrating to him. I think part of the problem is that they pick things up so quickly that when they get to something that they have to work at they don't want to do it. I know how it is for most kids to pick things up they keep trying but they're like it's not to be done. 
Then when there are certain things that they struggle with like this speech problem then its, it depends on their personality. It's not hard to work with Daniel on it, but it is hard to work with Carson. Because he just and then everything is terrible, he's just like 'I'm a bad person' 'I can't do this' Those are hard.

We went to this TAG workshop once for the parents and they talked about these TAG kids that are incredible under achievers because there are these expectations and they feel like they can't be perfect and then 'why aren't you doing well because you can?' but it's more complicated than that. It's interesting I don't know. Carson qualified for TAG, but it was in first grade and I don't know if it's really accurate. They don't do anything for you anyway. The teachers have to do more.

(Other people) think he's very sweet. We were just at a park and there were little kids there and he had a little girl's hand and was helping her on the slide. They say they're very nice boys and polite. They say he's fun and that he has good manners. Which he does.

Possibly some of that negative self -talk and then putting weird stuff in your mouth. I don't really know a lot about development, but if he could get some of those words out I don't think anything is going to be a big problem for him. He's also a bit like if I don't like what you're doing then so then I'm not going to play with you kinda kid, but I don't see it as any big red flag or anything. He has friends, I mean he gets invited to birthday parties, that's like my one thing.

(It helps) to say stop and look at me because sometimes if he is looking away I'm not sure if he's paying attention or getting the message. Sometimes, yes, he mumbles and then I say I can't hear you sometimes he gets quieter instead of louder. I don't quite understand why. Like he tries to talk in the car and I can't hear him and I say talk louder and he gets quieter so maybe we just take our time. If I don't understand it we kinda break it down.

A lot of times if he says something and there's an incorrect problem with it, I will repeat it with the right way and he will repeat it back to me because he's had enough speech therapy to know. So we're trying to work on those little things. We do homework with Trisha. Basically the homework is like his and her, and irregular verbs little things. Television is a big distraction. I think it's mostly too many things happening at once. I know they're messing with (the school's speech and language services) so much. I think the case load for those people is going to be huge. Last year I think they had 3 different speech therapists coming in so there was no consistency. They had different people on different days and then someone else doing the paperwork. I'm hoping it will just be one person this year. I know our principal used to be a speech pathologist so I think she's going to push for one but I don't really know what is going to happen. So we are going to focus with (our private SLP). I don't really know what they're supposed to be doing for us so we are just paying for our own. Because I know what Tricia does and I'm there. I don't really know what they do at school actually. I think they do little groups. 
It is easier to keep the goals with (our private SLP) because then the goals, I'm there, and we can change the goals. In an IEP situation it's more complicated it's like well this is the re-eval and it's good. I mean it's bureaucratic, I mean you can always change the goals but it seems like a lot of work, so I'm just like stick with those goals they're fine. Do whatever, talk to him. That's why we do our own. I'm grateful that he's getting help at school, but it's only a half hour and it's with other kids. I can have my own group right here at home. 